University of Louisville

ThinkIR: The University of Louisville's Institutional Repository

$12-2020$

\title{
Analyzing human resource competency development through the lens of adult learning theory: a qualitative case study on change management competency in a global U.S.-based firm.
}

Angela K. Jorgensen

University of Louisville

Follow this and additional works at: https://ir.library.louisville.edu/etd

Part of the Adult and Continuing Education Commons

\section{Recommended Citation}

Jorgensen, Angela K., "Analyzing human resource competency development through the lens of adult learning theory: a qualitative case study on change management competency in a global U.S.-based firm." (2020). Electronic Theses and Dissertations. Paper 3560.

https://doi.org/10.18297/etd/3560

This Doctoral Dissertation is brought to you for free and open access by ThinkIR: The University of Louisville's Institutional Repository. It has been accepted for inclusion in Electronic Theses and Dissertations by an authorized administrator of ThinkIR: The University of Louisville's Institutional Repository. This title appears here courtesy of the author, who has retained all other copyrights. For more information, please contact thinkir@louisville.edu. 


\title{
ANALYZING HUMAN RESOURCE COMPETENCY DEVELOPMENT THROUGH THE LENS OF ADULT LEARNING THEORY: A QUALITATIVE CASE STUDY ON CHANGE MANAGEMENT COMPETENCY IN A GLOBAL U.S.-BASED FIRM
}

\author{
By \\ Angela K. Jorgensen \\ B.S. University of Louisville, 1992 \\ M.A. University of Phoenix, 2006 \\ A Dissertation \\ Submitted to the Faculty of the \\ College of Education and Human Development of the University of Louisville \\ in Partial Fulfillment of the Requirements \\ for the Degree of \\ Doctor of Philosophy \\ in Educational Leadership and Organizational Development
}

Department of Educational Leadership, Evaluation and Organizational Development

University of Louisville

Louisville, Kentucky

December 2020 
Copyright page 2020 by Angela Booth Jorgensen

All rights reserved 



\title{
ANALYZING HUMAN RESOURCE COMPETENCY DEVELOPMENT THROUGH THE LENS OF ADULT LEARNING THEORY: A QUALITATIVE CASE STUDY ON CHANGE MANAGEMENT COMPETENCY IN A GLOBAL U.S.-BASED FIRM
}

\author{
By
}

Angela K. Jorgensen

B.S. University of Louisville, 1992

M.A. University of Phoenix, 2006

A Dissertation Approved on

October 28, 2020

by the following Dissertation Committee:

Dissertation Director Dr. Meera Alagaraja

Dissertation Committee Dr. Brad Shuck

Dissertation Committee Dr. Mary Brydon-Miller

Dissertation Committee Dr. Veronica Vargas 


\section{DEDICATION}

This dissertation is dedicated to my husband, Joseph Jorgensen, who has always encouraged me and sacrificed for the pursuit of my academic goals. 


\section{ACKNOWLEDGEMENTS}

I would like to thank my entire family for supporting me and encouraging me through this academic journey. I would especially like to thank my immediate family: Joe, Jackelyn, and Jordan who have each helped in their own way and are the reason I have made it through. I would like to thank my mom, dad, and brothers for cheering me on along the way. I would also like to thank my advisor and mentor, Dr. Meera Alagaraja for her encouragement to begin the program and endless encouragement and support that made it possible to finish. I would also like to thank my friends and colleagues who have been a sounding board and a resource during challenging times and share my enthusiasm for knowledge attainment. 


\begin{abstract}
ANALYZING HUMAN RESOURCE COMPETENCY DEVELOPMENT

THROUGH THE LENS OF ADULT LEARNING THEORY: A QUALITATIVE CASE

STUDY ON CHANGE MANAGEMENT COMPETENCY IN A GLOBAL U.S.-
\end{abstract}

\title{
BASED FIRM
}

Angela K. Jorgensen

October 28, 2020

HR as a profession has sought to be more strategic in order to address the increasing complexities of the business world, but many find that, in general, it is not happening in practice. Academic research has sought to define a set of competencies to guide the work and development of HR professionals; specifically, managing organizational change is one of the recommended core competencies. The extant literature suggests that there is a gap in the formal learning higher education offerings for HR professionals to be able to develop the set of knowledge, skills, and abilities required to be proficient in organizational change management. A case study design was used to explore how HR managers within one organization defined change management competency and had developed their knowledge, skills and abilities through the lens of adult learning theory. The results of the research suggest that informal learning is the primary type of learning experience for developing the competency of change management. Recommendations for further research and practice are provided to better 
align research and practice for organizational change management as competency for HR professionals.

Keywords: Organizational change management, HR competencies, adult learning theory, strategic HRM, formal learning, non-formal learning, informal learning 


\section{TABLE OF CONTENTS}

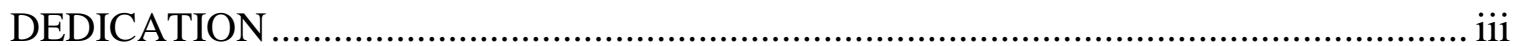

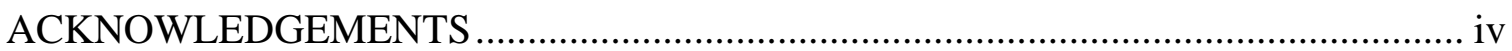

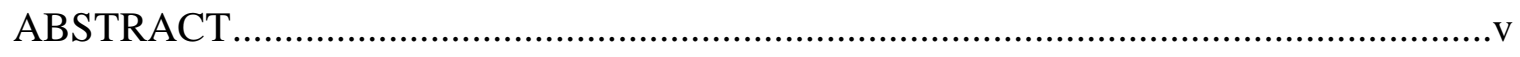

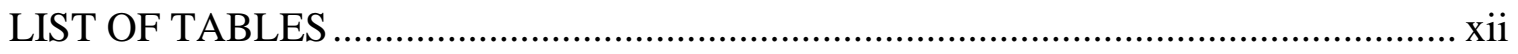

LIST OF FIGURES ................................................................................

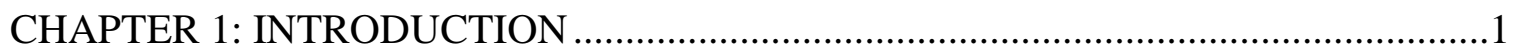

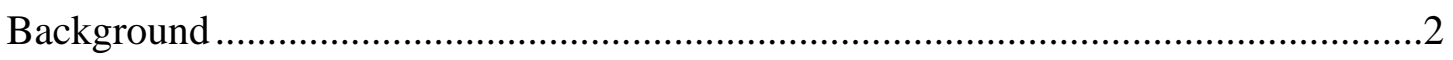

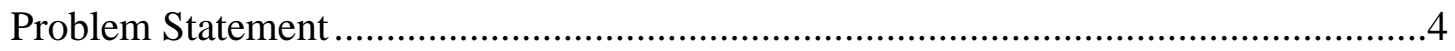

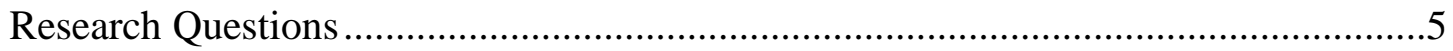

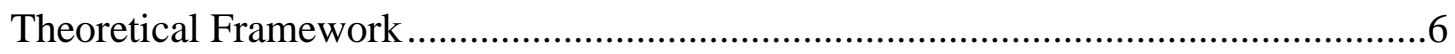

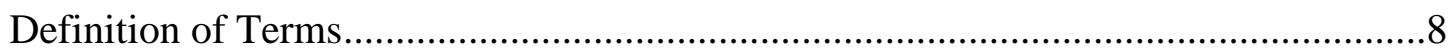

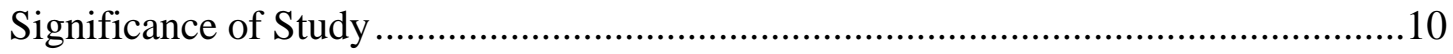

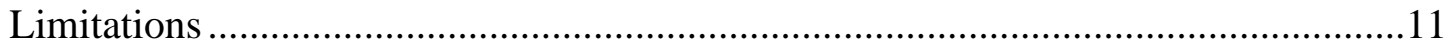

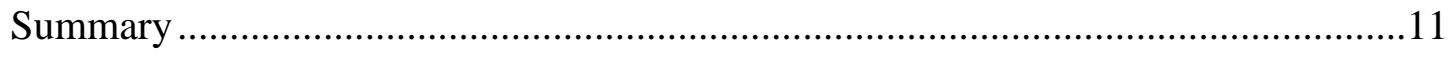

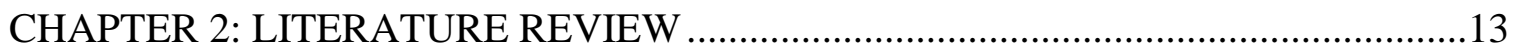

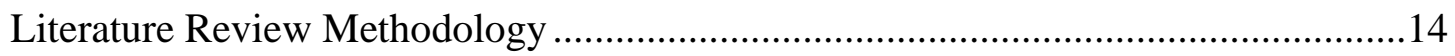

Research and Theory on Strategic Role of HR .....................................................14 
Overlap between HRM, HRD, and OD.

Change Management ……………………………………......................................19

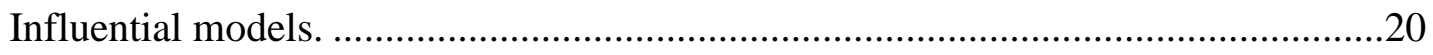

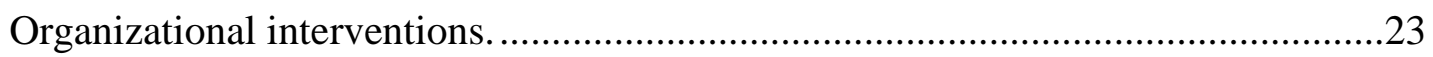

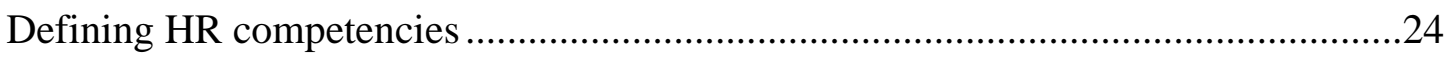

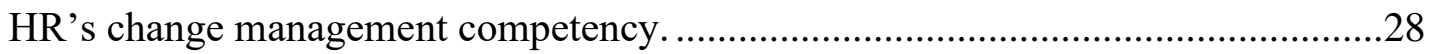

Alignment with Practice Literature..............................................................................

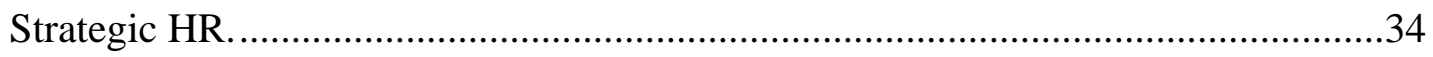

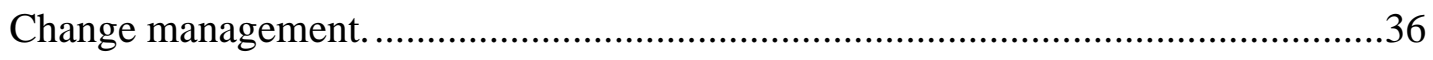

Gaps in Theory and Practice...................................................................................

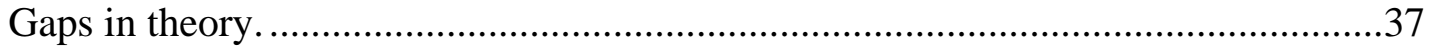

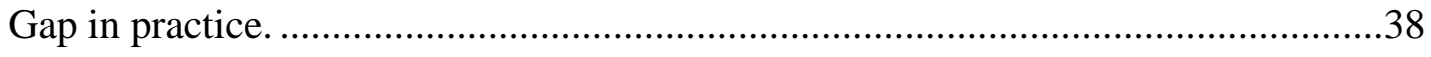

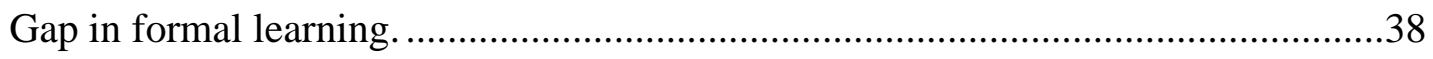

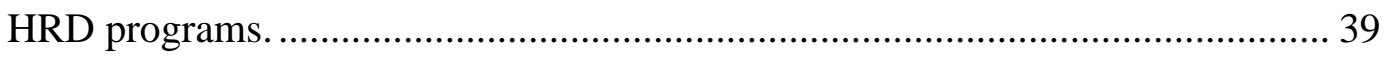

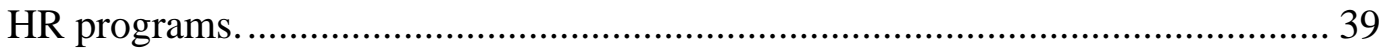

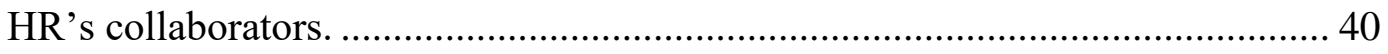

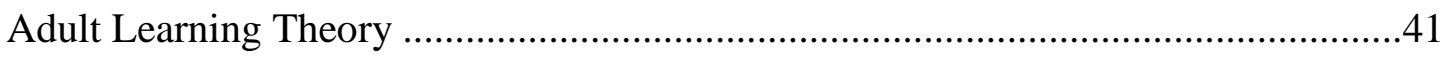

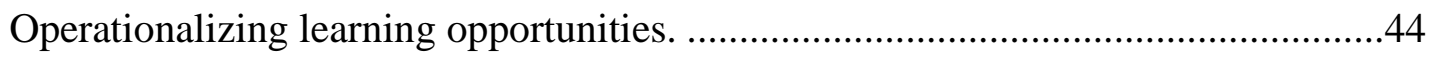

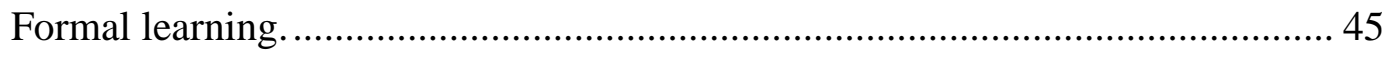

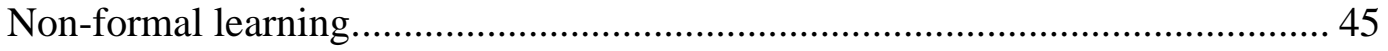


Informal learning.

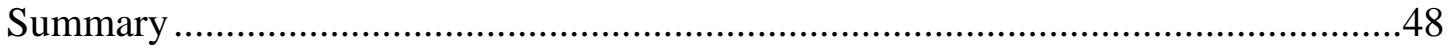

CHAPTER 3: RESEARCH DESIGN AND METHODOLOGY ………..........................50

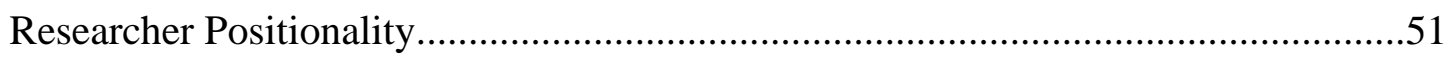

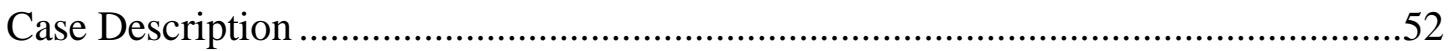

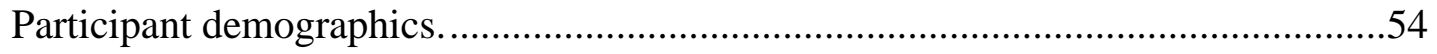

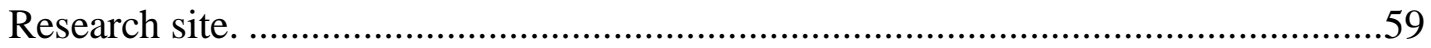

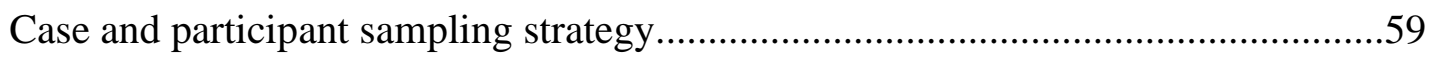

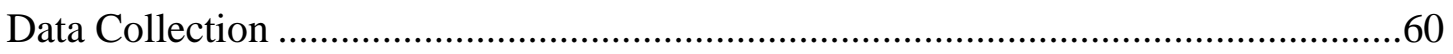

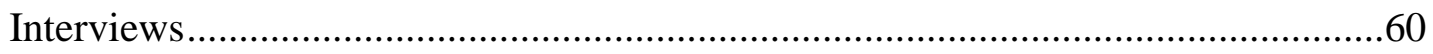

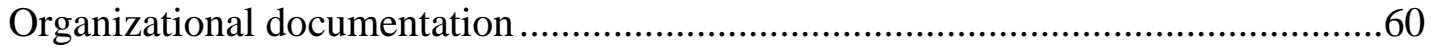

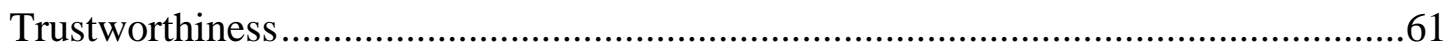

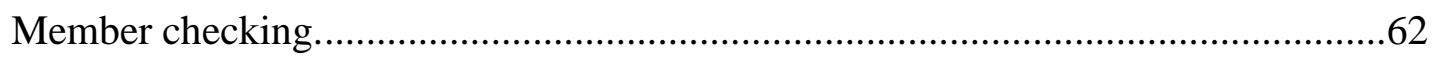

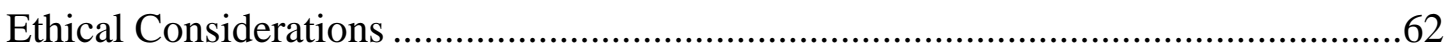

Managing and Recording Data .........................................................................63

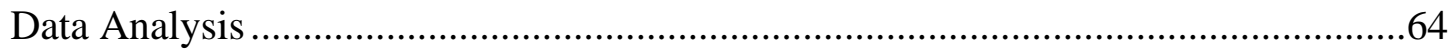

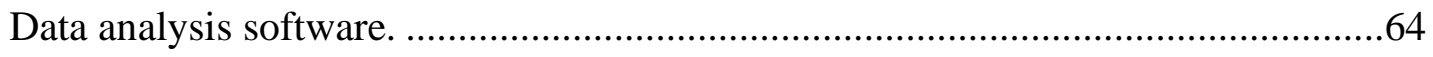

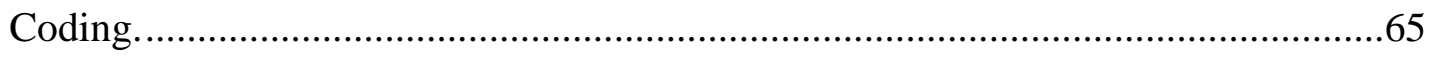

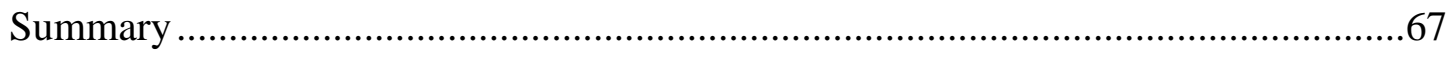

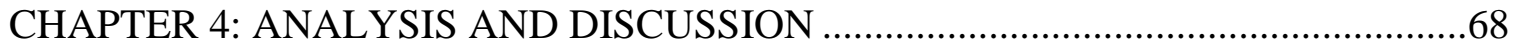


Strategic HR

Themes for the HR business partner. ............................................................... 70

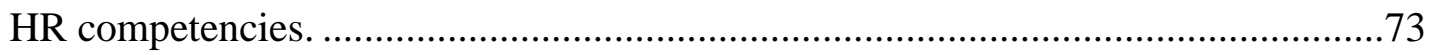

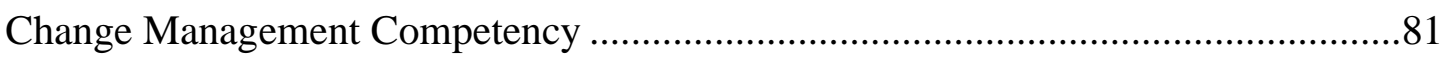

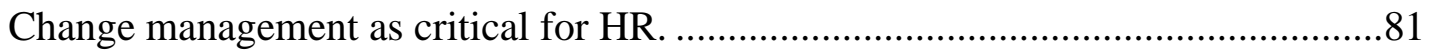

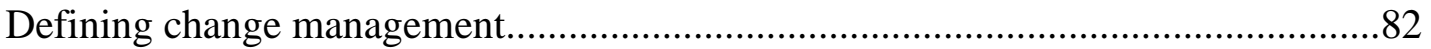

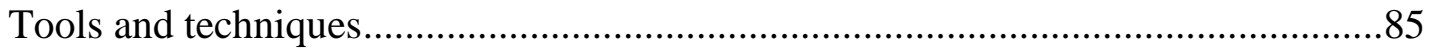

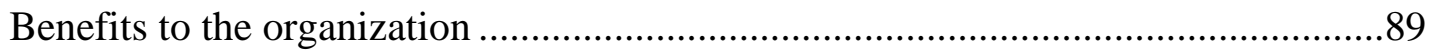

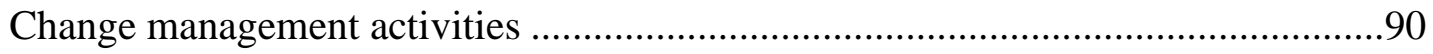

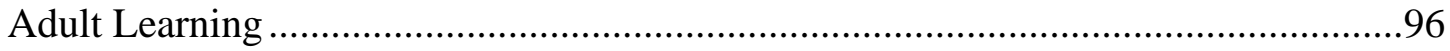

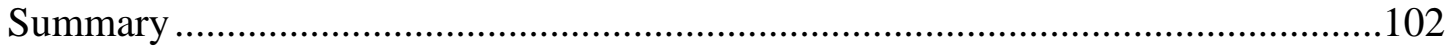

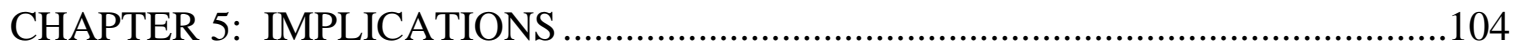

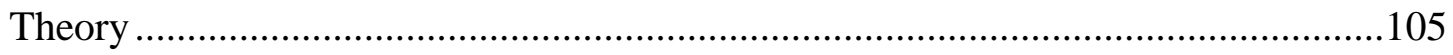

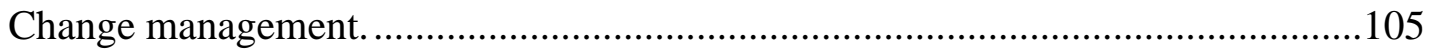

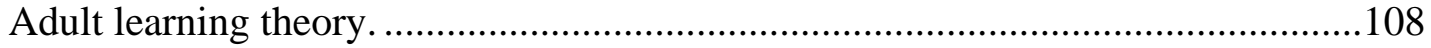

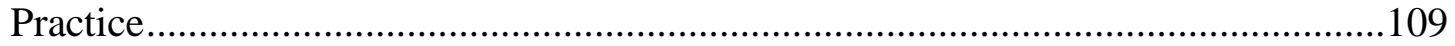

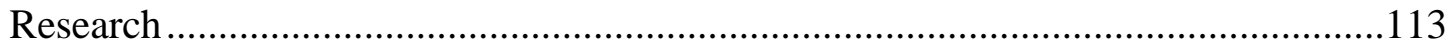

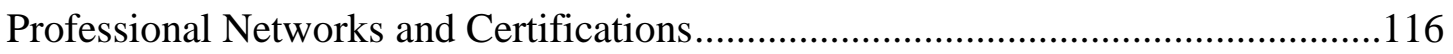

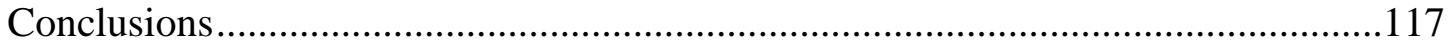

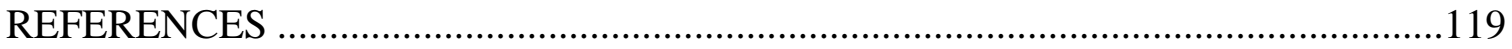


Appendix A: Interview Protocols

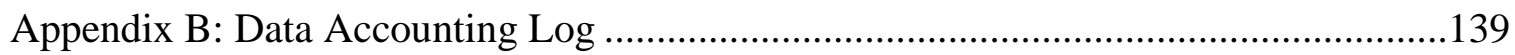

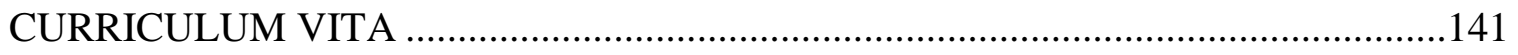




\section{LIST OF TABLES}

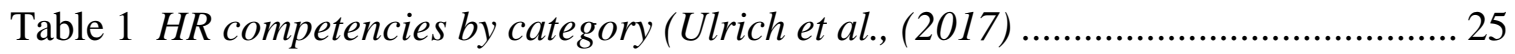

Table 2 Evolution of HR competencies by rounds (Ulrich et al. 2013; Ulrich et al, 2017,

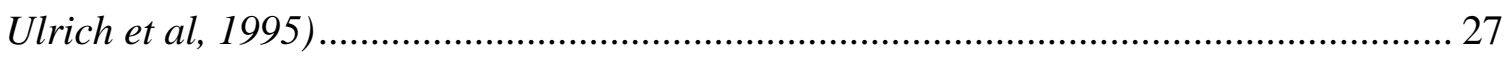

Table 3 Summary of Proposed Change Management Activities for HR Involvement by

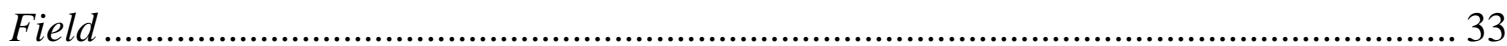

Table 4 Summary of characteristics and example learning opportunities by learning

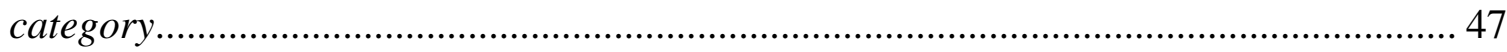

Table 5 HR experience by job title and percentage of participants ............................. 57

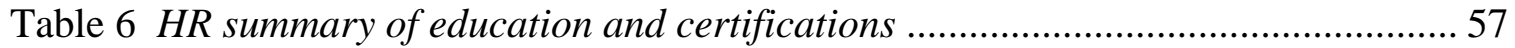

Table 7 Comparison of Self-assessment to manager rating of change competency and

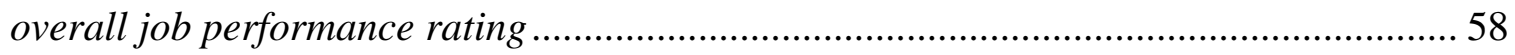

Table 8 Comparison of Ulrich et al., (2017) HR Competencies with HR Business Partner

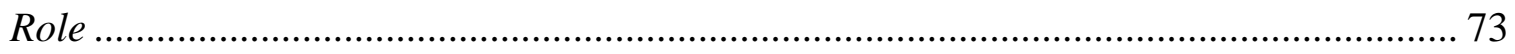

Table 9 HR competencies by category (Ulrich et al., (2017) compared to organizational

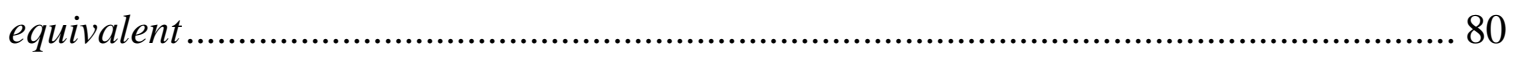

Table 10 Change management activities emergent codes ........................................... 90

Table 11 Comparison of change management proposed activity from research to

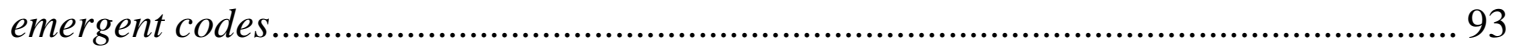

Table 12 Comparison of HR experience to the depth of change management elements

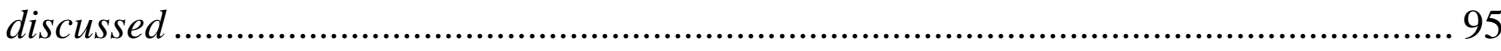


Table 13 Formal, informal, and non-formal learning opportunities ............................ 97

Table 14 Recommended change management topics for HR...................................... 112 


\section{LIST OF FIGURES}

Figure 1. Illustration of relationship between the background, literature review,

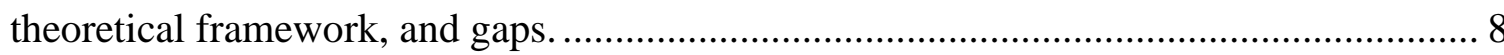

Figure 2. Organizational competency defining responsibility for change management by

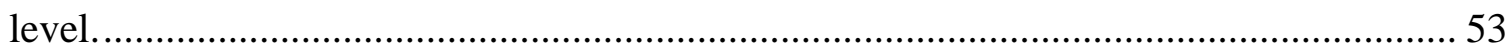

Figure 3. Illustration of the reporting relationship and business partners for the four

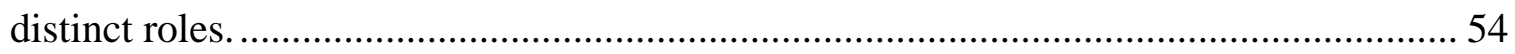

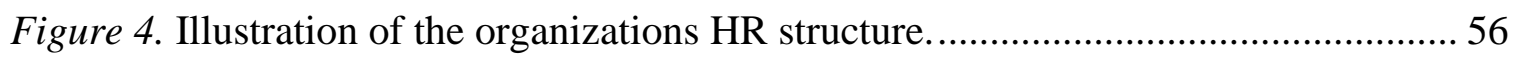

Figure 5. Research model updated to include influences on practice. ............................ 69

Figure 6. Leading in Transitional Times a change management model created by a

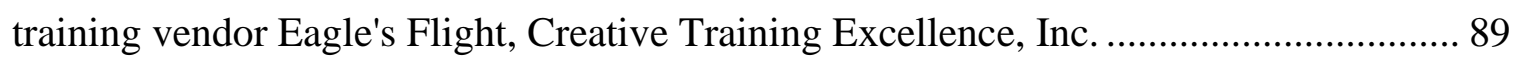

Figure 7. Tiered change model adapted from Kotter's model.................................... 108 


\section{CHAPTER 1: INTRODUCTION}

Current research, theory and practice examining the strategic role of human resource (HR) professionals in organizations is not well integrated or aligned. In research and theory, three academic disciplines: Human Resource Management (HRM), Human Resource Development (HRD) and Organizational Development (OD) have attempted to identify the strategic value of HR (Jamieson \& Rothwell, 2015; Ruona, 2016).However, the disciplines fail to agree on a set of competencies to guide further research or development of a strategic role for HR professionals. In practice, even though senior leaders seek additional skills from HR, such as understanding business context, navigating inherent business tensions, and providing innovative business solutions (Ulrich et. al., 2017), HR professionals are rarely invited to sit at the C-suite where key decisions are made concerning the strategies and initiatives influencing the performance of the organization. Both research and practice agree on the value of enhancing the strategic role of HR in organizations. What is lacking is a common language and set of skills to clearly define development and standard proficiency expectations. Without this foundational starting point, it is not surprising that as a group, HR professionals lack confidence and struggle to balance the tactical with the strategic elements of the role (Ulrich, Younger, Brockbank, and Ulrich, 2013). 
I begin by focusing on a review of the existing literature available in HR related research in the three academic disciplines contributing towards HR related research: HRM, HRD and OD (Ruona \& Gibson, 2004). I identify key themes and research findings from each one of the disciplines and identify gaps. Next, I focus on the extant practitioner literature to focus on key issues and challenges facing HR professionals. I integrate gaps from research and practice to present a summary of key challenges, issues and potential opportunities for enhancing the strategic role of HR.

Finally, using adult learning theory, I apply the tenets of formal, non-formal and, informal learning to understand how practitioners are developing one of the recommended strategic competencies for HR professionals.

\section{Background}

Many scholars have researched the challenges facing HR as the profession strives to be of value to organizations (Caldwell, 2008, Cohen, 2015; Ulrich, 1997; Ulrich 2016; Stone \& Deadrick, 2015). Ulrich's (1997) influential research asserted that HR professionals did not possess the needed skills to guide and advise organizations and ignored the need for defining a set of competencies for which the profession could aspire to. This original list of three competence domains have since been revised with subsequent rounds of research conducted surveying organizational leaders and HR professionals about their assessment of the performance of the HR professionals within their organizations. The original three were grouped as knowledge of business, delivery of HR, and managing change with multiple knowledge and skill areas under each. Ulrich (1995) stated at that time that managing change was the most elusive of the three. The latest study findings were published in 2017 (Ulrich, Kryscynski, Ulrich, \& Brockbank, 
2017). Although not all researchers agree with Ulrich's interpretations, his research is still often cited as the known standard to challenge (Caldwell 2008; Cohen 2015; Gerpott, 2015). In their own look back over the 18 years since publishing the first study findings, Ulrich and Dulebohn (2015) estimated only 20\% of HR professionals have proficiency in the competencies that have been recommended. Similarly, a qualitative study of HR professionals in Canada revealed a self-reported gap in proficiency in new competencies for their changing roles (Crouse, Doyle, \& Young, 2011). According to the U.S. Bureau of Labor Statistics (2020), the U.S. has 625,700 human resource related jobs with a 5\% growth rate expected over the next eight years. They note that a bachelors' degree is typical with a major in human resources, management or a related field and they also note the SHRM certification to prepare for one of those roles.

Human resource development (HRD) programs should include curriculum aligned with organizational context designed to "foster change management" (p.51) according to Johnston (2001). However, Ramlall and Sheppeck (2007) noted the number of programs for skill development in change management continues to remain low. Cohen (2015) notes a general lack of consistency in the curriculum for HR programs in universities across the country. Several researchers have quantified the issue among higher education institutions (Kuchinke, 2002; Lim \& Rager, 2015; Ramlall \& Sheppeck, 2007) with all noting low percentages of programs that included courses or content in organizational change management. They conclude that although the desire is for HR to be more of a strategic business partner, HR graduate programs remain more focused on technical aspects of the HR role (Ramlall \& Sheppeck, 2007). 
Techniques and practices intended to increase employee change adoption and mitigate employee resistance to change are the focus of change management practices (Griffith-Cooper \& King, 2007) aimed at improving the success of organizational change. The human resource (HR) function can provide value to organizations by leading and supporting organizational change (Ulrich, Younger, Brockbank, \& Ulrich, 2012). Specific HR skills for managing organizational change have been identified such as improving perceptions held by employees (Graham \& Tarbell, 2006), the ability to create, implement and evaluate business strategy (Ramlall, 2006), and establishing organizational core competencies (Alagaraja, 2013).

The literature agrees that HR's involvement in change management is needed yet suggests a gap in formal learning opportunities. If a change management based competency does become part of the competencies for HR in organizations, how do HR professionals develop the acumen?

\section{Problem Statement}

HR as a profession has sought to be more strategic in order to address the increasing complexities of the business world, but many find that, in general, it is not happening in practice (Crouse et al., 2011; Ulrich \& Dulebohn, 2015). Academic research has sought to define a set of competencies to guide the work and development of HR professionals (Caldwell 2008, Cohen 2015, Gerpott, 2015; Ulrich, 1997; Ulrich et al., 2017). Specifically, managing organizational change is one of the recommended core competencies (Ulrich, 2016).

Several challenges face HR professionals in practice. First, recommendations for their competencies come from three different academic fields of HRM, HRD, and OD 
and do not necessarily align. The popular practice literature and certifying agencies that provide recommendation and resources for HR professionals do not align on the competencies in general nor change management specifically. Second, the topic of organizational change management is complex and while there are separate studies suggesting how HR can be of value in supporting and leading organizational change, again there is not agreement or common language to establish a holistic view of HR's role. And finally, in spite of or perhaps because of the wide range of studies and suggestions for HR on this topic, the research suggests that there is a gap in the formal learning higher education offerings for HR professionals to be able to develop the set of knowledge, skills, and abilities required to be proficient in organizational change management.

\section{Research Questions}

In order to address the gap between theory and practice, the following research questions guided this case study:

1. What are the different ways HR professionals manage change within their organization?

2. Do and how do HR professionals perceive the competency of change management as critical to their work?

3. How do HR professionals define the HR competency of change management?

4. How have HR professionals developed their acumen in the change management competency? 


\section{Theoretical Framework}

A theoretical framework for qualitative research consists of theoretical assumptions that explain the relationships of a set of phenomena and is dependent on the researcher's worldview (Creswell, 2013). Ellinger and Yang (2011) state that qualitative research can apply theory deductively when the researcher uses theory to inform the development of the interview protocol and/or the data analysis. Two main theoretical frameworks will be used to guide this research. First, an interpretivist framework guided the research design to understand the lived experiences of the participants. Secondly, adult learning theory served as the framework to guide the interview protocol and the lens for the analysis of the data collected in the case study.

Although the intention of the case study is to be open to the experiences and interpretations of the participants, Yin (2011) recommends beginning with a theoretical perspective to organize study findings. Since I seek to understand the HR professional's perspective on how they have developed or learned the knowledge, skills, and abilities related to change management competency, I will utilize adult learning theory to guide the analysis of the findings. I propose to conduct the study from the perspective of adult learning theory using the life-long learning model (Jarvis, 2007). Adult learning theory (Merriam, 2004) is concerned with the role adults play in controlling their learning experience. Jarvis (2007) defines lifelong learning as “every opportunity made available by any social institution for, and every process by which, an individual can acquire knowledge, skills, attitudes, values, emotions, beliefs, and senses within global society" (p. 99). Since the literature suggests a gap in the formal development of change management as a competency area for HR professionals, this study will use a broader 
context in which to examine the opportunities that may be providing learning opportunities. The model of lifelong learning categorizes learning opportunities into three primary areas of formal, non-formal, and informal (Jarvis, 2007). Formal learning opportunities are primarily those associated with higher education while non-formal would be associated with structured workplace training. Informal and incidental learning takes place outside of a structured environment but can be enhanced by learner awareness (Marsick \& Watkins, 2001). This latter category of learning recognizes that the acquisition of skills and knowledge also occur during "critical moments of need embedded in the context of practice" (Manuti, Pastore, Scardigno, Giancaspro, \& Morciano, 2015, p.5). The fact that all three are overlapping and are both individual and social (Jarvis, 2007) is of interest to explore this concept of HR managers developing the competency for change management.

Figure 1 illustrates the relationships between the multiple interdependent topics in the research areas to guide this study. The overarching topic is Strategic HR with three primary fields comprising the research around that topic, HRD, OD, and HRM. Change management theories and models, also informed by those same three fields, has been suggested as one way in which HR can be more strategic. Adult learning theory is the framework used to align theory to practice by examining how HR professionals develop the knowledge, skills, and abilities that make up the change management competency in practice. The research indicates a gap in practice possibly explained by a gap in the formal learning opportunities for change management, therefore, informal and nonformal learning will be explored for understanding what is happening in practice. Dotted lines represent areas in which the existing literature is not as directly linked together. 


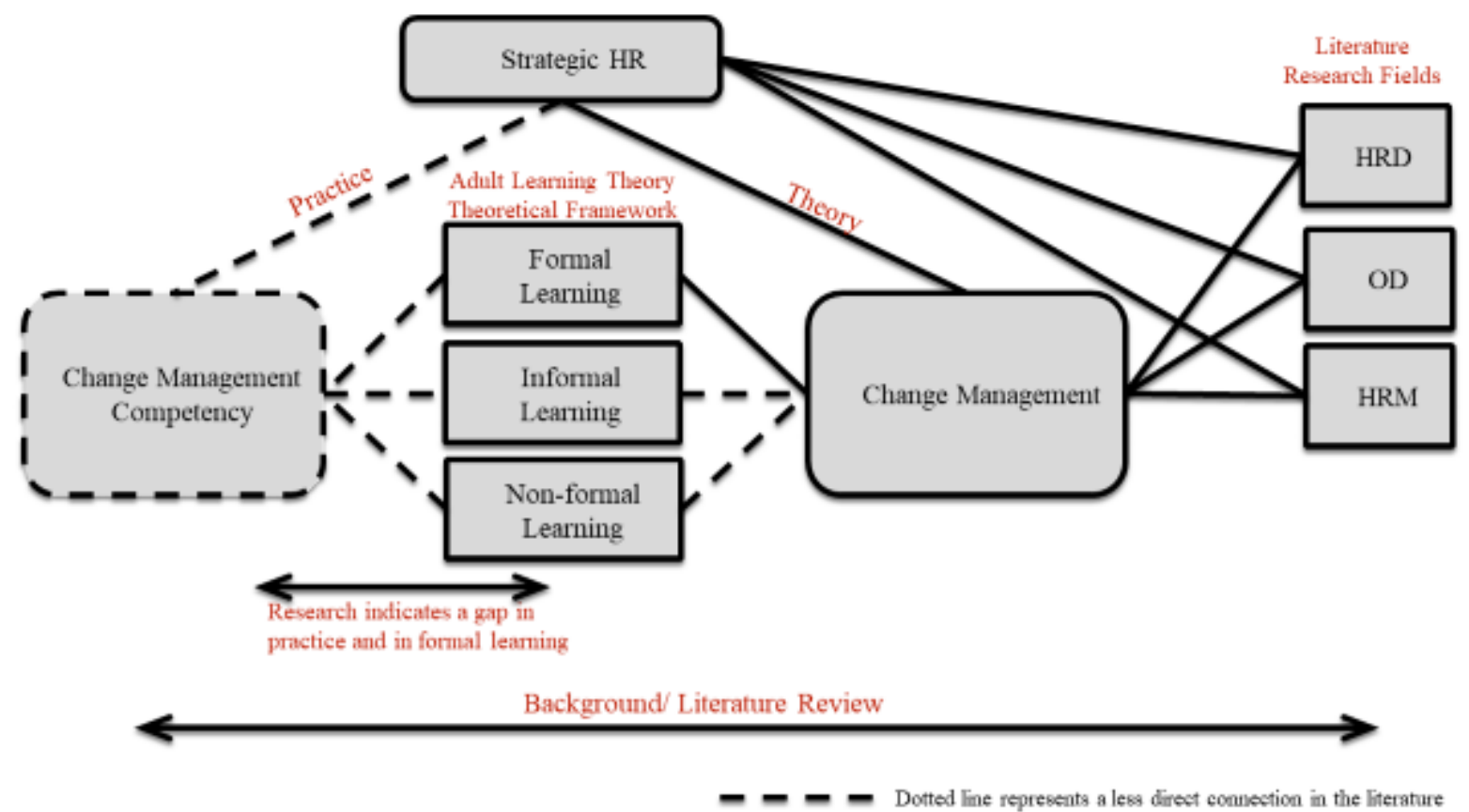

Figure 1. Illustration of relationship between the background, literature review, theoretical framework, and gaps.

\section{Definition of Terms}

Throughout this dissertation, several terms are used commonly found in the literature. Even though the terms are commonly used, each has been defined in different ways by different disciplines. The definitions selected for this dissertation represent a broad definition of the term to be inclusive of the slight variances in meaning while retaining the intended core concept.

Change Agent. From an organizational change perspective, "a change agent is any individual or group that initiates and/or facilitates change" (Duncan, 1978, p. 362).

Similar terms used are Change Champion or Change Steward.

Change Management. The definition used for change management is a "set of principles, techniques, or activities applied to the human aspects of executing change to 
influence intrinsic acceptance while reducing resistance" (Griffith-Cooper \& King, 2007, p. 14).

HR Competencies. Simply defined as the "the values, knowledge, and abilities of HR professionals" (Ulrich, Brockbank, Yeung, \& Lake, 1995, p. 1).

Human Resource Development. HRD can be defined as "a set of systematic and planned activities designed by an organization to provide its members with the opportunities to learn necessary skills to meet current and future job demands" (Werner \& DeSimone, 2006, p. 4).

Human Resource Business Partner. Also, more generally referred to as HR professionals; this term has grown out of the urgings for HR to partner with line managers and leaders in order to provide business solutions. Ulrich is generally credited with defining the role through his vision of the value a HR Business Partner could bring through "strategy execution, administrative efficiency, employee commitment, and cultural change" (Ulrich, 1997, p. 38).

Human Resource Management. The "personnel policies and managerial practices and systems that influence the workforce" (Bernardin \& Russell, 2013, p. 6) is the broad definition of Human Resource Management. In many cases truncated to HR, the definition is further detailed by listing types of activities such as hiring, scheduling, disciplining, and compensating.

Organization Development. OD is a "systematic process for applying behavioral science principles and practices in organizations to increase individual and organization effectiveness" (French \& Bell, 1999, p.1). 
Strategic Human Resource Management. Sometimes noted as strategic HRM or SHRM, the concept has been defined as "the pattern of planned human resource deployments and activities intended to enable the firm to achieve its goals," (Wright \& McMahan, 1992, p. 298).

\section{Significance of Study}

The information gained may provide insights across the multiple disciplines influencing the development of current professionals to inform further research. The use of case study is pertinent when the research seeks to answer a descriptive question regarding what is happening or has happened within a real-world context (Yin, 2011). This real-world context is one of many aspects at the center of the debate on how HR should be involved in change management, if they have the requisite skills, and, if so, how did they develop them. The findings could inform similar organizations in areas to enhance learning in both structured and unstructured settings. These insights may provide meaning and an interpretation of how HR managers perceive their role and whether that is more aligned to HRM, HRD, or OD, which can inform further research. By using a "theoretical framework to establish a logic that might be applicable to other situations" (Yin, 2011, p. 18), I strive for analytic generalizations in this qualitative study. This research can inform both theory and practice by exploring a setting, work experiences, and practices across multiple disciplines to understand how HR managers at a large U.S. organization understand their role in change management and how they have developed the knowledge, skills, and abilities to do so. This information will be viewed through an adult learning theory model of life-long learning to understand how all their experiences have contributed to learning. 


\section{Limitations}

Although this research case study will be in one specific setting, I do understand that this context is not representative of how HR is structured in all organizations and therefore experiences will be very dependent on the context. Although the benefits of the study are the ability to explore a context rich case that has the recommended competency in a manner that has not been done before, these also serve as limitations in other ways. The findings will be context specific and only focused on one specific area of experience for these HR professionals. Because the literature has been so divided on change management as a competency for HR, I feel that the insights gained from this in-depth exploration will add rich insight and enhance the transferability of the study findings to similar contexts.

\section{Summary}

Ulrich (2016) claims the HR profession is at a crossroads and needs to respond to opportunities of change and deliver business value. Over the last several decades, the changing needs of the business world have created the need for HR professionals to redefine the competency areas striving for a shift toward more strategic roles. This is further complicated by the often-confusing overlap of the HRM, OD, and HRD disciplines (Ruona \& Gibson, 2004). While there is not perfect consensus on what those new competencies should be or how well HR is doing, the literature illustrates a widely accepted need for HR professionals to aid in change efforts at a higher level of proficiency. Change management has several models and theories but has become a ubiquitous term making research and measures of effectiveness difficult. Perhaps that also makes development in this competency difficult to define and facilitate. The research 
does not reveal a clear way in which HR professionals can develop this proficiency. Although, HRD and business schools are calling for updated curriculum, this is not necessarily a solution for senior HR professionals who are already in the field. This research is intended to explore the lived experiences of HR professionals in order to understand their views and experiences through the perspective of the adult learning theory model of life-long learning. 


\section{CHAPTER 2: LITERATURE REVIEW}

This literature review begins with an overview of strategic approaches in theory and practice. Theories of strategic HR will help not only explain, predict, and give meaning to what is found in HR practice, but also challenge our assumptions related to practice. Strategic HR theories form a sound basis for practical action within the HR profession, which has set the stage for proposed updated competencies for HRM practice.

One of the proposed competencies is change management (Boudreau \& Lawler, 2014; Ulrich et al., 2017) and in this area there is considerable overlap with research in human resource development (HRD) and organizational development (OD). Therefore, change management is examined across all three fields of HRM, HRD, and OD including a brief history, influential models, and HR's role in leading and/or assisting organizational change management. Finally, the research indicates a gap between this recommended competency in theory and the abilities of HR in practice (Ulrich, 2016), so a brief review of common practice magazines and associations is also included. One possible explanation for this gap comes from research that documents a lack of formal learning opportunities in higher education for change management (Kuchinke, 2002; Lim \& Rager, 2015). In order to understand this gap better in practice, adult learning theory is explored to understand all the ways in which HR professionals might develop proficiency in change management. 


\section{Literature Review Methodology}

Three primary databases were utilized for the literature review search:

ABI/Inform, EBSCO (Psych Info) and Google Scholar. Various combinations of primary concepts were used in keyword searches including strategic HR, change management, organizational change, as well as the three primary research fields of HRM, HRD, OD.

Due to the common use of the word change and organizational change, many articles were excluded which did not relate to the concept of managing change in organizations. Much of the search was extended by a series of reference section reviews to find other relevant articles and/or seminal articles. In addition, several met-analytical articles were reviewed to better understand the evolution of each primary topic. Finally, since research indicates a gap in the development of the change management competency for HR professionals, an additional search was launched for literature on adult learning theory, specifically in the categories of formal, non-formal, and non-formal learning. Where possible, the research was limited to the last five to ten years, unless other related research could not be found, or earlier articles were considered the originator of the defined concepts.

\section{Research and Theory on Strategic Role of HR}

Ulrich et al. (2013) describe HR as a profession "plagued by self-doubt, repeatedly re-exploring HR's role, value, and competencies" (p. 457). This self-doubt and re-exploration may be due to some of the changing demographics within the profession such as the increased percentage of HR professionals with degrees, the increased number of HR professionals with less than 5-years of experience, and the decreased number of generalists giving way to specialization in the area of recruiting (Ulrich et al., 2013). 
With the move to a strategic focus and alignment with business strategies, Kalyani and Sahoo (2011) state HR professionals have too often attempted to tackle the new challenges with outdated tools and are trying to bring about major systemic change with incremental change programs. How has the evolution of strategic HR contributed to this self-doubt and what areas of academic theory and research need additional clarity to support the profession in confident practice?

Toward the end of the $20^{\text {th }}$ century, there was a push for HR to link practices to business strategy with major consulting firms implementing specialty programs in HR strategy and change management (Brockbank, 1999). HR began working in increasingly strategic areas such as establishing a desired culture, change management, and organizational development activities. Bartlett and Ghoshal (2002) warned, "Somewhere between theory and practice, precious human capital is being misused, wasted or lost" (p. 34). Many have agreed with this and similar warnings, calling for a continued shift of HR practices to be more strategic. The changing business environment has led to renewed emphasis in the importance of human resource management (Bernardin \& Russell, 2013). Trends such as the changing workforce, increased globalization of the economy, technological changes, and increased litigation and regulation increase the need for stronger human resource practices. Strategic HRM is interested in how these bundles of HR practices are implemented in combination to meet business objectives (Liao, 2005). Connecting functional level strategies with other levels of strategy, business and corporate, is a critical role for HR. Particularly, HRM needs to help increase an employee's understanding of the actions necessary to contribute to organizational goals, 
by creating the capability, culture, and motivation to accomplish goals (Buller \& McEvoy, 2012).

Ulrich (2016) finds only an increase in importance for HR practices into the new century with increased volatility, uncertainty, complexity, and ambiguity, termed VUCA, in the business world. The vision for $21^{\text {st }}$ century HRM includes linking business strategy and HR practices jointly planned and implemented by HR and line managers, focused on employee involvement and productivity, and remaining responsive to the competitive marketplace (Bernandin \& Russell, 2013). Finding little in support of what they consider the field's "complex core concepts" (p. 2), Jackson, Schuler, and Jiang (2014) describe these types of visions for HRM as aspirational due to the difficulty in pulling the multitude of elements into one empirical piece of work. Noting a general lack of rigorous empirical studies, they categorized 154 empirical studies over a 30-year period as focused on high performance, high commitment, strategically targeted, or unspecified. They identified only 11 of these studies as being strategically targeted meaning the researchers specified elements of the HRM system as organized around ensuring employee engagement and success. This lack of definitive empirical studies makes it difficult to identify verified HR methods and practices.

In the quest to be strategic, some fear the value of transactional or operational work has been largely ignored. HR must continue certain core transactional work, such as recruiting, or organizations will not meet their goals (Naznin \& Hussain, 2016).

Similarly, Wright and McMahan (2011) suggest there is risk HRM researchers will ignore the complexity of the "human" aspect when viewing human capital as just another form of capital. Some suggest there has been a decline in the employee focus resulting 
from the emphasis on the business strategy (Van Buren, Greenwood, \& Sheehan, 2011; Wright \& McMahan, 2011). Van Buren et al. (2011), noted the long-standing duality of roles for HR as an employer representative and employee advocate. However, the challenges of tough economic environments and increased competition have seen HR professionals prioritize the strategic HRM roles, which can conflict with the traditional stewardship of the employee relationship. As such, they have lost credibility in that area. HR professionals must better balance their dual role and be more critical of an organization's strategic language to understand employee implications. Very nicely developed.

Overlap between HRM, HRD, and OD. HRM is not the only field making recommendations for HR professionals. According to Ruona and Gibson (2004), the distinction between the fields of HRM, HRD, and OD continues to blur with competencies similar in each. Hamlin and Stewart (2011) suggest HRD, OD, and coaching should consider moving collectively to a new "all-embracing" (pg. 215) field of study due to the high degree of overlap. Another recommendation is for next generation HR to emerge as a meta-profession accommodating multiple fields under its umbrella so that HRM, HRD, and OD can work collaboratively together yet retain their important distinctions (Ruona \& Gibson, 2004). Haslinda (2009) mapped the overlap showing that the components traditionally thought of as HRD were now considered part of HRM and predicted new encompassing terms in the future since all aspects are needed together to support organizational change. Alagaraja (2012) similarly argues for a "pluralistic approach in treating HRD and HRM perspectives as complementary and doing so 
provides an enriched understanding of HR in the scholarship and practice of HRD/M (human resource development and management)" (p. 118).

Although each has emerged as a distinct field, similar purposes have led to some convergence of concepts and practices (Jamieson \& Rothwell, 2015; Ruona, 2016). According to Trehan (2004), there is an untidy overlapping of HRM and HRD in role and purpose, which is a source of confusion for line managers as well as HRD practitioners. Mankin (2001) states that ultimately HRD is a sub function of HRM and deals with the learning and knowledge needed to tie together communication actions and management styles. Likewise, Long (2013) lists HRD as one component of an HR professional's required knowledge and skills. A review of the Society for Human Resource Management (SHRM) certification supports the idea of HRD as a subset of HRM with $18 \%$ of the questions on the Professional in Human Resources (PHR $\circledast$ ) certification pertaining to HRD (Werner, 2014). Hamlin and Stewart (2011) contend that the core purposes and processes of HRD are virtually the same as those associated with OD and coaching. Overall, the field of OD is most recognized for theories and models in change management as defined by Griffith-Cooper and King (2007). However, HRM and HRD also address elements of change in their respective practices.

Regardless of the distinctions between the disciplines in academic research, those distinctions begin to blur within organizations (Alagaraja, 2012). With the overlap in research and the multiple hats that HR professionals may have to wear, for the purposes of this examination all three perspectives will be considered to have insights for HR professionals in the area of managing change. 


\section{Change Management}

I will explore just one of the recommended competencies for HR professionals, change management, due to the pervasive nature of change in the business world, coming in so many forms (Stone \& Deadrick, 2015; Worley \& Mohrman, 2014). Changing behaviors, changing culture, mergers and acquisitions, project management, technology implementations, responding to changes in the external market are just a few of the areas of interest for organizations (Ulrich, 2016; Worley \& Mohrman, 2014). It is not surprising the topic of change management or organizational change is of interest to many different fields (Griffith-Cooper \& King, 2007; Jick \& Sturtevant, 2017; Ruona \& Gibson, 2004). While the fact that change management has been researched from many different disciplines provides a broad perspective of the topic, it also leads to confusion, competition, and ultimately less than desired results (Kuna \& Nadiv, 2018).

Less than one-third of organizational change initiatives successfully meet the intended business objectives. This is a commonly accepted generalization regarding the bleak outlook for organizational change. Over two decades ago, John Kotter (1995) shared this view of the dismal state of organizations' efforts to transform. Since that time, many have tried to determine if businesses are making progress in change efforts (Hughes, 2011; Jick \& Sturtevant, 2017; Kerber \& Buono, 2005). Many organizations demonstrate more focus on change management, but most still fall short of full success (Kerber \& Buono, 2005). Hughes (2011) found that business leaders' belief in a 70 percent failure rate persists even though the empirical evidence is not strong. Parker, Charlton, Ribeiro, and Pathak (2013) use the 70 per cent failure rate as a call to action for managers to change their approach. Jick and Sturtevant (2017) found business executives 
are still being warned about this high rate of failure. The fact that these statistics are widely accepted indicates, at minimum, practitioners and business leaders are not satisfied with current results of organizational change initiatives.

Change management has grown in interest and the value to an organization is found in accelerating the adoption of change through pre-identification of potential resistance and putting measures in place to mitigate that resistance and institutionalize the change. Executives can underestimate how difficult it is to move people to change or can be too impatient for necessary change steps (Kotter, 1995). Although it seems a universal construct, what is meant by change is still unclear (Suddaby \& Foster, 2017). Organizational change remains a "generic term for all forms of change related activity in organizations (By, Oswick, \& Burnes, 2014). This review of the literature on change management includes some influential models and associated organizational interventions to provide the context and broad scope of the knowledge base. These models have been chosen not only for the influence on the origins of the concept of change management, but also for the connection to human resource development.

Influential models. Lewin's initial work in the field of psychology still influences change management models today (Kippenberger, 1998; Mitchell, 2013). His primary concern was the processes by which one could bring about desired social change (Lewin, 1947). He described forces enabling and restraining change. His three-phase model of unfreezing, moving, and, refreezing examines how to increase those forces enabling change while minimizing those forces restraining change (Jick \& Sturtevant, 2017). While his model has received some criticism, it is still the standard other change theories are based upon. The first phase, unfreezing, involves identifying key 
assumptions or incentives associated with the current behaviors and the second phase, moving, involves transitioning to new behaviors (Jick \& Sturtevant, 2017). While these remain relevant, it is the refreezing phase, or making the new behaviors permanent that does not work well with the idea of staying "poised for change" experienced today (Jick \& Sturtevant, 2017). Kippenberger (1998) summarized Lewin's work over 50 years later to highlight the robustness of the original work stating that over time some elements of his original model are lost. For example, part of Lewin's argument is that it is easier to change the way a group thinks than each individual separately and, as such, non-coercive group discussions allow for the best outcome for change. Mitchell (2013) illustrates how even subsequent models with additional phases could be clustered into Lewin's original model.

Another influential model in change management is Bridges' (1991) transition model. Like Lewin's model, Bridges introduces three stages of transition, all of which may be emotionally upsetting to individuals. Understanding the emotions and uncertainty tied to the internal transitions brought on by external change is important for leaders to know as they and employees go from goodbyes (endings), the neutral zone (explorations), and move forward (new beginnings).

Kotter's model remains a key reference in the field of change management (Appelbaum, Habashy, Malo, \& Shafiq, 2012). His model, derived from his experience with over 100 organizations, provides actionable and measurable steps to mitigate the most common errors in dealing with change (Kotter, 1995), adding to the popularity with practitioners. The eight steps (Kotter, 1995) are:

1. Establishing a sense of urgency, 
2. Forming a powerful guiding coalition,

3. Creating a vision,

4. Communicating the vision,

5. Empowering others to act on vision,

6. Planning for and creating short-term wins,

7. Consolidating improvements and producing still more change, and

8. Institutionalizing new approaches.

Appelbaum et al. (2012) examined the validity of Kotter's model fifteen years later and although they noted some limitations and less than expected empirical evidence, they concluded the model was still a good starting point for change.

By, Oswick, and Burnes (2014) note a rise in interest in organizational change and change management since the early 2000s based on text search for common change phrases. Others, such as Worley and Mohrman (2014) call for a rethinking of change management models due to the "new normal" of constant change. To clarify the construct of change, Suddaby and Foster (2017), introduced a taxonomy developed from a participant's view of organizational historical events. However, they admit this clarification does nothing to help with the concept of how to manage change or better prepare leaders to lead change efforts. Hughes (2007) challenges that the field of change management has not provided the tools and techniques managers need to manage change. Managers and business leaders often look outside of HR for assistance with change management. Several processes from project management are considered useful for 
change management such as the similar phase approach, reviewing lessons learned, and risk management (Hornstein, 2015; Parker et al., 2013). For senior leaders to have a better perception of the process, change management can also benefit from utilizing aspects of project ranking and performance management (Knodel, 2004). Another group filling that void are consultancy groups, however, the results lack the rigor of academic research. Jick and Sturtevant (2017) also noted, in their review of change management history, the prominence of consultancy groups such as McKinsey and Boston Consulting Group. According to Parker et al. (2013), efforts to keep pace with the changing business environment push as many as $30 \%$ of organizations to use project-based management.

Organizational interventions. Insight into the activities that organizations are using in managing change efforts can be gained from research on successful organizational interventions. All these studies mention areas that HR, either HRM or HRD, would typically be involved in although they do not mention HR directly.

Creating a specific change management group was found to be critical for one organization's success (Kanaane, Akabane, Peterossi, \& Endler, 2015). In this study, a consulting group provided the change management expertise, but the activities included mitigating risks and encouraging collaboration. Minimizing employee stress is another focus for organizations in change management. Smollan (2015) found stress experienced by employees' lack of resources is highest for most at the transition phase. This is the phase when they first become aware of the changes and the stress is due to uncertainty and even compounded by the stress of others. He found resentment could grow from poor communication on the purpose of change and the likely impacts of the change (Smollan, 2015). Petrou, Demerouti, and Xanthopoulou (2017) focus on what the employees can do 
for themselves to manage the stress related issues typically related to organizational change. Job crafting is the focus of their study, which includes encouraging employees to seek organizational resources as well as seek out challenges.

In their research, Higgs and Rowland (2009), found leadership behaviors linked to change effectiveness were motivating, communicating, and teamwork. Correspondingly, Mosca, Puches, and Buzza (2015) claim leaders need to influence and inspire employees, but HR may need to create development activities when leaders do not have the requisite communication and leadership skills. Ultimately, if employees are seeking resources or leaders require development, human resource professionals will likely be called upon to provide those services.

\section{Defining HR competencies}

For HR professionals to engage in the "right" business conversations, defining the core competencies is essential. McClelland (1973) introduced the concept of competency in the field of psychology. The term competency is commonly used, but that does not prevent concept confusion (Stevens, 2013). Campion, Fink, Ruggeberg, Carr, Phillips, and Odman (2011) define them as collections of knowledge, skills, abilities and other characteristics needed for effective performance in each job. Ulrich et al. (1995) highlighted HR's use of competencies to provide a foundation for HR to perform better.

Ultimately, HR professionals add value to organizational competitiveness by delivering talent, leadership, and capability or culture (Ingham \& Ulrich, 2016). Ulrich and others have been systematically researching and defining those competencies and corresponding domains since 1987 (Ulrich, Brockbank, Ulrich \& Kryscynski 2015). Since the first study, they have increased from roughly 10,000 participants to over 30,000 
worldwide including over 4,000 HR professionals up from approximately 1400 in the first iteration of the study (Ulrich et al., 2015; Ulrich, Kryscynski, Ulrich, \& Brockbank, 2017).

Ulrich et al., (2017), grouped all that HR should know and do into new competency domains evolving from six to nine. Table 1 below divides the recommended competencies into the areas of core competencies, organization enablers, and delivery enablers. Culture and change champion, defined as "able to make change happen and manage organizational culture" (Ulrich et al., 2017, p. 37), is categorized as an organization enabler which refers to the ability to position HR to deliver strategic value to an organization. For the purposes of this study, the focus is the competency domain of change champion (Ulrich, 2016), following a disciplined change process designed to make change happen, which is consistent with the general definition of change management.

Table 1

HR competencies by category (Ulrich et al., (2017)

\begin{tabular}{|c|c|}
\hline Category & Competency Name \\
\hline Core Competencies & $\begin{array}{l}\text { Strategic positioner } \\
\text { Credible activist } \\
\text { Paradox navigator }\end{array}$ \\
\hline Organization Enablers & $\begin{array}{l}\text { Culture and change champion } \\
\text { Human capital curator } \\
\text { Total reward steward }\end{array}$ \\
\hline Delivery Enablers & $\begin{array}{l}\text { Technology and media } \\
\text { Analytics designer and } \\
\text { Compliance manager }\end{array}$ \\
\hline
\end{tabular}


While change is included in this list, the prominence of change as an HR competency was established with the first round of the research (Ulrich, 1995) when change was one of only three domains and has remained in the list in some version since that time. Table 2 illustrates the evolution of the competencies recommended by Ulrich over the seven rounds of research. 
Table 2

Evolution of HR competencies by rounds (Ulrich et al. 2013; Ulrich et al, 2017, Ulrich et al, 1995)

\begin{tabular}{|c|c|c|c|c|c|c|}
\hline \multicolumn{7}{|c|}{ Rounds } \\
\hline 1987 & 1992 & 1997 & 2002 & 2007 & 2012 & 2016 \\
\hline $\begin{array}{l}\text { Business } \\
\text { knowledge }\end{array}$ & $\begin{array}{l}\text { Business } \\
\text { knowledge }\end{array}$ & $\begin{array}{l}\text { Business } \\
\text { knowledge }\end{array}$ & $\begin{array}{l}\text { Business } \\
\text { knowledge }\end{array}$ & Business ally & $\begin{array}{l}\text { Strategic } \\
\text { positioner }\end{array}$ & Strategic positioner \\
\hline HR delivery & $\begin{array}{c}\text { HR } \\
\text { delivery }\end{array}$ & $\begin{array}{c}\text { HR } \\
\text { delivery }\end{array}$ & $\begin{array}{l}\text { Strategic } \\
\text { contribution }\end{array}$ & Strategic architect & $\begin{array}{l}\text { Human resource } \\
\text { innovator and } \\
\text { integrator }\end{array}$ & Human Capital Curator \\
\hline \multirow[t]{7}{*}{ Change } & Change & Change & HR delivery & $\begin{array}{c}\text { Talent manager } \\
\text { and organization } \\
\text { designer }\end{array}$ & $\begin{array}{l}\text { Technology } \\
\text { proponent }\end{array}$ & $\begin{array}{l}\text { Analytics designer and } \\
\text { interpreter }\end{array}$ \\
\hline & $\begin{array}{l}\text { Personal } \\
\text { credibility }\end{array}$ & Culture & $\begin{array}{l}\text { Personal } \\
\text { credibility }\end{array}$ & $\begin{array}{l}\text { Operational } \\
\text { executor }\end{array}$ & $\begin{array}{l}\text { Change } \\
\text { champion }\end{array}$ & $\begin{array}{c}\text { Technology and media } \\
\text { integrator }\end{array}$ \\
\hline & & $\begin{array}{l}\text { Personal } \\
\text { credibility }\end{array}$ & $\begin{array}{l}\text { (Change and } \\
\text { Culture }\end{array}$ & $\begin{array}{c}\text { Culture and } \\
\text { change steward }\end{array}$ & $\begin{array}{c}\text { Capability } \\
\text { builder }\end{array}$ & $\begin{array}{l}\text { Culture and change } \\
\text { champion }\end{array}$ \\
\hline & & & $\begin{array}{c}\text { strategic } \\
\text { contribution) }\end{array}$ & Credible activist & Credible activist & Compliance manager \\
\hline & & & & & & Total rewards steward \\
\hline & & & & & & Paradox navigator \\
\hline & & & & & & Credible activist \\
\hline
\end{tabular}


Although widely cited, Ulrich is not the only researcher attempting to identify HR competencies. Buller and McEvoy (2012) suggest a need to increase the proficiency of the competencies of organizational design, managing change, and measuring performance based on their review of existing literature. According to Werner (2014), the 'big four" areas of responsibility in HRM for most practitioners are staffing, compensating, appraising employee performance, and training and development. Lee and Yu (2013) compared several different HR competencies models based on research at four major organizations. A competency for change expertise or change management was in place at three of the four organizations, with the fourth identifying organizational development, which generally includes components of developing for change. Like the research completed by Ulrich and others, Boudreau and Lawler (2014) have gathered HR information over time with the six different surveys conducted every three years between 1995 and 2010. Results show that little has changed in the areas of activities, time spent, and perceived effectiveness. Interestingly, the actual amount of time spent on activities in 2010 are very similar to prior surveys, but the perception held by the HR professionals of how they spent their time in the past was considerably different. In other words, HR professional perceive they are spending less time on tactical types of activities than they did in the past, but that perception is not consistent with actual time spent then and now. Boudreau and Lawler (2014) interpret this to mean that HR professionals perceive they have made more progress in strategic areas, including change management, than they have.

HR's change management competency. Ulrich's (2016) vision for HR's involvement as change champion does call for communication, providing resources, and 
continual learning. These are activities needed for sustaining change efforts, which is more impactful on business results than simply initiating change. Mosca et al. (2015) recommended that HR reinforce leaders' efforts by increasing awareness of organizational purpose and mission. A role as a consultant to the business has been found to support HR's ability to lead change (Younger, Younger \& Thompson, 2011). Other possible roles are influencing leaders, mediating common ground between the organization and employees, and negotiation between groups (Ogilvie \& Stork, 2003). The findings of a study comparing two organizations in the UK support the idea that consulting, and negotiation are suggested areas in which HR can provide organizational change assistance (Alfes, Truss, \& Gill, 2010).

More specific to HRD, Higgs and Rowland (2009) found creating capacity, which they define as creating employee and organizational capability and communication and making connections, positively correlated to change success. Crouse et al. (2011) noted the fast pace of change as a barrier to organizational learning, but at the same time the participants in their study felt learning was important to keep up with change. According to Edmonds, (2011), taking steps to prepare the organization for change contributes to successful outcomes. Thus, more agreement from the beginning that the change objectives are necessary correlates to more likely support of the change process. None of the changes can be executed well without first diagnosing the organization and need for change (Woodman, 2014).

Much of the research on change management includes the role of HR in leadership development because leadership behaviors are important during organizational change. Employees are limited by what they experience, as they are never able to see and 
participate in all the events or conversations at an organization. Ray and Goppelt (2011) find employees have in mind what the outcomes of certain real-life stories or narratives will be and when they "win" (part of their assumption comes to be), they assume their entire perspective is truth. Chen and Wang (2014) completed a study on the effects of the HR attributions of commitment-focus compared to control-focus on the employee outcomes during organizational change in China. Similar to findings in western cultures, attributions of commitment-focus were positively related to positive employee outcomes while control-focus was negatively related. This suggests that employees' perceptions of management's intentions behind communication and practices is very important. HR professionals can supplement leader communication, clarifying intentions for a more credible message. Employee perceptions should be measured during change events to inform HR practices (Maheshwari \& Vohra, 2015). Ray and Goppelt (2011) propose the use of leadership development programs to create organizational change by first changing the behavior of a leader, which will in turn have a cascading effect on the aggregate change of others.

HR must be diligent in their dual role of supporting the organization and the employee to avoid ethical dilemmas. Being too involved in the business partner role, HR may not want to risk their seat at the table with business leaders by advocating for employees (Ogilvie \& Stork, 2003). By the nature of change management, some feel HR is trying to persuade employees and is acting solely as an agent of the organization (Alfes et al., 2010). Burnes and By (2012) also warn HR to be involved with all organizational initiatives to minimize the risk of abuses of power and manipulation citing undue pressure to attain goals as a cause for scandal in recent years. 
Not all organizations are adopting this new role for HR at the same rate. In the UK, for example, Caldwell (2001) found the role of HR as change agent growing in importance in major organizations while Long (2013) saw change management as important but less adopted by HR professionals in Asia as compared to their western counterparts. Pylat (2016) did not find change management as an expected competency for HR, but rather effective communication, workforce planning, and business knowledge were considered crucial for HR success in the Ukraine. Alternatively, a 2003 quantitative study of a U.S. government agency recommended a competency model for HR that did not include any component of change management based on interviews with HR practitioners (Gorman, McDonald, Moore, Glassman, Takeuchi, \& Henry, 2003). Studies like this support the more situationalist view espoused by some researchers (Capaldo, Iandoli, \& Zollo 2006; Ripamonti \& Scaratti, 2012) making standardization difficult. From the situationalist perspective, competencies are influenced by the organizational context including culture and the way employees sense their role within the organization.

Others such as Caldwell (2008) challenge the idea of generalizing these competencies across organizations and found typically only large organizations were able to introduce the concept of HR business partner. Similarly, Gerpott (2015) warns the business partner model only addresses short-term tensions in HR practices and will not benefit all organizations depending on size and context. To be fair, Ulrich et al. (2015) concede that the extent to which these competencies are adapted or accentuated will vary based on the organizational context. In fact, they note in many cases line managers are also doing HR work which can sometimes overshadow a weak HR manager. 
The complexity of the change management competency as well as the interrelatedness to other complex competencies stimulates a consideration of macrocompetency versus meta-competency. Ulrich (2017) does refer to competency domains which is essentially the same as a macro-competency in which one complex competency is made up of many other micro-competencies. The challenge in the literature is that terms domains and competency are often used interchangeably. Maheshwari and Vohra (2015) explored HR processes in a systematic literature review to determine those have the most influence on change. They concluded that the abilities of HR in training, communication, technology, and cross-functional integration had the most influence on organizational change. The relationship with other macro-competencies suggests that a relationship may exist in which change management is a meta-competency. As defined by Fleming (1991), a meta-competence is one that acts on other competence thereby producing flexibility and the ability to use competence in a new context. Heery and Noon (2017) define meta-competencies as 'over-arching competencies that are relevant in a wide range of work settings and which facilitate adaptation and flexibility on the part of the organization (p. 380). Creating change along with learning and adapting are some of the examples they give for a meta-competency. However, I could not find any literature on this topic for organizational change. I found many citations for Boyatzis's (1999) book proposing self-directed change and learning as meta-competencies for employee success, but none dealing with organizational change as a meta-competency for leaders or HR.

Table 3 summarizes the change management activities that I have gathered in my literature review that include a recommendation for HR to be involved in and therefore proficient in to lead and support organizational change. As the table illustrates, these 
recommendations come from three different academic fields. These are distinct

knowledge and skill areas and as such lends itself to the view that change management is macro-competency made up of many other micro-competencies.

Table 3

Summary of Proposed Change Management Activities for HR Involvement by Field

\begin{tabular}{|c|c|c|}
\hline Proposed Activity & Field(s) & Source(s) \\
\hline $\begin{array}{l}\text { Communicate reasons/need for } \\
\text { change }\end{array}$ & $\begin{array}{l}\text { HRM, } \\
\text { HRD, OD }\end{array}$ & $\begin{array}{l}\text { Edmonds (2011); Maheshwari } \\
\text { and Vohra (2015); Ulrich } \\
\text { (2016) }\end{array}$ \\
\hline $\begin{array}{l}\text { Anticipate and mitigate } \\
\text { resistance to change }\end{array}$ & HRM, OD & $\begin{array}{l}\text { Chen and Wang (2014); } \\
\text { Griffith-Cooper \& King, 2007; } \\
\text { Kotter (1995) }\end{array}$ \\
\hline Mediation/Negotiation & HRM, OD & $\begin{array}{l}\text { Alfes et al. (2010); Ogilvie and } \\
\text { Stork (2003) }\end{array}$ \\
\hline $\begin{array}{l}\text { Help employees with stress of } \\
\text { change }\end{array}$ & HRM & Smollan (2015) \\
\hline $\begin{array}{l}\text { Create a coalition to support } \\
\text { change }\end{array}$ & HRM & $\begin{array}{l}\text { Kanaane et al. (2015); Kotter } \\
\text { (1995) }\end{array}$ \\
\hline $\begin{array}{l}\text { Create awareness of } \\
\text { organizational purpose and } \\
\text { mission }\end{array}$ & HRM & Mosca et al. (2015) \\
\hline Consultant to business leaders & HRM & $\begin{array}{l}\text { Alfes et al. (2010); Younger et } \\
\text { al. (2011) }\end{array}$ \\
\hline Training and creating capacity & HRD & Higgs and Rolland (2009) \\
\hline $\begin{array}{l}\text { Establish organizational } \\
\text { competencies }\end{array}$ & HRD & Alagaraja (2013) \\
\hline Leadership development & HRD & $\begin{array}{l}\text { Higgs and Rolland (2009); Ray } \\
\text { and Goppelt (2011) }\end{array}$ \\
\hline Diagnose organizational need & OD & Woodman (2014) \\
\hline
\end{tabular}

\section{Alignment with Practice Literature}

Scholarly academic research is not regularly consumed by the typical HR professional, so how do the studies and recommendations make their way to the 
workplace? In addition to formal education, the U.S. Bureau of Labor Statistics (2020) lists certifications, specifically SHRM certifications, as way to prepare for HR roles. HR professionals also turn to professional certification associations to keep their skills updated even after they have attained an academic degree. Such organizations as the Society for Human Resource Management (SHRM) and Association for Talent Development (ATD) provide resources and testing for proof of skill proficiency. Similarly, popular management magazines such as Harvard Business Review (HBR) are used by many organizations to stay informed on practice trends. Harvard Business Review, a general management magazine published by Harvard Business Publishing wholly owned by Harvard university, continues to increase in paid subscriptions and has an average of 7 million unique visitors each month (Harvard Business Review, 2019). Many of the same academic authors submit summary articles based on their academic research such as Ulrich. However, the same scholarly peer-reviewed standards do not apply. Ulrich's most cited article, for example, is one he published in 1998 in Harvard Business Review (Google Scholar, 2020) only exceeded by two books he authored/coauthored published by Harvard Business Press.

Strategic HR. As of 2017, SHRM (2017) proclaimed it was the fastest growing human resource credential program and had surpassed 100,000 certificate holders and the society itself is the largest in the world and represents 285,000 members worldwide. As such the SHRM competency model is influential in when HR professionals seek to determine what their knowledge areas should be for success. The model itself consists of nine competencies with multiple sub-competencies under each. The nine are HR Knowledge, Ethical Practice, Leadership and Navigation, Business Acumen, 
Consultation, Critical Evaluation, Communication, Global and Cultural Effectiveness, and Relationship Management (SHRM, 2016). In addition to the competency guide that outlines the certification content areas, SHRM website features many articles and resources such as the one by Susan Milligan (2018) forecasting her thoughts on HR in 2025 with seven broad strategies including getting your certification. Although some loose parallels could be made to the SHRM competency model, there was no research or studies offered as the basis of these projections.

Harvard Business Review (HBR) as a management magazine is primarily focused on business leaders as the audience. However, human resource topics are common, although they may be focused on a company executive as the reader. In fact, many articles disparage the role of HR professionals. For example, an article titled "Why More Executives Should Consider Becoming a CHRO” (Boudreau, Navin, \& Creelman, 2017) stated that the CHRO position is seen as an undesirable role for executives. They further explain why "outsiders" or those not formally trained in HR make better CHROs primarily due to their business acumen and propensity to embrace risks rather than focus on reducing it. Other titles tend to focus on what needs to be fixed about HR such as "How Netflix Reinvented HR" and "It's Time to Split HR". HBR does not attempt to define an HR competency model, but it does influence how business leaders view the human resource departments. Cappelli (2015) wrote about why we love to hate HR in an edition of HBR that featured a statement on the cover; "It's time to blow up HR and build something new". The focus of articles such as these indicate a perspective that HR has not updated its programs to keep up with the changing business needs. Schulz and Nicolai (2015) completed a bibliometric analysis of the Harvard Business Review and 
their findings suggest that not only is HBR widely quoted as a source, but it has influence on scientific discourse in research.

Change management. The SHRM (2016) competency model has change management listed as a sub-competency both in HR Knowledge and Leadership and Navigation competencies and mentions such behaviors as supporting organizational change and gaining buy-in. In an article on the future of HR, Milligan (2018) used the word change multiple times to underscore the importance and urgent need to use the seven strategies consider critical for the forecasted future. However, she had no mention of change management as a competency or strategy for HR.

The Association for Talent Development (ATD) also has a competency model for HR professionals. Although more generally sought after by those in training and development roles, the competency model is much more comprehensive for developing the capacity of the entire organization. The model begins with three major impact areas including Building Personal Capability, Developing Professional Capability, and Impacting Organizational Capability. It is under this last area that we find change management as a stand-alone knowledge area. Instead of the general "gain buy-in" statements, the ATD competency has four broad knowledge areas with the first knowledge in influential change management models, the second knowledge of how change impacts the organization and people, the third skills in assessing risk and resistance to a defined change management approach, and finally skill in designing and implementing a change management strategy (ATD, 2019). This is more aligned to the academic research recommendations for HR professionals leading and supporting change. 


\section{Gaps in Theory and Practice}

As illustrated above, although we can pull together many suggestions for HR competencies and definitions and activities for change management, a comprehensive aligned set of knowledge skills and abilities does not currently exist. A cohesive competency agreement is needed to inform job performance (Campion et al., 2011). Without this foundation, even further research findings may lack full or correct interpretation of the implications to practice. Even if we take a situationalist perspective to both competency development for strategic HR and more specifically the competency of change management, stronger empirical evidence is needed to understand how the context and structure of the HR group impacts practice.

Gaps in theory. The primary gap can be found in the lack of consensus and cohesion surrounding the deployments and activities in which HR should engage to help organizations reach their company goals. The three disciplines separately focus on parallel tracks of thought for how HR can provide value to organizations through resource management (HRM), developing employee capability (HRD), and organizational performance and capability (OD). The issues remain that these three areas must work collectively within an organization to provide the value to the organization, but very little literature exists that consider the overlap. Without a comprehensive view of the activities and competencies needed for strategic HRM, then higher education programs do not consistently include key topics like change management in the curriculum. Ulrich's successive rounds of competencies are the most cited, but they are not universally agreed upon and have changed significantly in the last ten years. 
Gap in practice. Younger et al. (2011) warn that line managers consider HR as inadequately trained in the area of consulting and change management. This came from their global research of line managers and HR professionals across several industries. Bernardin and Russell (2013) also expressed concern over the capabilities of HR practitioners. A study of 44 global companies found many organizations were struggling with developing their HR professionals fast enough due to the pace of business (Kelly \& Rapp, 2018). Citing an unpublished research study conducted by Bernardin in 2011 of over 1,000 HR professionals, the overall results demonstrated a very low knowledge of the HR basics common in academic programs, with average grade determined to be a "D". One potential reason for this, they note that many organizations hire HR candidates with MBAs that may not include any HR curriculum (Bernardin \& Russell, 2013). Consistent with this finding, Cohen (2015) found that the "seasoned strategic senior HR professionals" (p. 213) many times do not have HR degrees because degrees were not required in the past. Specific to change management, the proficiency of HR professionals in change from Ulrich's (2017) 1987 round of research to 2016 had improved over the course of the seven rounds, however it was the least improved of the four larger groupings of business, HR delivery, change, and personal proficiency.

Gap in formal learning. One possible explanation for the gap in practice for the HR competency of change management is the lack of formal learning opportunities in associated higher education curriculum. There is a concern that graduate and undergraduate $\mathrm{HRD}$ programs are not appropriately structured to prepare candidates for the needs of the business environment (Beyerlein, Jones, \& Peck-Parrot, 2017; Gaudet, 
Brown, \& Lunsford, 2017; Kuchinke, 2002; Lim \& Rager, 2015). Beyerlein et al. (2017) propose that part of the problem is due to the struggle to define the discipline.

HRD programs. Both Gaudet et al. (2017) and Beyerlein et al. (2017) found the need for components of supporting change efforts to be added to HRD curriculum. The work of Kuchinke (2002) and the repeated study by Lim and Rager (2015) reveal a gap between the HR competencies and the supporting HRD graduate programs. Kuchinke (2002) sampled 55 major HRD graduate programs in the US comprising 44 doctorate and 11 Masters programs. The most commonly required curriculum content areas were instructional design and instructional delivery and evaluation. Change management was an included content area by $45 \%$ of the programs; the extent of that inclusion was not fully examined. When Lim and Rager (2015) repeated Kuchinke's study, they did not find much improvement even in an expanded sample of university programs. In fact, change management as content area in these programs was well less than his original findings at only $19 \%$.

HR programs. Just as Kuchinke, Lim, and Rager examined HRD programs, Ramlall and Sheppeck (2007), examined HR programs for the curriculum in support of specific competencies. They found in their study of 127 programs in 31 states that most HR programs (104) were in the college of business with the few remaining in the education or psychology departments. Consistent with the HRD program findings, only $18 \%$ of the HR graduate programs required organizational change courses. In a subsequent study (Ramlall \& Sheppeck, 2007), they compare the HR graduate program findings to what HR professionals revealed as time spent in different $\mathrm{HR}$ activities. A survey of $108 \mathrm{HR}$ professionals illustrated most of their time was spent in activities 
associated with staffing and being an internal consultant for human capital issues.

Activities associated with managing change were among the lowest; in fact, it was lower than time spent on general administrative tasks.

HR's collaborators. The same can be seen in some studies of the curriculum for the management that HR ultimately partners with. Although his research does not specifically address the recommended curriculum for those leading companies, Spender (2014) also acknowledges a perceived gap in management education in the business schools compared to the needs in practice based on changing business environments.

Many organizations turn to internal or external consultants for expertise in change management, but there can be a gap in their knowledge of change management as well. Pries and Stone (2004) interviewed senior external consultants across three different countries. They were surprised to find that the consultants did not receive continuous training as expected, but rather most mentioned some sales training earlier in their career and occasional conferences. None noted any type of training on change management. Deficiencies in change management adoption were generally ascribed as a fault of the client for challenges such as lack of time allowed for change. Creating internal change consultants is another option for organizations in need of expertise, but challenges exist here as well. In a comparison of project managers and change managers, Pollack and Algeo (2014) found considerably fewer managers identified themselves as change managers than project managers at $14 \%$ and $5.6 \%$ respectively. When asked about their training in change management, the most common responses were "In-house or uncertified training" at 39\% and "No training" at 31.7\%. Crouse et al. (2011) found that HR professionals felt they needed more training on change management, but also more 
training in other areas of their particular business in order to be more successful as change agents.

It is not surprising that change efforts are not considered fully successfully when there seems such a lack of training and preparation for a something as complex as managing change in a complex business world.

\section{Adult Learning Theory}

As a theoretical framework to understand the alignment of practice and theory, adult learning theory allows the exploration of competency development to understand how HR professionals prepare for strategic work. Merriam (2004) identifies the three major areas informing adult learning theory as andragogy, self-directed learning, and transformational learning. In a meta-analysis she reviewed the works of Malcolm Knowles and Mezirow as the founders of these theoretical areas. The work of Malcolm Knowles is credited with the idea of defining an adult learner in andragogy as opposed to how children learn in pedagogy (Merriam, 2004). In his later works, Knowles (1980, as cited in Merriam, 2004) began to think of it more as continuum of those characteristics rather than opposing theories since there is overlap of these concepts between children and adults, such as self-motivation. Mesirow, the founder of the transformational learning theory, and it is truly dependent on adult experiences (Merriam, 2004). "At the center of these theories and models is the adult engaging in formal and informal learning activities that address some perceived need or interest" (Merriam, 2004, p.199).

Jarvis (2007) suggests that rather than implying a broad and ranging knowledge

attainment, lifelong learning is being driven by employers' demand for skilled workforce in complex and changing economy, thus resulting in a more narrow, vocational focus. 
Informal learning can supplement other formal and non-formal learning by overcoming some of the challenges of generic, not specific to situation, timeliness, and difficulty of keeping up with the changing demands (Decius, Schaper, \& Siefert, 2019). Decius et al. (2019) suggest that HR professionals can support and optimize the impact of informal learning of employees in the workplace. There findings from an empirical research study among blue collar manufacturing workers to establish a measure of informal learning in the workplace.

Mahajan (2017) maintains that the context or motivation for the learning activity is needed to understand what type of learning is taking place. He illustrates this with an example of a student at a science museum and the category of learning is dependent on the reason the student attended and if it was structured or spontaneous. He describes the three as related and closer or further away from each other based on the degree of systemization and organization of the particular learning activity. He sees informal learning as supporting the both formal and non-formal learning. Galanis, Mayol, Alier, and García-Peñalvo (2016) note challenges to validating the learning of informal learning activities and are typically done by methods associated with formal and non-formal learning. They question the effectiveness of these methods since the type of learning is so different. They recommend a more social peer collaboration type of validation of learning. However, I feel that the structured way in which they propose for individuals approach informal learning and validation pushes it over in the category of non-formal learning.

Manuti et al. (2015) suggest that the "acquisition of skills and knowledge" do not take place in classrooms alone. "Transitions from school to work are not as distinct and 
linear as they once were. Learning is no longer confined to occasional formal activities in classroom environments." (p. 2). They propose that there are elements of both formal and informal present regardless of the learning context and it is an oversimplification to consider that only formal learning present in formal learning contexts and vice versa. The main distinction that is important for this dissertation is the criteria of intention to learn and if the participant understands it as structured learning or as part of their daily interactions. Therefore even though the adult learning process for the how a topic is learned may be essentially the same and/or so overlapped as to be indistinguishable for non-formal and informal learning, in the context of the work place, the exact content of what is being learned is influenced greatly by the intent to learn and a structured event with content and topics pulled together from experts.

Malcolm, Hodkinson, and Colley, (2003) identify differences between formal, non-formal, and informal learning. They concluded they could not discern any substantial difference between non-formal and informal learning. They noted the criteria they encountered in the literature was too varied and numerous thus citing that as a challenge to a concise definition. They agree that the characteristics of both formal and informal learning are present in all learning situations. Although they note these challenges, they do not recommend a complete avoidance of those designations altogether, but rather to use them with the purpose of distinguishing aspects of learning without making broad assumptions or trying to justify the superiority of one over another. They see the main distinction made over time as a political perspective and use of the term non-formal learning intended to "empower underprivileged learners" (p. 314). Ultimately, they see informal and non-formal as essentially defined by the opposites of those characteristics 
attributed to formal learning. "informal and formal learning as essentially different, but capable of greater combination" (p. 313).

Eraut (2004) actual findings are that most learning is the result of working on the job, even though most respondents equated formal learning with something very different than work. He prefers to define informal learning as that takes place on the informal end of a continuum as opposed to the formal end. Eraut (2004) feels so much learning goes unrecognized, which makes it challenging to research, but did find four main types of work activities that led to learning: Working with clients, participating in group activities, working alongside others, tackling challenging tasks. Malcolm et al. (2003) conclude that non-formal as a point in between formal and informal is redundant. However, they also state they are not recommending avoidance of the use the designators, but rather to ensure that the terms are used with the context and purpose clearly stated. Regardless of the overlap, the distinction here based on context is critical to understanding in practice in order to be able to distinguish between and make appropriate recommendations to higher education, certifying associations, and organizations.

Operationalizing learning opportunities. While research indicates some overlap and difficulty in pinning down the exact criteria of each form of learning, it also suggests that being particular about the context and intentions is best when attempting to categorize these different types of learning along a life-long learning continuum. For the purposes of this dissertation, I pull together the distinctions made for each of these three learning categories. The attributes are detailed here and summarized in Table 4 with some example learning opportunities included for each one. 
Formal learning. Eraut (2004) finds that most respondents in his research equate learning with formal education or training and very different than work. The context or setting is the key here with a formal, typically academic or vocational classroom highly structured setting (Merriam, 2004). As a structured formal learning opportunity, there is also an intention to learn, guided by stated learning objectives, and typically results in academic credit (Manuti et al., 2015).

Non-formal learning. Non-formal learning is in the middle of the continuum by being less structured than formal learning, but decidedly more structured than informal learning (Merriam, 2004). Kyndt, Dochy, and Nisj (2009) define non-formal as anything outside of a school setting, but more structured than informal learning. Usually with a strong emphasis on practical experience. McCall (2004) sees workplace training as better viewed as a supplement to experiential learning than as core of learning. So non-formal training can provide the opportunity to reflect and make sense of experiences or provide a substitute for situations that future state is too risky/difficult to provide. He believes that there is no substitute for experience in leadership development, but learning is not automatic from experiences. Therefore, it is important to develop non-formal learning programs in which people can purposely learn from experiences. According to Mahajan (2017), a key distinction between non-formal and informal learning is the intention to learn which would include objectives of what is to be learned.

Informal learning. Informal learning can take place inside of formal and/or nonformal learning opportunities since it has more to do with learning that occurs incidentally without the participant being aware (Eraut, 2004; Manuti et al., 2015). For the purpose of this dissertation; however, I will use informal learning as the distinction of 
learning taking place outside of formal and non-formal learning environments. Informal learning takes place outside of a structured environment but can be enhanced by learner awareness (Marsick \& Watkins, 2001). The most distinctive characteristic being that it may happen out of an "critical moments of need embedded in the context of practice" (Manuti et al., 2015, p.5). 
Table 4

Summary of characteristics and example learning opportunities by learning category

\begin{tabular}{lll}
\hline $\begin{array}{l}\text { Learning } \\
\text { Category }\end{array}$ & Characteristics & $\begin{array}{l}\text { Example Learning } \\
\text { Opportunities }\end{array}$ \\
\hline $\begin{array}{l}\text { Formal } \\
\text { Learning }\end{array}$ & $\begin{array}{l}\text { Highly structured (Merriam, 2004) } \\
\text { Academic setting (Eraut, 2004) } \\
\text { Intention for learning (Manuti et al., 2015) } \\
\end{array}$ & $\begin{array}{l}\text { Academic Degree Programs } \\
\text { Academic Courses }\end{array}$ \\
& Results in Academic Credit (Manuti et al., 2015) & \\
Non-formal & Less structured (Merriam, 2004) & \\
Learning & Non-Academic Setting (Kyndt et al., 2009) & \\
& Intention for learning (Manuti et al., 2015) & Workshops \\
& Stated learning objectives (Mahajan, 2017) & Conference Break-out \\
& Experiential practice (Kyndt et al., 2009) & Sessions \\
& & Certification Programs \\
& & On-line Training \\
Informal & Outside of a structured environment (Marsick \& Watkins, 2001) & Job-Shadows \\
Learning & May not be recognized as learning (Eraut, 2004) & Trial and error \\
& No intention for learning (Manuti et al., 2015) & Learn as you go \\
& May occur in critical moments of need within the context of & Learn from others \\
practice (Manuti et al., 2015) & Learn from past experience \\
& Reactive to situations (Eraut, 2004) & \\
\hline
\end{tabular}




\section{Summary}

The existing research is plentiful in empirical studies attempting to define the competencies needed for HR professionals to succeed in Strategic HRM. Although there is not perfect agreement, generally the competencies defined by Ulrich (2016) stand out as the most widely accepted. Over twenty years of repeated studies demonstrate simultaneously that we know what HR professionals should know and do, however, as a profession they are no closer to being proficient in those competencies. HR Practice literature and certifying bodies are not completely aligned to the academic research, further exacerbating the challenge for HR professionals.

The existing research is very strong in the area of models for understanding organizational change and the benefits for HR involvement in leading and supporting the change. There is truly a convergence of the three disciplines in this area. Where they diverge, is the area where the research and practice begin to weaken. Organizational boundaries are not always aligned with those separate discipline lines of HRM, HRD, and OD and regardless of the structure, the HR professionals must work together as one organization. The different terminology and narrowed focus on just one part of the employee experience from each discipline continues to move the research further from an aligned set of organizational interventions.

Perceptions of effectiveness of organizational change efforts remains low. There is little academic research to either confirm or challenge these perceptions. Barends, Janssen, ten Have, and ten Have (2014) find the body of evidence for the effectiveness of organizational change interventions is both sparse and low quality. They challenge scholar-practitioners to do better 
research even though it has been difficult to gain senior management's commitment to do so within organizations. Further, Jackson et al. (2014) encourage the next generation of strategic HR scholars to engage in research to address the challenges of contemporary organizations. Krysynski and Ulrich (2015) stated they did not find much in the academic research about how HR can deliver on the need to redirect behaviors of employees to meet changing external market demands.

There is a need to focus the research in areas that can bridge the gap between the multiple disciplines, which are proposing theories, roles, and interventions, and the lived experiences of HR professionals in the field. While several studies have focused on what proficiency HR is perceived to have, few have examined how HR professionals have gained the knowledge, skills, and abilities associated with the change management activities they are expected to perform. Those studies have been limited to surveys of HR manager's formal education degrees. The next chapter outlines the research design used to explore this topic through the lived experiences of HR professionals in practice to gain insights into how they have developed their change management competency. 


\section{CHAPTER 3: RESEARCH DESIGN AND METHODOLOGY}

From an interpretivist framework, the intent of the research is to rely on the participants' view of their situation and life setting (Creswell \& Poth, 2018). Interpretivism guided the exploration of the HR managers' perceptions and interpretations of their described experiences. The research design was an instrumental single site case study (Stake, 1995). The study included HR managers within one organization that fit the research criteria by having change management as a stated competency and were part of a large organization that had experienced many organizational change initiatives over the last 5 years. A qualitative research design allowed for the inclusion of the rich detail and context that added to the understanding of this case (Miles, Huberman, \& Saldaña, 2013). The design allowed for a focus on the issue of developing a change management competency at one site to provide insight about the research questions (Yin, 2011). Change management is a complex construct and highly dependent on the context (Capaldo et al., 2006). The case was bounded to one organization with a focus on positions and roles that identify change management as core and essential competency required for HR managers. The unit of analysis was a HR manager at this site (Creswell \& Poth, 2018). These parameters were selected because it was a real-life case that was in progress (Creswell \& Poth, 2018) and provided a descriptive and holistic view of this case (Glesne, 2015). 


\section{Researcher Positionality}

As recommended, I share here the potential bias and experiences that influence my interpretation of results (Creswell \& Poth, 2018). In exploring my positionality as a researcher, I understand my interest in this topic stems from personal experiences as an HR manager given assignments in which change management was suddenly a major responsibility. At the time, I had some familiarity with the concept, but did not feel I possessed an adequate understanding to perform well. I sought out "training" in the form of books, articles, videos, webinars, and local conferences on the topic. As an HR manager, I feel change management is an important set of competencies to master given the many change initiatives I have been expected to lead. However, as a researcher, I want to understand if others in similar roles also view it is as important to their success and how they developed their acumen. In addition, I have extensive experience with similar large global organizations with very distinct roles for HR business partners and other specialized HR roles such as learning, talent management, and organizational development managers. While this type of HR structure is consistent with the recommendation of the competency being researched, it is not the HR structure of many smaller organizations in which the distinction between HR roles is diminished. This large organization perspective that I share with the participants, could also influence my interpretation of the results and I remained mindful of this when determining implications and recommendations.

Based on my prior experience in a similar role to the HR managers, I had three primary assumptions that could influence my interpretation of the data collected. The first is that few, if any all at, HR managers would have taken a college level course directly related to managing organizational change. I hold this assumption due to finding myself in the position of needing to 
acquire more knowledge in change management and very few if any of my colleagues had any training or knew of any opportunities to learn about change management. Change management was mentioned in one of my chosen electives on consulting, but not covered in depth in my own doctoral program. The second assumption is that the HR managers would consider their proficiency in change management as sufficient for their role. Again, I base this on my quest for knowledge in which most colleagues felt they knew enough about change management because they were involved in so many change initiatives. Of course, a few shared my view that there was so much more we needed to know to help employees and organizations through the onslaught of changes. The final assumption is that the primary ways in which HR managers would contribute their learning in the topic would be categorized as the informal learning category. Although this seems to have been my experience in my work life, I was eager to hear about the lived experiences of these HR managers. Careful data collection, member checking and analysis were used to ensure my assumptions did not incorrectly influence my findings.

\section{Case Description}

The human resource managers were from a large global firm in the hospitality industry based in the U.S. The organization had initiated several large-scale change projects led and/or supported by the HR function over the previous three to five years. Those large-scale change projects include organization-wide change to talent management processes, organizational structure changes, and new technology implementation projects. Of importance for this study were the research criteria that this organization had change management as a stated competency for the organization as well as specifically included in three of the four HR manager job descriptions. There was one standard change management competency called Leadership 
Courage for all appropriate job models scaled to the appropriate proficiency level for the management level of the position.

Figure 2 below details the stated proficiency levels for the change management competency. This was from an organizational document, which defines the expected competencies for all positions by management level. The roles that were explored fall into the mid-level leadership (manager, senior manager, director, and senior director roles) and the senior-level leadership (vice presidents up to the executive leadership including the officer roles). The mid-level leadership "supporting change" is the standard for three of the four roles and the senior-level leadership "leading change" is the standard for the fourth role.

\begin{tabular}{|c|c|c|}
\hline Individual Contributor & Mid-level leadership & Senior-level leadership \\
\hline $\begin{array}{l}\text { active learning: } \\
\text { Demonstrating } \\
\text { flexibility and } \\
\text { maintaining own } \\
\text { performance during the } \\
\text { change } \\
\text { - Learns quickly when } \\
\text { facing new problems } \\
\text { - A relentless and versatile } \\
\text { learner } \\
\text { - Open to change } \\
\text { - Analyzes both successes } \\
\text { and failures for clues to } \\
\text { improvement } \\
\text { - Experiments and will try } \\
\text { anything to find solutions } \\
\text { - Enjoys the challenge of } \\
\text { unfamiliar tasks } \\
\text { - Quickly grasps the } \\
\text { essence and the underlying } \\
\text { structure of anything }\end{array}$ & $\begin{array}{l}\text { Supporting Change: } \\
\text { Maintaining team } \\
\text { member engagement and } \\
\text { workplace performance } \\
\text { during the change } \\
\text { - Gives extra thought when } \\
\text { responding to any team } \\
\text { member concerns over the } \\
\text { change } \\
\text { - Communicates early } \\
\text { success stories to promote } \\
\text { learning and change } \\
\text { - Speaks to the need for } \\
\text { team members to learn from } \\
\text { their mistakes and think } \\
\text { outside the box } \\
\text { - In a compelling manner, } \\
\text { communicates the 'What's } \\
\text { in it for me?" (W.I.I.F.M.) } \\
\text { factor of the change for } \\
\text { team members } \\
\text { - Clearly communicates the } \\
\text { business rationale behind } \\
\text { the change } \\
\text { - Explains how each team } \\
\text { member will be impacted by } \\
\text { the change }\end{array}$ & $\begin{array}{l}\text { leading Change: } \\
\text { Ensuring the right } \\
\text { environment and } \\
\text { processes are in place for } \\
\text { the change to be a } \\
\text { success } \\
\text { - Ensures that energy and } \\
\text { resources are sustained } \\
\text { over the long-term of the } \\
\text { change } \\
\text { - Leverages technology, } \\
\text { processes or systems to } \\
\text { enhance organizational } \\
\text { learning and change } \\
\text { - Clearly defines the } \\
\text { expectations and how they } \\
\text { will change for internal and } \\
\text { external stakeholders } \\
\text { - Manages any resistance to } \\
\text { change within teams } \\
\text { - Fosters an environment } \\
\text { where team members' and } \\
\text { leaders' egos and sense of } \\
\text { entitlement are kept in } \\
\text { check } \\
\text { - Monitors the team's } \\
\text { successes and failures, and } \\
\text { shows a willingness to } \\
\text { course correct whenever } \\
\text { necessary }\end{array}$ \\
\hline
\end{tabular}

Figure 2. Organizational competency defining responsibility for change management by level. 
Participant demographics. In the organization, there were ten total positions considered an HR business partner to the different business units or levels of the organization in four different job roles. All ten incumbents were invited to participate in the research, and they all agreed. The four distinct roles report up to the head of HR for the organization, the Chief HR Officer (CHRO) who is a business partner for the Chief Executive Officer (CEO) and Executive Leadership Team (ELT). Reporting directly to the CHRO was the Senior Director HRBP (Sr Dir HRBP) who was responsible for the all other HR business partner roles and was a business partner for the ELT and their direct reports. There were eight individuals in two different HR business partner roles with one a business partner for the operations group in the field, the HR Director (HR Dir), and the other a business partner for the corporate functional groups, the HR Business Partner (HRBP). Figure 3 illustrates the four distinct roles in the reporting relationship. This allows for different perspectives with the same focus on the relationship and responsibilities of the business partner relationship.

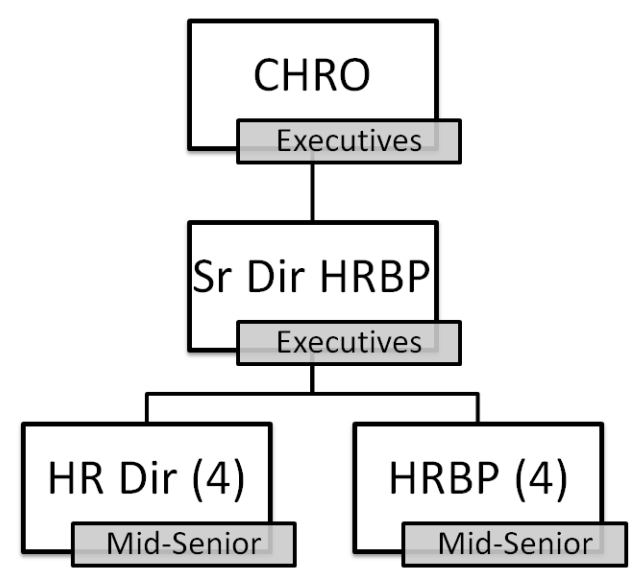

Figure 3. Illustration of the reporting relationship and business partners for the four distinct roles. 
It was also important to understand how the organization positioned the HR business partners within the organization and the rest of the HR department. In Figure 4 the structure illustrates that the HR business partner had a two-way relationship with the customers, meaning internal business customers, as well as the HR functions grouped as centers of excellence (COE) and the people services group responsible for human resource data and the systems that record that data. In this two-way relationship, the HR business partner shared information from each group with the others to facilitate and implement HR processes across the organization. Additionally, the HR business partner might suggest or request changes to processes or resources based on the needs of their internal customers. The centers of excellence were the functional groups within HR that focus specifically on one or more topic areas to provide expertise for the organization in talent management, talent acquisition, total rewards, and employee relations. This structure was officially put in place approximately 10 months prior to the data collection interviews, however, this was loosely being followed for the previous two years. This model was adapted from the Deloitte's High-Impact HR Operating Model (Mazor \& Johnsen, 2017). 


\section{Align Talent Strategy to Business Strategy}

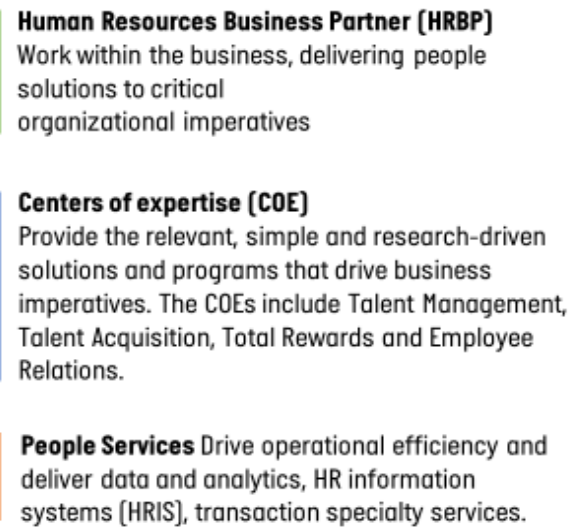

People Services Drive operational efficiency and deliver data and analytics, HR information

systems [HRIS], transaction specialty services.

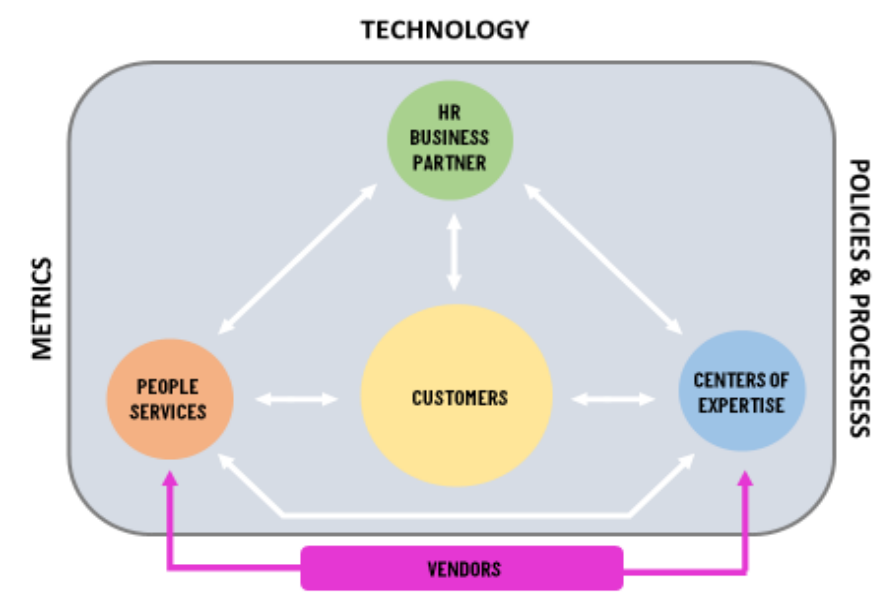

Figure 4. Illustration of the organizations HR structure.

During the process of scheduling the interviews with those that were in the four roles, it was discovered that two additional individuals within the organization had each held one of those four positions, CHRO and Sr Dir HRBP, within the past year and they were invited to participate as well. This brought the total to 12 individuals within the organization who could provide insight on the lived experiences in these HR business partner roles and 100\% participated. The details of the breakdown of the roles and the number of participants by years of HR experience is shown in Table 5. The experience ranged from 5 years to 22 years among the participants, which were $58 \%$ female and $42 \%$ male. 
Table 5

HR experience by job title and percentage of participants

\begin{tabular}{lcccl}
\hline & $\begin{array}{l}5 \text { years } \\
\text { but less } \\
\text { than 10 }\end{array}$ & $\begin{array}{l}\text { 10 years but } \\
\text { less than 20 }\end{array}$ & $\begin{array}{l}\text { 20 or } \\
\text { more } \\
\text { years }\end{array}$ & $\begin{array}{l}\text { \% of } \\
\text { participants } \\
\text { per role }\end{array}$ \\
\hline CHRO* (2) $^{\text {SH Dir HRBP* (2) }}$ & 1 & 1 & 2 & $17 \%$ \\
HR Dir (4) & 2 & 1 & 1 & $33 \%$ \\
HRBP (4) & 1 & 2 & 1 & $33 \%$ \\
Total (12) & 4 & 4 & 4 & $100 \%$ \\
\hline
\end{tabular}

Note. $*$ indicates the total includes one individual who previously held the position.

Since the research was seeking to understand the development opportunities of the participants, the organizational documents called talent profile cards were obtained which provided the degree programs and certifications that the participants had obtained. Table 6 is a summary of that information by gender.

Table 6

HR summary of education and certifications

\begin{tabular}{lcccc}
\hline Gender & $\mathrm{n}$ & Degree & $\begin{array}{c}\text { HR Specific } \\
\text { Major }\end{array}$ & $\begin{array}{c}\text { HR } \\
\text { Certifications }\end{array}$ \\
\hline Male & 5 & $40 \%$ & $40 \%$ & $80 \%$ \\
Female & 7 & $86 \%$ & $14 \%$ & $71 \%$ \\
Total & 12 & $67 \%$ & $25 \%$ & $75 \%$ \\
\hline
\end{tabular}


Other organizational documents provided data on performance ratings as well as a rating on the change management competency if available. Although either supporting or leading change was a stated competency for each of the roles, the annual performance review only included a sub-set of competencies for each role. Table 7 is a comparison of the self-assessment the participants gave during the interviews regarding their proficiency in change management categorized as above, below, or at average compared to other HR professionals against their manager's most recent assessment of that same competency. Also included was an overall performance rating inclusive of all job-related performance. All participants rated were considered as meeting expectations (3) or higher in their job performance and were similarly rated on the change competency if included. A few participants rated themselves one level higher or lower than their manager rated them, but the information overall indicates fairly consistent performance and knowledge of change management.

Table 7

Comparison of Self-assessment to manager rating of change competency and overall job performance rating

\begin{tabular}{lrcc}
\hline & $\begin{array}{l}\text { Interview } \\
\text { Self-Assessment }\end{array}$ & $\begin{array}{l}\text { Manager Rating of } \\
\text { Change Competency } \\
\text { (5-pt scale) }\end{array}$ & $\begin{array}{l}\text { Overall Job } \\
\text { Performance Rating } \\
\text { (5-pt scale) }\end{array}$ \\
\hline CHRO 1 & Above Average & N/A & N/A \\
CHRO 2 & Above Average & N/A & 4 \\
Sr Dir HRBP 1 & Average & N/A & N/A \\
Sr Dir HRBP 2 & Above Average & N/A & 3 \\
HR Dir 1 & Average & 4 & 4 \\
HR Dir 2 & Above Average & 3 & 3 \\
HR Dir 3 & Above Average & 4 & 3 \\
\hline
\end{tabular}




\begin{tabular}{|c|c|c|c|}
\hline HR Dir 4 & Average & 4 & 4 \\
\hline HRBP 1 & Average & 3 & 4 \\
\hline HRBP 2 & Average & 3 & 3 \\
\hline HRBP 3 & Above Average & N/A & 4 \\
\hline HRBP 4 & Average & N/A & 3 \\
\hline \multicolumn{4}{|c|}{ Note. Competency rated is Supporting Change the mid-level leadership of Leadership Courage. } \\
\hline \multicolumn{4}{|c|}{ throughout the US and the world. The key services of this organization are food service, supply } \\
\hline \multicolumn{4}{|c|}{ chain, and print service in the hospitality industry. The site was selected for one primary reason, } \\
\hline \multicolumn{4}{|c|}{ the size of the organization makes it possible to interview a sufficient number of HR } \\
\hline
\end{tabular}

Case and participant sampling strategy. For this study, purposive criterion-based sampling was used by selecting the HR professionals within an organization with the specific competency of change management and employed in a setting that had undergone enterprise change initiatives in the previous five years. The ideal or sufficient sample size in qualitative research is not easy to determine. The purpose is to understand a typical case and the participants were all from one organization and considered homogeneous in relation to this topic, these conditions do not call for as large of a sample size (Creswell \& Poth, 2018; Yin, 2011). The idea of saturation of data is the main consideration for qualitative research. Guest, Bunce, and Johnson (2006) found thematic and coding saturation after the twelfth interview. In order to ensure a small enough sample for the rich detail needed in this case study, but large enough to determine themes among the participants (Creswell \& Poth, 2018), the goal for the study was to 
include a minimum of ten participants. In this case, $100 \%$ of the participants in these HR roles were willing to participate and the total participants exceeded the minimum for the study.

\section{Data Collection}

As a case study, interviews were the primary source of data collection. As such, the researcher acted as an instrument of data collection and care was taken to ensure accuracy and consistency of the data collection (Creswell, 2014). Creswell (2014) also recommends the addition of data collection beyond the typical interview data. Therefore, organizational documents regarding all HR managers self and manager assessment of their proficiency in the change management competency as well as any documentation of organizational provided training on this topic were also included.

Interviews. Semi-structured interviews with open-ended questions were employed for this case study to have the benefit of the same primary questions for each participant, but also allowed the opportunity to explore and probe areas of interest (Brewerton \& Millward, 2001). Appendix A details the interview protocol.

Organizational documentation. Organizational documentation enhanced the ability to describe the real-life context in which the HR managers were working and experiencing organizational change. Organizational documents determined to provide context and insights for this dissertation included the organizational competency documents, a training report for all participants, talent profile cards for each participant, job descriptions, and 2019 performance and competency assessment data. The learning management system for the organization was also queried for all training content pertaining to change management and a total of four online 
training modules were available to all participants. The available training titles were Change Management, Delivering Organizational Change, The Catalyst CFO: Managing Change, and Creating a Mindset for Change.

\section{Trustworthiness}

The ideas of validation and reliability from quantitative research do not correspond directly in qualitative research and has been much debated (Creswell \& Poth, 2018). Although it cannot be achieved in the same manner or for the same intent as in quantitative research, there are steps that influenced the design process to improve the trustworthiness and transferability of the research (Creswell \& Poth, 2018). Trustworthiness and confirmability were improved by using a recording of each interview and transcribing the entire interview including what might be otherwise considered trivial, such as pauses and overlaps (Creswell \& Poth, 2018). Miles et al. (2013) contend that both validity and reliability are, in large part, dependent on the skill of the researcher. A few areas they share as indicators of good qualitative "researcher-as-instrument" (p. 41) which were incorporated into my dissertation are my familiarity with the phenomenon and setting as well as multidisciplinary approach. The remaining indicators represented areas I strove to accomplish such as meticulous attention to detail, being non-judgmental, and balancing empathetic engagement with objective awareness.

Creswell and Poth (2018) view validation in qualitative research as "an attempt to assess the accuracy of the findings, as best described by the researcher, the participants, and the readers (or reviewers)" (p. 258). They recommend the researcher establish accepted validation strategies categorized by each of those views of researcher, participant, and reader. Following their recommendation to employ at least two different strategies, I employed triangulation, clarified 
my researcher bias (positionality), completed member checking, and generated a rich, thick description. This thick description is the most important aspect for ensuring transferability of the research findings to other contexts or situations (Creswell \& Poth, 2018). For triangulation, the interviews of multiple participants at one site and review of archival data allowed the examination of this topic from multiple sources. Member checking was completed by having participants review initial analysis to allow them to suggest alternative meanings or interpretations based on their experiences.

Member checking. After the initial analysis was completed and organized into sub-codes and themes, the information was shared with participants as member checking to allow them to suggest alternative meanings or interpretations based on their experiences. At least one participant from each of the different roles was willing to review the initial analysis to compare interpretation and meaning. All felt the initial analysis fit with their experiences and no one suggested any alternate meanings. Many expressed their excitement about the topic and the hope for development recommendations resulting from the study.

\section{Ethical Considerations}

Several processes and protocols were employed to minimize the risk of any psychological or social harm to the participants as well as provide clear expectations. First, the approval of the Institutional Review Board (IRB) approval was gained prior to data collection. Information was provided to the participants to ensure their full understanding of purpose of the study, how data was collected, an estimate of the time required, and who would have access to the full and summarized data. An overview of this information was provided in a summary email along with an informed consent document for their review and attestation (Yin, 2014). 
Confidentiality of the participants responses was maintained by using a code name for each participant and only the researcher and committee panel have access to the real names. A summary of findings and recommendations was provided to the case study site organization, but not the full research information. The benefits to the participants were primarily being listened to and possibly gaining some insight while their cost was limited to the time allocated to the interviews and member checking (Miles et al., 2013). Each participant was thanked for the time they so generously gave to the study both verbally and through a handwritten note.

\section{Managing and Recording Data}

Following the guide of Miles et al. (2013), all pertinent data and files were managed in the NVivo software as well as a well-organized physical storage for notes and edited copies. A data accounting log has an inventory of all the data that has been collected as well as the location and can be found in Appendix B. All electronic locations were password protected and physical items were stored in a dedicated locked file box. All interview data was captured both in handwritten notes taken by the researcher during the interview as well as a transcript of the recorded interview, with permission from each participant. A code name was created for each participant with participant personal information password protected.

The organizational documents required the redaction of confidential employee id information which is un-related to the case study. All organizational documents were obtained through an internal liaison with authority to approve and/or dictate the permitted uses of the organizational documents. 


\section{Data Analysis}

The data collected was analyzed using qualitative methods. In accordance with the data collection plan, the data analyzed interviews and relevant organizational documents pertaining to the participants experience, education, and most recent annual performance reviews. The first step in data analysis was to become thoroughly familiar with the data (Roberts, 2010).

Transcription assisted in this aspect of data analysis by providing many additional details beyond the written notes from the interviews. Initial analysis began with memoing which consists of highlighting and writing notes in the margin of a printed copy of the transcript. The comparison of the handwritten notes taken while interviewing with memoing during transcription revealed much more details than I had originally captured. Most notable were all the supporting skills that participants associated with change management, such as negotiation and facilitation.

Data analysis software. Next the transcripts were loaded into NVivo software. The data analysis software was used to organize transcripts, record participant demographic data, and identify codes and themes. The first step was to auto-code the transcripts by interview question. This allowed the multi-page transcript documents to be organized based on the transcript responses for each interview question. In this way, a comparison of the responses for each question was easily visible and offered additional codes. Auto-coding was also used to populate an initial set of themes across the entire set of transcripts. Although this initial grouping was not surprising since it was largely driven by the interview questions, it was interesting to see all the different ways that the word "change" had been used. In this initial analysis, the key words change, business, management, and people aligned directly to my interview questions. Another auto-coded keyword was "team" with 27 references. I am not sure I would have captured that 
exactly this way, but after analyzing it in the auto-coded themes, I understood that being part of a team was a very strong element of the culture in this organization and important to the participants.

The software was also be used to generate word frequencies both for specific words as well as for synonyms for any initial insights. Creswell and Poth (2018) do not recommend showing frequencies in qualitative research but suggest they can be helpful in initial analysis. This is because the frequencies disregard the context of the statements and potentially groups together contrasting views. Following this advice, I found it invaluable in ensuring that I did not miss nuances of participants' responses that should be included in specific codes. As a case study, it was also important to analyze the data for elements that will provide the rich description of the context and real-life setting. Similarly, key word searches and word queries were helpful in finding similar sub-codes across interview participants and interview questions. For example, the detail given by participants when asked to describe change management events provided much more insights into what participants viewed as change management than the question of how they would define change management in their own words. Taken all together, the participants noted numerous nuanced skills included in change management.

Coding. Using the research questions as a guide, I analyzed the data for themes in three main areas or elements of change management in terms of how participants manage change, tools and techniques they employ, and how they developed skills in change management. I started with pre-existing codes as recommended by Creswell and Poth (2018). Miles et al. (2013) recommends continued analysis from this first cycle of coding to a second cycle coding in which I moved from multiple codes to themes. In this case study, the pre-existing codes were based on 
the elements and definitions of change management from the literature as well as grouping the development activities into formal, non-formal, and informal learning categories based on those distinctions. Creswell and Poth (2018) warn against jumping from codes to themes and recommend some strategies to make analysis and interpretation more rigorous. Strategies used were memoing, highlighting quotes, and draft summary statements in my reflection on the data. Glesne (2015) also recommends being more descriptive, holistic, and less thematic in interpreting the findings. I made use of several different analysis tools such as use of a partially ordered meta-matrix to assemble the most relevant data into a summarized view and then moved to partitioning and/or clustering data in successive analysis steps (Miles et al., 2013).

The pre-existing codes for my first cycle analysis were based on the original definitions of formal and informal learning from Marsick and Watkins (2001) and the further distinction of informal from non-formal learning by Eraut (2004). The summary of these can be found in chapter 2, Table 4. Some of the characteristics of formal learning included the intention for learning, highly structured, instructor-led, institutionally sponsored, and generally results in some type of educational credits (Manuti et al., 2015). Non-formal is noted as retaining the intention for learning, but with less structure and learning takes place through others in experiential ways. The distinction for informal is the lack of intention and structure, takes place as a reaction to the situation, and at the time may not be recognized as learning (Eraut, 2004). These distinctions are important to understand since the gap from the literature indicates a lack of formal learning opportunities for the change management competency. As my theoretical framework, this portion was important to start with the pre-existing codes to analyze the data collected through that lens. 
Allowing for emergent codes in the data was also important. The responses across the entire interview were analyzed for emerging codes related to change management elements since they were describing different scenarios and examples rich with context. These results were then compared to the operationalized change management elements collected in the literature review (Table 3). I felt it was important to allow these to emerge instead of starting with pre-existing to ensure I did not overlook potential elements of change that I did not discover in the existing research.

\section{Summary}

This instrumental single-site case study was designed to understand the lived experiences of HR business partners in a large global U.S. based firm with change management as a stated competency using qualitative analysis of semi-structured interviews and organizational documents. Analysis began with pre-existing codes based on the literature review in the areas of change management elements and the operationalized concepts of adult learning theory formal, non-formal, and informal learning. The analysis was seeking to understand answers to the research questions to determine if the findings of what is happening in practice can help inform the gaps in research and theory. The results of this analysis are further described in the next chapter. 


\section{CHAPTER 4: ANALYSIS AND DISCUSSION}

After completing the literature review and the analysis, it was evident that professional associations such as SHRM and ATD have significant influence on the concept of change management competency in practice and the research model was updated to illustrate that influence in Figure 5. This model will be used to organize the discussion of the analysis beginning with the overarching topic of Strategic HR and associated competencies. Next, I explore the definitions, activities, and influences on change management competency for HR as viewed by the participants. Finally, I examine how these HR professionals have developed their understanding and knowledge of change management competency through the lens of adult learning theory formal, non-formal, and informal learning. 


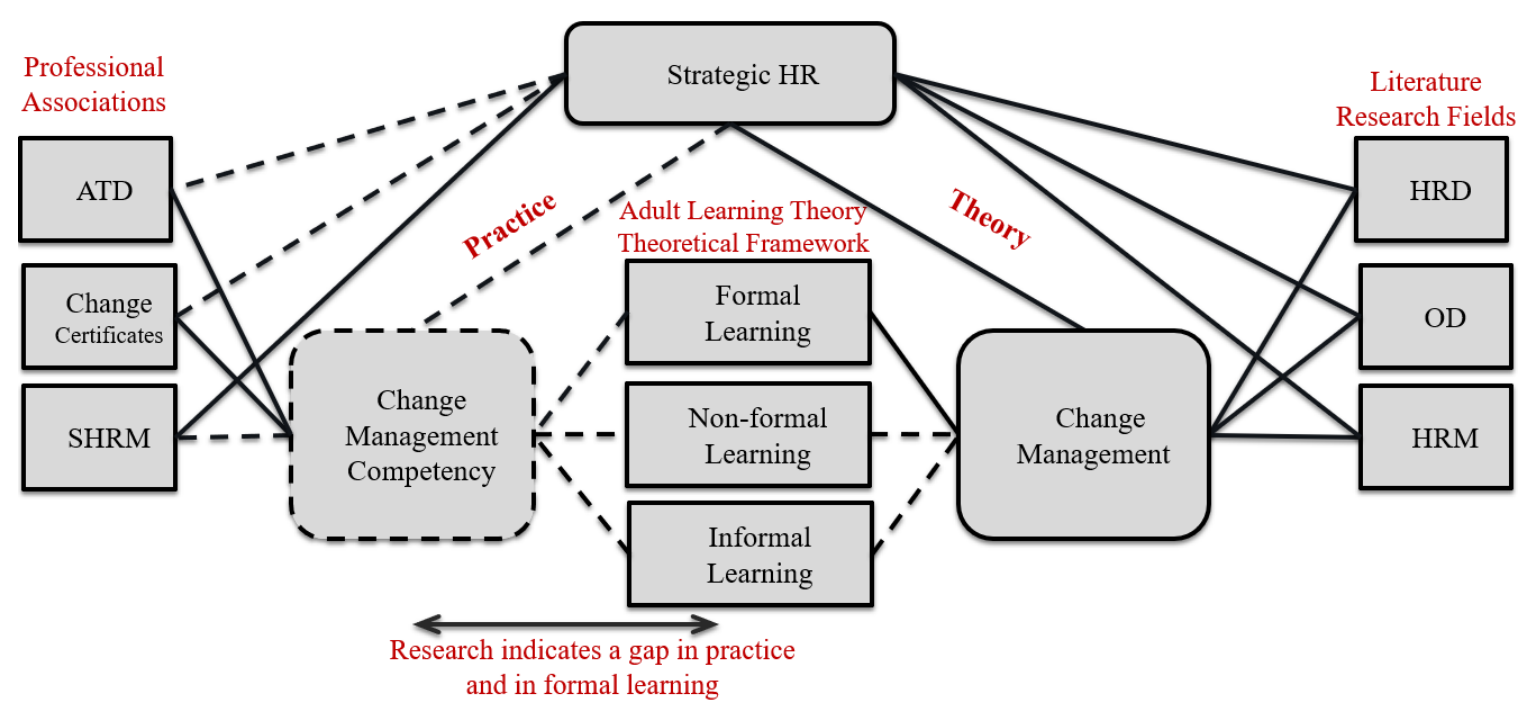

Background/ Literature Review

$\mathbf{- ~ - ~ - ~ - ~ - ~ D o t t e d ~ l i n e ~ r e p r e s e n t s ~ a ~ l e s s ~ d i r e c t ~ c o n n e c t i o n ~ i n ~ t h e ~ l i t e r a t u r e ~}$

Figure 5. Research model updated to include influences on practice.

\section{Strategic HR}

The backgrounds of most of the HR professionals mirrored the evolution of the HR profession in some ways. Most of the participants began their career in HR working in administrative roles before transitioning to the role of HR generalists. These transitions facilitated their growth as HR business partners to key organizational stakeholders. Although this case study is primarily focused on one specific competency of change management, the discussion of the HR business partner role afforded the opportunity to compare views of their role with all the competencies recommended for Strategic HR by Ulrich et al. (2017).

Subtle nuances emerged as participants discussed the key job duties and competencies required for success in their role. Those with longer tenure in an HR role talked about the evolution from a compliance-based approach to a business support-based approach. The 
compliance-based approach was perceived as labor intensive and not as welcomed by the business. The business partner approach is perceived as utilizing that same HR expertise combined with a clear understanding of the business and/or client department to provide solutions rather than policing. This was considered the key to being invited to the table with business leaders and is consistent with the strategic positioner and credible activist competencies from Table 1 within Ulrich's model (Ulrich et al., 2017).

For the business partner, so the primary duties and I stick behind this and will likely say it often throughout our conversation is, in my opinion, you never take HR to the business... I just went to learn and went to listen. And then, it was like, it was top of mind, where is HR, we need them here, because I didn't just go and preach (Sr Dir HRBP 2). I tried to convey to the client groups that I worked with that you know my job isn't to come in here and tell you what to do or how to do. It is to give you the value and the benefit of the experience that I've had on both sides of business and to help you accomplish whatever your goals are legally and ethically and within our policies (HR Dir 4).

Themes for the HR business partner. One theme that emerged across all the responses was the value and importance that HR professionals placed on "knowing the business". When they made these statements, they were not only referring to the overall organizational business, but more specifically the function within the company they were partnered with. This knowledge held the key to being able to provide better organizational solutions. The job descriptions supported this business focus stating it specifically as a top functional skill for the role, termed "broad business knowledge" with the key responsibility "to enable your partner groups' 
successful business strategy execution". The role of the HR business partner to "know the business" was consistent across all the participants, but six of the participants mentioned this directly in their response and two specifically stated this as the primary area in which they needed more development in order to be more proficient in change management. This is consistent with the stages of effective HR departments as stated by Ulrich and Grochowski (2018) where the two highest stages strategic and outside in are progressively better at understanding the business environment. Sr Dir HRBP 1 described the relationship as "really just having a business mindset first and an HR mindset second". Other participants felt similarly, and this was consistent across all three levels of the HR roles.

The HR business partner, from my perspective, sits halfway between the business and HR. They are responsible for understanding how a business operates, whatever function or overall business that may be (CHRO 1).

In my opinion, you never take HR to the business. So, you actually go and learn the business and you learn the departments, you learn what works, what doesn't work, what obstacles they have. As you learn each department, you really learn how to connect the departments and that is what really grows the business ( $\mathrm{Sr}$ Dir HRBP 2).

I think first and foremost they have to understand the business and then understand how HR can support, not even, support is a bad word, really drive and enable the business strategy to succeed (Sr Dir HRBP 1).

I believe that we are to be kind of a strategic partner to all of the leaders. So specifically, like in my role right now having different directors over different distribution centers and also like our executive leadership, we are there to partner with them to help them 
understand this is how the business can be better, this is how we can drive our team members to be better, to be more engaged (HRBP 4).

I found it interesting that so many stated that knowing the business was first and then HR knowledge. But this order is specific to how they apply that HR knowledge not the order of acquisition of knowledge. Most participants have developed their HR knowledge over several years and are now in a new business setting, so HR knowledge acquisition is first. Additionally, this idea of sitting between the business and HR suggests that the context is significant in determining the competencies needed for success in that specific environment. This supports the situationalist perspective in which it is difficult to standardize a set of competencies outside of the context (Ripamonti \& Scaratti, 2012).

A close second, the theme of being of help or support was prevalent in the responses across all interview questions. This theme was two-fold where some were focused on supporting the leader and providing business solutions and others were more focused on helping individual employees. This did not seem like a dichotomy, but rather just the focus of the level of the role. Those that were focused on helping the individual employees used language descriptive of a heavier burden. Some of thoughts of participants in this area were:

But I do think the key is to be customer, and by customer, I mean your internal customer, support oriented. I think you have to be relationship and support oriented (HR Dir 2). Other duties would be being responsive so being able to have a response to whoever reaches out within 24 to 48 hours. So, really fast paced and if I can't email back then pick up the phone or are face to face (HRBP 3). 
So, talking through, you know, offering counseling and things like that for major changes (HR Dir 2).

So, I had the wonderful opportunity to work with two individuals to transition from their day-to-day lives as a director of operations into more of a leadership role. And as a partnership it was very interesting, beneficial, fun in some ways, tough in other ways (HR Dir 3).

These themes are consistent with the focus of the role in this organization as confirmed by the HR structure and the written job descriptions. The focus here on knowing the business and being a support for the business appears to be at the exclusion of knowing, understanding, and demonstrating all the HR specific competencies even within their own job description.

HR competencies. I was curious to compare the participants' understanding and experience of their roles with other competencies recommended in literature. This was completed by exploring their responses to their HR experience and their understanding of the job responsibilities and competencies needed for their roles. Table 8 illustrates the analysis of the discussion that were coded for these competencies.

Table 8

Comparison of Ulrich et al., (2017) HR Competencies with HR Business Partner Role

\begin{tabular}{lll}
\hline Competency & Sub-Codes & Coding examples \\
\hline $\begin{array}{l}\text { Strategic } \\
\text { positioner }(7,10)\end{array}$ & Help the business to & "mainly helping operations achieve \\
& & their business goals", "what is the \\
& business strategy and what are the \\
& implications", "establishing \\
& relevant goals from an HR \\
& perspective that meet the business \\
& needs", "aligning the teams in all
\end{tabular}




\begin{tabular}{|c|c|}
\hline $\begin{array}{l}\text { Credible activist } \\
(6,11)\end{array}$ & $\begin{array}{l}\text { Build trust } \\
\text { Provide proactive } \\
\text { view }\end{array}$ \\
\hline $\begin{array}{l}\text { Paradox } \\
\text { navigator }(4,4)\end{array}$ & $\begin{array}{l}\text { Manage tensions in } \\
\text { businesses }\end{array}$ \\
\hline $\begin{array}{l}\text { Culture and } \\
\text { Change } \\
\text { Champion }(6,7)\end{array}$ & $\begin{array}{l}\text { Make change happen } \\
\text { Manage } \\
\text { organizational culture }\end{array}$ \\
\hline
\end{tabular}

Human capital curator $(9,16)$
Manage the flow of talent

Develop people and leaders

Driving individual performance "let me give you advice based on my perspective", "to be proactive, to be a thought leader", "anyone in an HR position has to have integrity and trust", "we're judged upon a lot of the trust we build with those leaders"

"after understanding those two things, they need to help devise a plan for solving that", "you have to have an idea of what's important, like what's most important and what takes precedence over things"

"I think that ties into change management and how we can help the organization change for the better", "what are we seeking to improve on or make that change, and all for the betterment of the company and the employees", "if I want to move my organization from one state to another, what that is culture, whether that's process, whether it's a business decision"

"help them have strategic foresight that they need to achieve their goals through talent", "what the team needs to look like to get them where they need to go", "where are our people issues, you know, our strengths and weaknesses there?", "how do you tie the people 
strategy, your talent strategy to

your business strategy?"

\section{Total reward steward $(1,2)$}

Technology and media integrator $(1,1)$

Analytics
designer and
interpreter $(2,2)$
Compliance
manager $(4,4)$

Manage employee well-being through financial and nonfinancial rewards

"working closely with the benefits team and at least having that ground-level knowledge in order to steer the team member in the right direction", "or if they just need to understand what their benefits plan looks like"

"resources they need in order to be successful... the systems, whatever it is"

"whether it is a business decision, do we fully understand what it is that we want to achieve"

"same thing with ensuring that our team is well informed of policies, practices, and adhering to those", "that may include compliance development and policy development", "being responsible for like confidential information"

Interestingly, no HR professional used the terminology associated with Ulrich's et al. (2017) nine competencies. However, their descriptions provided insight into these areas and some association with the competencies. For example, competencies such as strategic positioner, credible activist, culture and change champion, and human capital curator were closely linked to the participant responses. The weakest associations were in the following competency areas: analytics interpreter, total rewards steward, and technology and media integrator as there were only indirect references in the data. 
In their discussion of their roles, culture and change champion was limited in mention; however, there were other competencies that were even less directly related to their experiences. Particularly, the competencies of paradox navigator, technology and media integrator, total reward steward, and analytics interpreter were only loosely connected to their perceptions of the primary job responsibilities and competencies for their roles. An examination of the job descriptions that were available did mention these areas more specifically except for technology and media integrator. Below are a few examples from their job descriptions:

Dealing With Paradox: Can act in ways that seem contradictory; is very flexible and adaptable when facing tough calls; can combine seeming opposites like being compassionately tough, stand up for self without trampling others, set strong but flexible standards; can act differently depending upon the situation; is seen as balanced despite the conflicting demands of the situation. Collects and analyzes data to identify, coordinate and execute preventative training. Makes good decisions (without considering how much time it takes) based upon a mixture of analysis, wisdom, experience, and judgment; most of his/her solutions and suggestions turn out to be correct and accurate when judged over time.

Work closely with and through centers of excellence functions (talent acquisition, total rewards, payroll, employee relations, legal, training, risk management and safety) to deliver quality solutions to partner functions

A few participants expressed sentiments of being overwhelmed when responding to a question regarding the job responsibilities and competencies. This may help us understand why the participants did not mention all the competencies that are required of the role. 
Especially in an HR business partner role you're juggling a ton of different things so, you have to be able to be organized and keep on track. You have to have an idea of what's important, like what's the most important and what takes precedence over things. And there's so many things. I don't know why I wasn't prepared for that question, but it is a big role (HR Dir 2).

Every day is different, I think that is why I am having a difficult time to really identify the duties. Because every day is completely different (HRBP 3).

Also, consistent with other research, this group certainly wears multiple hats within the HR space (Alagaraja, 2013). In describing their HR experience, participants mentioned on average three other distinct type of HR roles they have held such as recruiting, HR generalist, benefits specialist, and talent management specialist. So, even though we were discussing the HR business partner role, many had moved in and out of that role. It was a new role for the organization and for many of the participants. The structure of the HR function (Figure 4) also suggests that the analytics designer and interpreter and technology and media integrator are areas of expertise for the people services group and would not necessarily be viewed as a skill required by the HR business partner. Some organizations also have HR generalists in addition to the HR business partners (Ulrich et al., 2013) to be able to answer general employee questions regarding HR policies, programs, and benefits. This organization previously had HR generalists, but now without the HR generalist role, the HRBPs and the HR Directors find it necessary to cover both roles. This is consistent with Ulrich's (2016) findings of reduction in the number of HR generalists for more specialized roles. 
Overall, the case study provided a view of an organization dealing with a lot of organizational change with a recent focus on the role of the HR business partner. The participant stories of their lived experiences are most closely aligned to the competencies that Ulrich et al. (2017) group as "core drivers" of the business. HR business partners demonstrated awareness and some skill for those competencies that were grouped as "organization enablers" even though this was not as strong of a connection. Other than Compliance Manager, the weakest connection was to the competencies grouped as "delivery enablers". This is very consistent with the findings of Ulrich et al. (2017) where stronger links to credible activist and compliance manager were expected and most closely relate to the "old" or traditional set of HR skills. Since all these competencies except for technology and media integrator are defined in their job descriptions or the organizational leadership competencies, the reason for the lack of connection is not an unawareness of importance for the role. However, the information is woven throughout two different documents and several sections, therefore a concise list is not readily available. Additionally, the annual performance ratings did not include manager evaluations of all the required competencies for the role, just the "top" three. This suggests that documentation alone is not sufficient for HR professionals to have clear expectations for their roles and may need to be supplemented for more awareness.

The documentation of expectations for the HR roles were woven through several different sections of organizational documents including the organizational leadership competencies and the following sections of the job descriptions including the job summary, essential duties and responsibilities, functional competencies, and functional skills. Below, Table 
9 illustrates the comparison of the closest organizational equivalent to the recommended competencies of Ulrich et al. (2016) and where it is documented. 
Table 9

HR competencies by category (Ulrich et al., (2017) compared to organizational equivalent

\begin{tabular}{|c|c|c|c|}
\hline Category & Competency Name & Organizational Equivalent & Location \\
\hline \multirow[t]{3}{*}{ Core Competencies } & Strategic positioner & $\begin{array}{l}\text { Enable successful business strategy } \\
\text { execution }\end{array}$ & $\begin{array}{l}\text { Job description -essential } \\
\text { duties and } \\
\text { responsibilities }\end{array}$ \\
\hline & Credible activist & $\begin{array}{l}\text { Demonstrating credibility and } \\
\text { influence }\end{array}$ & Leadership competencies \\
\hline & Paradox navigator & Dealing with paradox & $\begin{array}{l}\text { Job description - } \\
\text { functional competencies }\end{array}$ \\
\hline \multirow[t]{3}{*}{ Organization Enablers } & Culture and change champion & Leadership courage & Leadership competencies \\
\hline & Human capital curator & Harnessing value and potential & Leadership competencies \\
\hline & Total reward steward & Deliver quality HR solutions* & $\begin{array}{l}\text { Job Description - Job } \\
\text { summary }\end{array}$ \\
\hline \multirow[t]{3}{*}{ Delivery Enablers } & Technology and media integrator & N/A & N/A \\
\hline & Analytics designer and interpreter & Collect and analyze data & $\begin{array}{l}\text { Job description -essential } \\
\text { duties and } \\
\text { responsibilities }\end{array}$ \\
\hline & Compliance manager & Ensure compliance & $\begin{array}{l}\text { Job Description - } \\
\text { functional skills }\end{array}$ \\
\hline
\end{tabular}

Note: *Total rewards was one of eight HR solution areas specified 


\section{Change Management Competency}

The descriptions of their change management experiences varied from the most common communicating reasons for change to the more complex descriptions such as designing change and building change capability. CHRO 1's narrative was a gripping story of a previous organization on the brink of failure without a successful change intervention that was planned carefully but the approach also had to be adapted again based on some unanticipated cultural reactions. Other stories were more frequently shared experiences about being thrown into the middle of a change initiative where HR professionals had to figure ways to communicate the rationale for these organizational decisions.

Change management as critical for HR. What I found interesting was that all participants were in general agreement when asked directly about the importance of change management competency for their role.

I would think, yeah absolutely. I would think super important for an HR business partner (HRBP 1).

It should, absolutely, be an HR Competency for any organization, you know, regardless of what role you have (HRBP 2).

I, $100 \%$ yes, think it should be a competency and now that you said it is probably one of the most important ones (HR Dir 2).

However only 5 of the 12 mentioned change management when asked to describe the roles and responsibilities of the HR manager. None of them mentioned the company stated change competency for their roles. One participant articulated a potential reason for this disconnect. 
I'll be honest, until you sent me this, and I'm glad you did, but until you sent me this, said would you like to participate in this, I never really thought about change management as a specific skillset. I thought of it more as a process or just something you do. But I've never really put any attention on I'm going to seek out something that's going to help me through this part of the job better as its own kind of standalone competency or set of skills (HR Dir 4).

One participant said that change management enabled all other strategic capabilities.

Well, I would just say it is vital. I don't believe you could do what we do every day without having that competency because of everything that's tied to it. If you think about what change management is, about identifying the issue, working through the issue, what's the plan, what are the resources, everything you have to do for change management. I think it's just it is probably the cornerstone of the HRBP role here and probably most other companies (Sr Dir HRBP 1).

Even if they felt change management is critical for HR, the fact that it is not top of mind as a day to day skill needed for their position will impact their intent to learn this topic. Without the intent to learn, then the participants would only be left with informal learning opportunities.

Defining change management. In considering their definition of change management, I sought to understand the intention behind their descriptions of the topic. Although none of the participants mentioned the company competency model or their job descriptions, the organizational definition for HR's role in change management is to "participate, lead, and deliver organizational change and development initiatives, ensuring desired outcomes and execution". 
The most common elements of their definitions included communication, specifically helping people understand the change, rationalizing the reasons for it, and the idea that change management is about an organizational improvement moving from a current state to a more desired state. Their definitions indicate a difference between the process side of change management and dealing with the human aspect of change.

I think a lot of times you might get caught up in change management as a process, but there is a big human element in there because there is fear in change (HR Dir 4). But I have used change management a lot of different ways.... But, I've also found that once you sit down and start talking about, you know, Ok so here's why we need to do this and explain to people and get their engagement and once you get them engaged the whole process goes a whole lot better (HR Dir 3).

So, when I think about it from HR, it's the ability to either lead or help others lead their transition from addressing where they are from where they want to be. And either lead or help that organization by creating a model and/executing on that model (CHRO1). You know actually, I think organizations, not just ours, they act like change is just business... But work is a pretty big part of most people's lives that do work and to not give it the credit that is due when there's a major change that happens.... but it doesn't always get the credit it should for how much it impacts people emotionally and I just think that should be something people are more aware of (HR Dir 2).

One definition poignantly summarized the intended outcome of change management understanding there is an inherent struggle and challenges present in any type of change. "I 
would say change management is the thoughtful process of helping an organization or an individual evolve in the most organic way possible" (CHRO 2).

These inherent struggles and challenges in the human aspect of change can be emotional. I analyzed the emotions indicated in the responses and stories the HR managers relayed. The primary emotional themes were the ideas of discomfort, difficulties, fear, challenges, concerns and having to try hard. Sr Dir HRBP 2 saw change management as having difficult conversations, "it's so people-oriented my mind comes to, you know, hard discussions." Helping employees understand what the change is and the reasons behind the change continued to be the tactic used to help deal with these emotions.

Yeah you know that's one of those things that that's where I saw the true tangible benefit was when people were realizing that somebody cared about them, that they were afraid of what was going to happen with the company and someone reached out to them to help them manage their own emotions and their own questions, and their own fears with the change. That human element to that (HR Dir 4).

People are human beings, you know, and we have emotions and we have feelings and when your feelings aren't good it's hard to do your job. (HR Dir 2).

Because change does have an emotional toll on people, several participants discussed the concept of change fatigue due to dealing with continuous change. While this was noted, there were not any recommendations offered to deal with change fatigue other than spacing major change initiatives further apart. 
Right, because we're going through so much change and we just we've been going through change for a long time. As soon as something changes it's going to change again, so people are super uncomfortable around here (HRBP1).

But, you know, at my last company, as an example, we hit a change fatigue that whatever was going to change, the organization was so fatigued it wasn't withstanding the change (Sr Dir HRBP 1).

There's been so much of it that, you know, fortunately or unfortunately, change always happens sometimes it just means growth (HR Dir 4).

No one mentioned any of the ethical considerations of change management. The closest comments around ethical considerations were the HR Directors who mentioned a reminder to leaders that change is difficult for people. One participant discussed sitting between the employees and the business but did not elaborate further on the dual responsibility here as was a concern stated by Ogilvie and Stork (2003). Given the fact that change management is attempting to change the perceptions of employees, this could lead toward manipulation if not done ethically (Burnes \& By, 2012). The mention of change fatigue was also possibly linked to ethical considerations, but not expanded upon by participants.

Tools and techniques. Most participants ( 8 out of 12) stated they were not aware of any tools or techniques for dealing with change management but expressed interest in learning more. The only tools and techniques noted by a few participants were models, primarily Kotter's 8-step model or a variation of it, and the RACI model which is a tool from project management. The two participants, HRD1 and HRD2, who mentioned the RACI model (Project Management Institute, 2004, p 206), noted it because they had been introduced to it during the same week as 
the interview. The RACI model stands for Responsible, Accountable, Consulted, and Informed and is a tool used within project management to clearly define roles and responsibilities of stakeholders and determine when and what type of communication is needed. This is consistent with the recommendation from some researchers to incorporate change management with project management (Hornstein, 2015; Parker et al., 2013). This is another element where those with the HRD background were the only ones to mention the change management models. The RACI model was the exception, however with those participants just being introduced to it by another HR group for project management. Other participants also mentioned overlap with the role of a project manager.

I spent a little bit of time as a project manager there and you learn to anticipate issues and you learn what you are not being told - the information behind what is coming out (HR Dir 3).

I also think when we go through change management you have to think about your project management office. So yeah, I mean that having individuals who can help with that especially when you're trying to implement some big changes (HRBP 2).

Models were the most referenced tool for managing change with Kotter's eight step model noted as a standard, which had later been adapted for use in a specific situation. CHRO 1 had specifically created a questionnaire outlined by Kotter's model that he had used with his business partners before to guide the thought processes of leadership teams through the eight steps.

I've been a fan of using John Kotter's eight step change model. What I have done in my time is I changed that and tried to simplify the words of it and turned the steps in the 
model into questions. And I've used this approach, standardized that approach and I've used that to facilitate conversations when I've been managing change with leaders and I've taught others to use that same approach when managing any kind of change process....But what I appreciate every time when I look through it, it continues to force me to look at things and I said did I really understand who all stakeholders are? Did I miss something of information that is going to come back to bite us? Those kinds of things are things that I find invaluable that if I don't use that approach it's easy for me to miss (CHRO 1).

These types of tools are consistent with the literature on change management. HR professionals in this case study who were familiar with them felt they were invaluable as a guide to managing change. CHRO 2 expressed his views on models as a framework and starting point.

So that's the first thing that I would say is the change management model that gives you the framework to begin working from and I do mean to begin working from, because each one of those change management models still require a ton of work. I mean there's multiple workstreams under each step in any change management model and those workstreams have to be specific to your current situation, your current organization, where you are in your journey, just assessing you know what you know of the organizational capabilities (CHRO 2).

Below in Figure 6 is an example based on Kotter's eight step change model provided by a vendor Eagle's Flight, Creative Training Excellence, Inc. that had been used in the past by CHRO 2. This is a great example of a tool that provides the basis and benefits of academic research in a ready to use format that allows the practitioner to apply to their direct context 
without hours of research. The only concept from Kotter's model that is not directly included here is the idea of forming a powerful coalition, but it is implied in the fact that this model was intended for leaders within the organization that are going to help lead the change. However, without some knowledge of academic research, practitioners can be at the mercy of content providers and consultants for models that look good, but do not provide this same level of accuracy. Kotter's model remains relevant in examples like this, in large part, because it was based on his analyses of common change failures. The beauty of the tool below is that it takes the academic model and translates it into actionable check lists with terminology more familiar to the practitioner such as objectives, priorities, big picture, line of sight, and milestones. The way it is graphically organized also provides a certain polish and professionalism for a pulledtogether look that assists the practitioner in both understanding and implementing the information while also feeling confident in presenting and using the tool. 


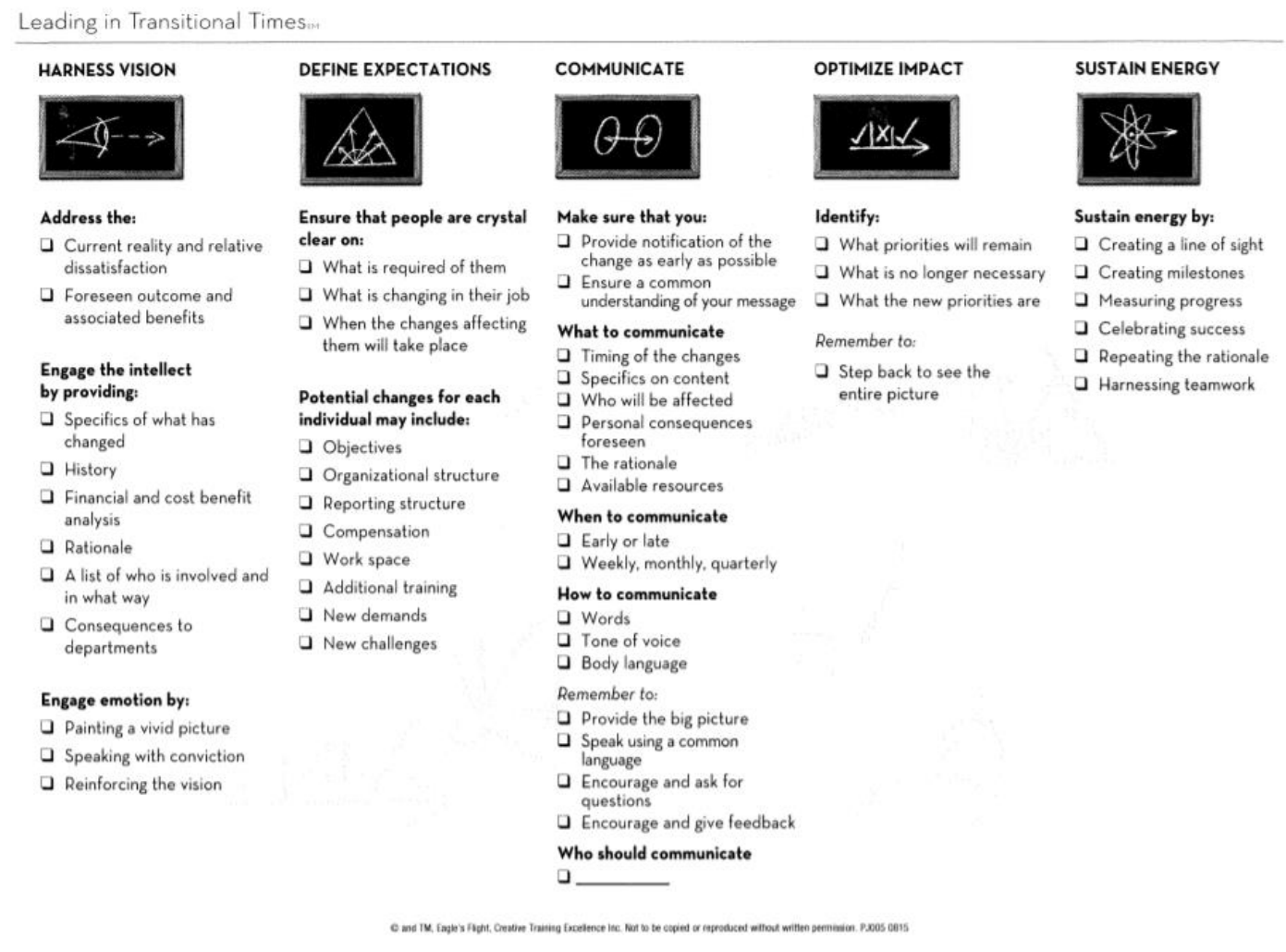

Figure 6. Leading in Transitional Times a change management model created by a training vendor Eagle's Flight, Creative Training Excellence, Inc.

It would be beneficial to HR business partners to at least be aware of some of the tools and techniques that are recommended to assist with change management. This is another possible reason for why their focus is primarily on explaining the change since they are not aware of other tools and techniques to employ.

Benefits to the organization. Not surprisingly, the top benefit that emerged from their comments on the benefits to the organization when HR is proficient in change management was business success with phrases such as return on investment, productivity, and profitability frequently referred to. The next three areas benefiting the organization were the closely related 
concepts of enabling a positive work environment, having a people focus, and engagement. A positive work environment was associated with improved quality of life, less stress, and clear expectations. Similarly, the engagement was about making things better for employees but was more specific to employee's wanting to belong and be involved. Finally, the idea of just having a people focus was important to most participants associating this with being a people company and people as a priority.

Change management activities. Table 10 illustrates the themes from participants' discussion of change management activities analyzed across each of the interview questions. The table is organized from highest mentions to lowest with explaining the change being the most common theme mentioned by all twelve participants.

Table 10

Change management activities emergent codes

\begin{tabular}{|c|c|c|}
\hline Theme & Sub-Codes & Coding examples \\
\hline $\begin{array}{l}\text { Explain the } \\
\text { change }(12,36)\end{array}$ & $\begin{array}{l}\text { Communicate } \\
\text { Train } \\
\text { Help understand } \\
\text { Gain buy-in }\end{array}$ & $\begin{array}{l}\text { "showing the team members what's } \\
\text { in it for them", "he like draws this } \\
\text { picture for them", "there's usually } \\
\text { some people facilitation to get that } \\
\text { change down to the GM level", } \\
\text { "making sure to repeat the things that } \\
\text { they really get that central message } \\
\text { and they walk away with it" }\end{array}$ \\
\hline $\begin{array}{l}\text { Anticipate and } \\
\text { mitigate barriers } \\
\text { to change }(8,19)\end{array}$ & $\begin{array}{l}\text { Listen to understand } \\
\text { Collaborate with } \\
\text { others } \\
\text { Identify challenges } \\
\text { Offer solutions }\end{array}$ & $\begin{array}{l}\text { "identify as many bottle necks and } \\
\text { barriers as you can and work } \\
\text { tirelessly to remove them", "let me } \\
\text { listen let me understand why they } \\
\text { feel this way", "I feel like that had I } \\
\text { not realized the importance of that, } \\
\text { and getting their full buy-in, and not } \\
\text { knowing what I should really drill } \\
\text { down into in the workshop, that we }\end{array}$ \\
\hline
\end{tabular}


Calm emotions

of change $(7,16)$

Someone to talk to

Empathize

Demonstrate caring

Design the

change $(5,10)$

Prepare self first

$(4,6)$

Implement technology

Implement new structure or strategy

Understand the change could have gotten lost in the grey area quite a bit and not focus on what the change was that we are really making"

"be sounding boards for people who are frustrated with the change", "be willing to listen to any concerns that they had and try to talk them through how it was going to be all right", "it's a business decision, please don't take it personal", "We had several team members that just wanted to talk it out, just wanted to have an ear for someone to hear", "true tangible benefit was when people were realizing that somebody cared about them, that they were afraid of what was going to happen with the company"

Create new function

Prepared for questions "implement a new strategy, new org structure", "So the organization that never had a centralized recruiting talent acquisition function and when Marvin came in first of this year", "one of the changes that I made was to help them move things to be more electronic"

'I think it's very important that as change management practitioners, you're always trying to understand the why", "you gotta be $100 \%$ in agreement yourself before you go to facilitate it for one or to give the information before you can get that same buy-in from the group that you are working with", "I have to be comfortable with the change myself" 


\begin{tabular}{|c|c|c|}
\hline $\begin{array}{l}\text { Build change } \\
\text { capability }(4,7)\end{array}$ & $\begin{array}{l}\text { Assist leaders } \\
\text { Organizational } \\
\text { capability }\end{array}$ & $\begin{array}{l}\text { "help others lead their transition", } \\
\text { "facilitating that discussion within } \\
\text { the organization so that the } \\
\text { organization develops those } \\
\text { capabilities", "help that organization } \\
\text { by creating a model and/or executing } \\
\text { on that model" }\end{array}$ \\
\hline
\end{tabular}

The analysis of their collective experiences on change management was compared to the findings available in the extant research literature. In

Table 11, the emergent codes were mapped with key findings from prior research (Table 3). Creating a coalition to support change and establishing organizational competencies were reported in the extant literature but did not emerge in the findings from this study. Creating a coalition to support change is a prominent step in the Kotter model, yet no one mentioned it even though this model was noted specifically by three participants. They did bring up negotiation (two participants); however, it was in the context of a separate, yet complementary skill set and therefore was not coded under the change management category. Only those three participants with an HRD background mentioned building change capability, suggesting a distinction in the view of change management from the different disciplines. While establishing organizational competencies could fall into the category of building change capability, none of the participants mentioned this activity specifically. Since this activity is primarily from the field of HRD, it is not surprising that it would not be mentioned for an HR business partner role. 
Table 11

Comparison of change management proposed activity from research to emergent codes

\begin{tabular}{ll}
\hline Proposed Activity from Research & Emergent Code \\
\hline Anticipate and mitigate resistance to change & $\begin{array}{l}\text { Explain the change (12) } \\
\text { Anticipate and mitigate barriers } \\
\text { to change (8) }\end{array}$ \\
Mediation/Negotiation & $\begin{array}{l}\text { Not coded; viewed as separate } \\
\text { but, complementary }\end{array}$ \\
Help employees with stress of change & Calm the emotions of change (7) \\
Create a coalition to support change & Not mentioned \\
$\begin{array}{l}\text { Create awareness of organizational purpose } \\
\text { and mission }\end{array}$ & Explain the change (12) \\
Consultant to business leaders & Design the change (4) \\
Training and creating capacity & Build change capability (3) \\
Establish organizational competencies & Not mentioned \\
Leadership development & Build change capability (3) \\
Diagnose organizational need & Design the change (4)
\end{tabular}

Note: (\#) indicates number of participants who mentioned the emergent code

The one emergent code that did not correspond to prior research was the importance of preparing oneself for change before attempting to bring other organizational members onboard. Four of the participants stressed this as a challenge within change management. 
But I think it's...you know, for me, I have to be comfortable with the change myself.

Like, I need communication. I mean it should be communicated to me, so I can properly communicate, coach, and train the people I am working with on the changes (HRBP 1). I think it's very important that as change management practitioners, you're always trying to understand the why (CHRO 1).

A piece that I've always, always been told and supported was that you gotta be $100 \%$ in agreement yourself before you go to facilitate it for one or to give the information before you can get that same buy-in from the group that you are working with (HR Dir 1).

This was a surprising finding due to how important it was for HR professional to prepare themselves first and become comfortable with the change before they could help others. While this seems intuitive, I did not find this idea explicitly called out in the research on change management. Before HR can be of assistance in change management, they must understand the why and the details of the change to a level to not be caught off guard and to know what is coming "before the shoe drops". My interpretation is that so much is changing all the time and it cannot be assumed that all HR employees have the same level of understanding for all initiatives. HR business partners in this type of model are the execution and implementation arm. Many of the change initiatives are conceptualized by centers of excellence (specialized HR roles) or nonHR areas of business so when HR business partners are asked to implement and help employees through the change process, they are not intimately familiar with the reasons for the change.

A related finding to the above theme implicates the role of organizational partners. Increases in the complexity and depth of understanding and experience with change management did not seem to be associated with years of experience, but rather the level within the 
organization of those with whom they were partnering and experience in leading the organization. Table 12 is a summary of the participants' years of experience in HR, the types of roles they held in HR, the highest level of their business partner with the types of change management elements that they referred to in their responses across all questions.

Table 12

Comparison of HR experience to the depth of change management elements discussed

\begin{tabular}{|c|c|c|c|c|}
\hline Participant & $\begin{array}{l}\text { HR Years } \\
\text { of } \\
\text { Experience }\end{array}$ & $\begin{array}{l}\text { Primary } \\
\text { Roles/ } \\
\text { Experiences }\end{array}$ & $\begin{array}{l}\text { Level of } \\
\text { Business } \\
\text { Partner }\end{array}$ & $\begin{array}{l}\text { Change } \\
\text { Management } \\
\text { Elements }\end{array}$ \\
\hline CHRO 1 & 18 & $\begin{array}{l}\text { CHRO, OD, } \\
\text { HRD, HRBP }\end{array}$ & Executive & $\begin{array}{l}\text { Build Change } \\
\text { Capability } \\
\text { Design the Change } \\
\text { Anticipate \& } \\
\text { Mitigate } \\
\text { Explain the Change } \\
\text { Prepare Self First }\end{array}$ \\
\hline CHRO 2 & 6 & CHRO, HRD & Executive & $\begin{array}{l}\text { Build Change } \\
\text { Capability } \\
\text { Design the Change } \\
\text { Anticipate \& } \\
\text { Mitigate } \\
\text { Calm Emotions } \\
\text { Explain the Change }\end{array}$ \\
\hline $\begin{array}{l}\text { Sr Dir } \\
\text { HRBP } 1\end{array}$ & 20 & $\begin{array}{l}\text { CHRO, } \\
\text { HRD, HRBP }\end{array}$ & Executive & $\begin{array}{l}\text { Build Change } \\
\text { Capability } \\
\text { Design the Change } \\
\text { Anticipate \& } \\
\text { Mitigate } \\
\text { Explain the Change }\end{array}$ \\
\hline $\begin{array}{l}\text { Sr Dir } \\
\text { HRBP } 2\end{array}$ & 20 & $\begin{array}{l}\text { HRBP, } \\
\text { Generalist, } \\
\text { Recruiter }\end{array}$ & Executive & $\begin{array}{l}\text { Design the Change } \\
\text { Anticipate \& } \\
\text { Mitigate } \\
\text { Calm Emotions } \\
\text { Explain the Change }\end{array}$ \\
\hline
\end{tabular}




\begin{tabular}{|c|c|c|c|c|}
\hline HR Dir 1 & 5 & HRBP & $\begin{array}{l}\text { Mid- } \\
\text { Senior }\end{array}$ & $\begin{array}{l}\text { Anticipate \& } \\
\text { Mitigate } \\
\text { Calm Emotions } \\
\text { Explain the Change } \\
\text { Prepare Self-First }\end{array}$ \\
\hline HR Dir 2 & 22 & $\begin{array}{l}\text { HRBP, } \\
\text { Generalist }\end{array}$ & $\begin{array}{l}\text { Mid- } \\
\text { Senior }\end{array}$ & $\begin{array}{l}\text { Calm Emotions } \\
\text { Explain the Change }\end{array}$ \\
\hline HR Dir 3 & 9 & HRBP & $\begin{array}{l}\text { Mid- } \\
\text { Senior }\end{array}$ & $\begin{array}{l}\text { Anticipate \& } \\
\text { Mitigate } \\
\text { Explain the Change }\end{array}$ \\
\hline HR Dir 4 & 15 & $\begin{array}{l}\text { HRBP, } \\
\text { Generalist, } \\
\text { Recruiter }\end{array}$ & $\begin{array}{l}\text { Mid- } \\
\text { Senior }\end{array}$ & $\begin{array}{l}\text { Calm Emotions } \\
\text { Explain the Change }\end{array}$ \\
\hline HRBP 1 & 20 & $\begin{array}{l}\text { HRBP, } \\
\text { Benefits }\end{array}$ & $\begin{array}{l}\text { Mid- } \\
\text { Senior }\end{array}$ & $\begin{array}{l}\text { Explain the Change } \\
\text { Prepare Self-First }\end{array}$ \\
\hline HRBP 2 & 15 & $\begin{array}{l}\text { HRBP, } \\
\text { Generalist, } \\
\text { Benefits, } \\
\text { Recruiter }\end{array}$ & $\begin{array}{l}\text { Mid- } \\
\text { Senior }\end{array}$ & $\begin{array}{l}\text { Anticipate \& } \\
\text { Mitigate } \\
\text { Calm Emotions } \\
\text { Explain the Change }\end{array}$ \\
\hline HRBP 3 & 15 & $\begin{array}{l}\text { HRBP, } \\
\text { Generalist, } \\
\text { Recruiter }\end{array}$ & $\begin{array}{l}\text { Mid- } \\
\text { Senior }\end{array}$ & $\begin{array}{l}\text { Anticipate \& } \\
\text { Mitigate } \\
\text { Calm Emotions } \\
\text { Prepare Self-First } \\
\text { Explain the Change }\end{array}$ \\
\hline HRBP 4 & 8 & $\begin{array}{l}\text { HRBP, } \\
\text { Generalist, } \\
\text { Recruiter }\end{array}$ & $\begin{array}{l}\text { Mid- } \\
\text { Senior }\end{array}$ & Explain the Change \\
\hline
\end{tabular}

\section{Adult Learning}

Since the existing research indicates a gap in formal learning opportunities, I was most interested in how participants developed their proficiency in change management. I identified terms associated with the existing research on formal, non-formal, and informal learning (Table 
4), and also analyzed data from participants as well as illustrated in Table 13. For instance, several participants mentioned a lack of formal learning opportunities. Informal learning was the most noted type of learning activity (52 individual phrases coded) with participants describing learning from peers and being exposed to change management on the job. Activities operationalized as non-formal learning were mentioned when participants were asked what would help them further develop their change management skill set. This was consistent with learning outside of an academic setting but was driven by a clear intent to learn.

Table 13

Formal, informal, and non-formal learning opportunities

\begin{tabular}{|c|c|c|}
\hline $\begin{array}{l}\text { Learning } \\
\text { Category }\end{array}$ & Sub-Codes & Coding examples \\
\hline $\begin{array}{l}\text { Formal Learning } \\
(4,9)\end{array}$ & $\begin{array}{l}\text { Academics } \\
\text { Degree programs } \\
\text { Lack of formal } \\
\text { learning }\end{array}$ & $\begin{array}{l}\text { "I don't have formal training in } \\
\text { change management", "because I, } \\
\text { I've not seen a lot of training out } \\
\text { there on change management, } \\
\text { right?", "my first area would } \\
\text { probably be academics", "Then my } \\
\text { next place was also academic in } \\
\text { Graduate School when I started } \\
\text { thinking and learning about } \\
\text { organizational change." }\end{array}$ \\
\hline $\begin{array}{l}\text { Non-formal } \\
\text { Learning }(6,15)\end{array}$ & $\begin{array}{l}\text { Workshops } \\
\text { Conferences } \\
\text { Certifications } \\
\text { Practice exercises }\end{array}$ & $\begin{array}{l}\text { "breakout session at the SHRM } \\
\text { conference at some point", "seminars } \\
\text { or the conferences that you go to, the } \\
\text { leadership workshops outside of the } \\
\text { organization", "I was a certified } \\
\text { change agent and went through all of } \\
\text { the training on change management", } \\
\text { "It showed you basically a } 6 \text { month } \\
\text { project in a four or five hour } \\
\text { workshop, but where you make } \\
\text { decisions on what you } \\
\text { communicated, how you }\end{array}$ \\
\hline
\end{tabular}




\begin{tabular}{|c|c|c|}
\hline & & $\begin{array}{l}\text { communicated it, when you } \\
\text { communicated certain things, what } \\
\text { the change looked like to you." }\end{array}$ \\
\hline $\begin{array}{l}\text { Informal } \\
\text { Learning }(10,52)\end{array}$ & $\begin{array}{l}\text { Trial and error } \\
\text { Learn as you go } \\
\text { Learn from past } \\
\text { experience }\end{array}$ & $\begin{array}{l}\text { "it's on the job", "you get exposed to } \\
\text { certain pieces of it you can then say } \\
\text { OK this is what they mean by change } \\
\text { management.", "it was being a part } \\
\text { of all of those HR functions and } \\
\text { actually doing them, it helps me to be } \\
\text { able to learn change management } \\
\text { when I was asked about a specific } \\
\text { area." "leaning on my peers and the } \\
\text { other HR directors to say how are } \\
\text { you handling that", "a process of } \\
\text { going through the experience and } \\
\text { realizing that next time I need this } \\
\text { piece. So very informal, very organic } \\
\text { and, again, not very much } \\
\text { structured.", "experience of multiple } \\
\text { change management initiatives as I } \\
\text { have grown up within the } \\
\text { organization." }\end{array}$ \\
\hline
\end{tabular}

Consistent with the research in this area (Kuchinke, 2002; Lim \& Rager, 2015), the participants mostly noted a lack of formal learning opportunities in their perspective for change management. However, based on the responses they would likely not seek out that opportunity if it were available. When asked what most would help them develop further, learning opportunities categorized as non-formal learning was by far the preference for these HR professionals.

I think, honestly, it's kind of, probably sounds kinda cheesy, but almost like a workshop on it of some sort that gives, you know, scenarios of change and then you talk through 
with the group or whatever of how you would deal with it, what you would do (HR Dir 2).

However, none of the participants had accessed nor mentioned the primary non-formal learning resource that were readily available to them in the form of the four on-line training modules. I interpret this to be associated with the fact they each felt they were average to above average in this competency; therefore, did not feel an urgent need to seek out available opportunities to further develop their knowledge, skills and abilities in this topic.

Interestingly, informal learning was the most cited type of learning from which they had developed their knowledge and skill in change management to this point, yet non-formal learning was the most cited for how they would like to continue their development. This difference can likely be explained by the intent to learn which is generally not associated with informal learning. Overall, most of the participants value and try to learn from those who can confidently answer questions and most successfully calm the fears of change management and many of their informal learning opportunities that they sought out were around this ability.

Well, to be honest, to start with I learned from watching my mentor that was my boss at Coca-Cola. She was just fantastic at change management and her skill set there. We were a union environment and we had a lot of things going on with that. So, I was able to be exposed to many things early on where I got to watch someone in action and I saw the way she talked to people and how her communication was and how important that aspect was to getting the change made with success (HR Dir 2).

Other than learning from experience the second most mentioned type of development was associated with practice literature with books like Who Moved My Cheese, The Six Thinking 
$\boldsymbol{H A T s}$, and SHRM articles and webinars. HRD and ATD particularly seemed to be more holistic in the topic of change management. Three participants with an HRD background seemed to have a broader knowledge of change management than most of the others. Of those, the participant with the least HR experience had an ATD certification along with the HRD background and mentioned some of the more complex change management activities such as building change capability. Those with a SPHR certification were more likely to mention gain buy-in as the primary change management method, while the one participant with the ATD certification used terminology related to building organizational capability.

Of the development that was mentioned in either formal or non-formal learning none were associated with a recent event. One participant mentioned a SHRM Webinar but stated that it was not helpful. The topic of the webinar would fall in the category of technology integrator, which was one of weakest competency connections, so this may explain why it was not perceived as helpful.

We've had some different webinars and things that I've gotten on through SHRM. I can't think of any specific ones, but as different things come out, I will listen in and sit on one. I was one today that was change management, but it was more of moving into using more like the artificial intelligence, technology- based basically. It wasn't really as informative as I thought it would be (HR Dir 1).

One participant (Sr Dir HRBP 1) felt strongly about the benefit of a non-formal training event that he had participated in years earlier. Even though non-formal, there was a still a level of structure paired with the intent to learn. What he felt was critical to the success was the ability 
to immediately apply the learning by being assigned to a project team to put the skills and knowledge to use. This is consistent with the idea that non-formal and informal are linked in the actual learning environment.

I can't even remember the first big course that I took where we went through a certification process. But, what I immediately, what I still remember about it is as soon as we completed the course we got assigned to a project as a kind of a change agent for that project. So, immediately it was putting "here's what we learned" into application.

Because I don't think, while the course was very good, I don't know that it would, as a standalone, been near as productive to be able to immediately see it and use different resources and templates and processes that we learned during the training ( $\mathrm{Sr}$ Dir HRBP $1)$.

He also felt that he had lost some of that knowledge over time by not using it as directly as before, suggesting that continued learning opportunities are needed to reinforce skill sets. $\mathrm{He}$ said, "Say 5 years ago I would have, 5 to 10 years ago, I would have said high. Today I would say medium. So, I'd say I'm out of practice a bit.”

Overall, the HR professionals predominantly attributed their learning to informal learning and their definition of change management revolved around communication. This is consistent with the potential drawbacks of informal learning noted by Manuti et al. (2015) in which employees in the workplace may only learn a narrow part of a task or concept or may learn wrong behaviors. This study suggests that the concept of change management as primarily communication is being perpetuated by the learning activities being limited to informal learning among the group of HR professionals. Since change management was not stated by most in their 
description of their job responsibilities, suggesting that the intent to learn this topic would not exist for most. Without the intent to learn, then more structured learning activities in the formal and non-formal learning activities would not be sought out.

\section{Summary}

The three assumptions with which I began my research were further supported by the responses and experiences of these HR managers. Like my first assumption, most of the participants had not participated in academic courses related to change management. In fact, only one of the participants mentioned academics in a very general way and did not note a specific course. My second assumption was also supported because the participants did rate themselves as average or above average in change management competency based on their experience with several change initiatives and the organizational performance documents provided consistent ratings in this area as well. Finally, I assumed that most would attribute the knowledge that they do possess in change management primarily to activities associated with informal learning opportunities.

The use of key word searches based on the existing research garnered nuanced detail within their rich descriptions of lived experiences supporting and leading change management. Based on my handwritten notes of the interviews, the primary change management activity identified was communication; however, in a detailed analysis of their descriptions 18 separate concepts were revealed which made up 7 distinct change management elements. The HR business partners in this case study did not directly mention a list of competencies that they were aware of for HR. However, in their discussions and organizational documents they covered all the recommended competencies except for technology and media integrator. Since it was part of 
the criteria for the study, the expectation was they would include change management as important for their role. The analysis of their experiences was consistent with the existing research that change management is a complex topic and many different skills and activities can be employed to provide change management.

Another key area of analysis based on the research questions was how HR professionals developed their skill also provided a wealth of detail with those categorized as informal learning comprising the most mentions. This analysis is consistent with the gaps in formal learning opportunities for change management. In the next chapter the implications of the findings of this case study will be discussed in response to the research questions and gaps in theory and practice. 


\section{CHAPTER 5: IMPLICATIONS}

This case study sought to understand if HR professionals considered change management as a critical for their role, how they defined it, and how they had developed their acumen. While most agreed that change management competency is critical to the success of the HR

professional, this competency was not top of mind for the job duties or skills needed. Although it was a stated competency for this organization, it did not come to mind for most participants.

Without a clear understanding of the required competencies, the HR professionals are not seeking development opportunities to increase their skill. They defined change management primarily as communication, specifically helping people understand the change and reasons for it. When compared to the definition used for change management in this dissertation is a "set of principles, techniques, or activities applied to the human aspects of executing change to influence intrinsic acceptance while reducing resistance" (Griffith-Cooper \& King, 2007, p. 14), what is left out is really the holistic approach with principles and techniques being applied specifically. This is consistent with the findings in the case study that almost none of the participants were aware of any specific tools or techniques that are used in change management.

In this case study, HR professionals were most likely to attribute their learning of change management to informal learning opportunities but would want to seek out non-formal learning opportunities to further develop their skill. While informal learning can be a very valuable 
learning experience, if the organization or other professionals that they are learning from are not skilled in change management, then they are perpetuating a lower level of understanding and skill.

In addition, the exploration of the lived experiences of these HR professionals were examined for any insights in the noted gaps in theory and practice. The chapter will bring together the implications for theory, practice, research, and professional networks stemming from the results of this study.

\section{Theory}

The results of this study have implications for theory in three main areas; HR's involvement in change management, change management models, and adult learning theory. HR's involvement was noted as a gap in theory from the literature review with no clear consensus on whether HR should lead change management efforts or how. In the area of change management models, participants in this study suggest an additional step that is not found in current models and the differences in their experiences suggest a tiered set of change management steps. The implications of this study suggest that the distinctions between formal, non-formal, and informal learning are critical to understand adult learning theory and peer group alignment may impact learner awareness in seeking out learning opportunities.

Change management. The literature review indicated a gap in theory as a lack of consensus on if and how HR should be involved in change management. The original models of change management were not focused on HR leading change efforts, rather the business leaders. Since that time, three fields of research have contributed to the view of HR professionals leading 
activities associated with change; HRM, HRD, and OD. The participants were primarily from either a pure HRM background or an HRD and HRM background. The results suggest that the those with an HRD background had a more comprehensive knowledge of change management as compared to those with a purely HRM background, regardless of the years of experience in HR. This additional knowledge was in a broader understanding of the elements of change management beyond communication as well as knowledge of change management models that are a key to understanding how to apply change management in different contexts. Depending on the structure of HR in an organization, there may not be specialized HRD or OD functions to lead change management efforts. The organization in this case-study was in the process of implementing COEs to support more specialized knowledge in HRD and OD, but in smaller organizations the HR professionals must wear all those hats. Regardless of the overlap of roles in the organization, HR business partners need knowledge of change management if they are going to advise business leaders on human resource solutions to business challenges. They may look to their HRD and OD partners for assistance if available, but they are involved in some capacity in any change initiative impacting the groups they support and must have competency in this area. Being expected to lead and support change initiatives was certainly true for the HR professionals in this study

Therefore, this study supports the recommendation that HR should be involved in leading organizational change efforts, but what about the how? The results and context reinforce the recommendations that the fields of HRM, HRD, and OD need to collaborate in the area of Strategic HRM and particularly with respect to change management theory (Ruona \& Gibson, 2004). One area for further research would be to explore a framework for change management as 
a series of tiered responsibilities and related skills. In this case study, all participants had been involved in communicating or explaining change and indicated this was more specific than other business communication primarily due to the importance of managing emotions during the change process. However, as other participants had been involved in some of the more complex elements of change management, it appears that there are tiered sets of processes that may be dependent upon when in the change process HR business partners are involved.

Future exploration could begin by examining current models, seek to understand the hierarchy of skills and processes, and determine how they work together for organizational change. Within this hierarchy of skills and related processes, preparing self-first in anticipation of change should be examined as a foundational concept. This was of importance to several of the participants, yet this is not mentioned in prior research. The assumption may be that it is implied that those leading change management should be prepared, but those participants felt strongly this was an important separate step they found challenging. Figure 7 represents a potential way to consider the tiers of change management steps based on Kotter's model by categorizing them into areas of designing the change, creating change capability, and preparing the employees. This distinction is supported by the fact that some HR professionals in this study have been involved in designing change and creating change capability while others have been brought in primarily at the prepare employees steps. In this model we can also insert the view of prepare self-first (4a) for the HR team that will be expected to communicate the vision. If they have not been involved in the change steps prior to this step, they are both an employee and an HR leader supporting employees. 


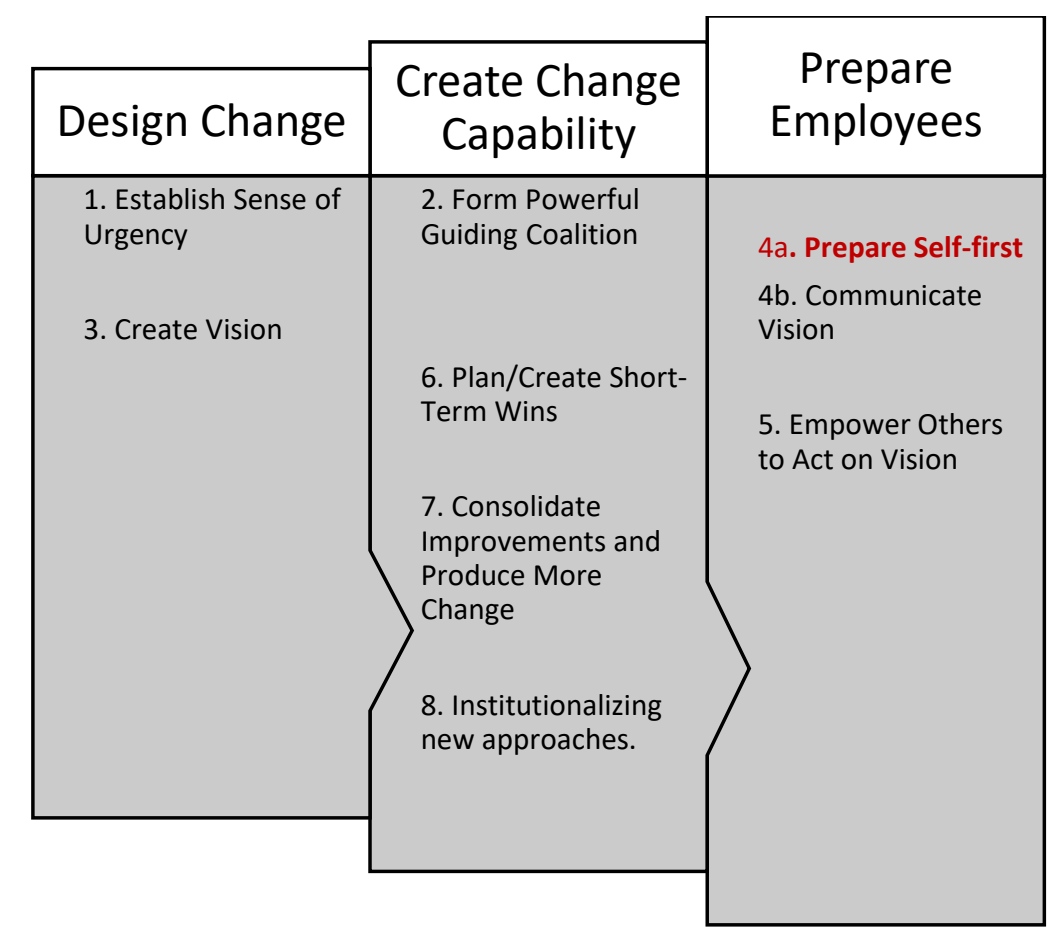

Figure 7. Tiered change model adapted from Kotter's model.

According to Kotter (1995), the steps should be completed in the specific order to ensure success, so the numbers retain the intended sequence. This is also an important consideration that these steps need to work together as one process, therefore this is another supporting reason for HRM, HRD, and OD to collaborate for an overarching change management model instead of focusing on specific steps and capabilities.

Adult learning theory. The analysis of this case study also has implications for the adult learning theory of lifelong learning (Jarvis, 2007) and the further discussion of the continuum of formal, non-formal, and informal learning (Decius et al., 2019, Malcolm et al., 2013, Manuti et al., 2015, Merriam, 2018). Although there is some challenge in defining the distinctions between the three (Eraut, 2004, Malcolm et al., 2013) this study suggests those distinctions are critical to understand context and learner awareness (Marsick \& Watkins, 2001). In this case study, learner 
awareness was impacted most by the knowledge within their peer group and not by the available documented scope and training on change management. Even though they were not all completely comfortable with change management, they did not necessarily see it as a critical moment of need since they were in alignment with their peer group. Peer support can enhance learning (O’Neil \& Marsick, 2009), but this study suggests that comfort within your peer group can prevent adult learners from seeking additional learning without an external influence.

\section{Practice}

The literature review revealed a gap in the perceived capability of HR professionals in the topic of change management potentially due to the known gap in formal learning higher education opportunities in change management for HR professionals. While these HR professionals were considered as meeting expectations in the change management competency, they did note a lack of formal learning opportunities. In addition, their educational backgrounds were consistent with the literature that most HR professionals do not have an HR specific major. Overall, these case study findings support the idea that HR should be involved in and knowledgeable of change management. However, most were not aware of tools or techniques to guide that in practice. Collectively they mentioned most of elements associated with change management in the literature. However, most primarily associated change management with communication on the steps and reasons for change. Their responses suggest this limited view of what change management consists of is one of the reasons why they have not sought out nonformal or formal learning opportunities for broadening their knowledge skills and abilities in this area. As a result, the informal learning opportunities are likely to perpetuate the idea of change as primarily communication. Non-formal learning opportunities paired with immediate 
opportunities to apply in the workplace was the consensus of the group to be the best way to provide further development. I contend that all three learning opportunities are needed for a full understanding of what change management consists of how to demonstrate the competency in the particular work context. This case study supports several recommendations for practice in organizations to help minimize this gap in development opportunities.

Adult learning theory posits that learner motivation and awareness are important to enhance the intent to learn and realization that learning has occurred. Although there were nonformal learning opportunities available to the participants to expand their knowledge of change management, none had accessed any of the modules. The organization in this case study can increase learner motivation and awareness by setting clear expectations of and expanding the definition of the competency of change management, providing regular assessment and feedback on the demonstrated proficiencies in change management, and providing non-formal learning opportunities.

For this organization, many of the HR business partners are still primarily wearing the hat of HR generalist either because they are more comfortable with that role and/or are not sure what they should do differently. For example, several of the participants spent much of their time focused on supporting employee questions rather than helping prepare leaders for change discussions. Although an expanded definition of change management was available in both the stated competencies and in the job description it did not appear that all the participants were aware of it. Change management is a complex topic and it would be beneficial for HR professionals to have a clearer understanding of the expectation in this competency. For adult learning, regular feedback is important for attaining and maintaining a competency skill set. It is 
important for organizations to provide regular assessments of the competencies required of the employee. This should also include an assessment completed by the business leader that the HR professional partners with. Currently, each HR level assesses the next lower HR level, but no one outside of that hierarchy. Those either benefiting or not from the HR professional's knowledge do not have the opportunity to inform that feedback.

If informal learning is embedded in moments of need in the organization (Manuti et al, 2015), that suggests that an organization could enhance those opportunities with clear expectations around the HR role to increase that intent to learn. Both clear expectations and feedback on where they are compared to those expectations would enhance learner awareness that they need to further develop their knowledge and skills. When a suitable formal learning opportunity is not available, organizations can consider creating a non-formal learning opportunity for a holistic overview of the complex topic of change management. However, I do encourage organizations to reach out to local higher education institutions for partnership in creating this training opportunity. I recommend that all HR professionals working in business partner capacity participate in a change management non-formal course. Topics to cover would include the history of change management, the contributions of each of the fields of HRM, HRD, and OD, various models from each field, types and differences of organizational change, tools and techniques for change management, certifying agency contributions, the ethical considerations, measurement, and popular literature contributions. This course would also provide the opportunity for HR professionals to learn from each other based on the collective experiences that they have had from their informal learning opportunities. Due to the large amount of content, the recommendation would be to split this into multi-week condensed 
sessions around each topic. Table 14 further defines each topic and the rationale behind including that topic in the non-formal learning activity.

Table 14

Recommended change management topics for $H R$

\begin{tabular}{|c|c|c|}
\hline Topic & Description & Rationale \\
\hline $\begin{array}{l}\text { History of } \\
\text { change } \\
\text { management }\end{array}$ & $\begin{array}{l}\text { Discussion of history of change } \\
\text { management in organizations and } \\
\text { research }\end{array}$ & $\begin{array}{l}\text { Comprehensive } \\
\text { overview of evolution } \\
\text { of change } \\
\text { management }\end{array}$ \\
\hline $\begin{array}{l}\text { Contributions } \\
\text { of each field }\end{array}$ & $\begin{array}{l}\text { Discussion of the overlap and unique } \\
\text { contributions of HRM, HRD, and OD } \\
\text { to change management }\end{array}$ & $\begin{array}{l}\text { Comprehensive } \\
\text { overview of } \\
\text { relationships of the } \\
\text { fields and where } \\
\text { recommendations } \\
\text { come from }\end{array}$ \\
\hline $\begin{array}{l}\text { Various } \\
\text { models }\end{array}$ & $\begin{array}{l}\text { Discussion of various seminal models } \\
\text { from each field }\end{array}$ & $\begin{array}{l}\text { Comprehensive } \\
\text { understanding of use } \\
\text { and purpose of } \\
\text { multiple models }\end{array}$ \\
\hline $\begin{array}{l}\text { Types of } \\
\text { organizational } \\
\text { change }\end{array}$ & $\begin{array}{l}\text { Discussion of the different types of } \\
\text { organizational change }\end{array}$ & $\begin{array}{l}\text { Comprehensive } \\
\text { understanding type of } \\
\text { organization change } \\
\text { and how to respond to } \\
\text { each }\end{array}$ \\
\hline $\begin{array}{l}\text { Tools and } \\
\text { techniques }\end{array}$ & $\begin{array}{l}\text { Discussion of the tools and techniques } \\
\text { useful for each type of organizational } \\
\text { change }\end{array}$ & $\begin{array}{l}\text { Comprehensive } \\
\text { understanding of tools } \\
\text { and techniques and } \\
\text { how to employ }\end{array}$ \\
\hline $\begin{array}{l}\text { Certifying } \\
\text { agencies }\end{array}$ & $\begin{array}{l}\text { Discussions of the different certifying } \\
\text { agencies and how they handle change } \\
\text { management }\end{array}$ & $\begin{array}{l}\text { Comprehensive } \\
\text { understanding of the } \\
\text { where to seek } \\
\text { additional practitioner } \\
\text { information }\end{array}$ \\
\hline
\end{tabular}




\begin{tabular}{|c|c|c|}
\hline $\begin{array}{l}\text { Ethical } \\
\text { considerations }\end{array}$ & $\begin{array}{l}\text { Discussion of the ethical } \\
\text { considerations of change management }\end{array}$ & $\begin{array}{l}\text { Comprehensive } \\
\text { understanding of their } \\
\text { responsibilities in } \\
\text { upholding ethics when } \\
\text { leading change }\end{array}$ \\
\hline Measurement & $\begin{array}{l}\text { Discussion of the ways in which to } \\
\text { measure the outcome of change } \\
\text { management efforts }\end{array}$ & $\begin{array}{l}\text { Comprehensive } \\
\text { understanding of } \\
\text { metrics associated } \\
\text { with change } \\
\text { management and how } \\
\text { to employ }\end{array}$ \\
\hline $\begin{array}{l}\text { Popular } \\
\text { literature } \\
\text { contribution }\end{array}$ & $\begin{array}{l}\text { Discussion of the most prevalent } \\
\text { popular literature contributions to } \\
\text { change management }\end{array}$ & $\begin{array}{l}\text { Comprehensive } \\
\text { understanding of how } \\
\text { popular literature } \\
\text { compares to academic } \\
\text { research }\end{array}$ \\
\hline
\end{tabular}

With clear expectations, feedback, and either formal or non-formal learning opportunities, the informal learning that takes place on the job and between co-workers will enhance their understanding and ability to apply their knowledge rather than limit them to a narrow view of the topic.

\section{Research}

The findings of this case-study reveal that practice literature has more influence on the development for this strategic HR competency, even though there are key overlaps with findings from the academic research. For this reason, scholars should also consider including a review of the practice literature to enrich academic insights. Based on the literature review and the results of this case study, I recommend further research in the areas of ethical considerations, measurement, further clarifying the change management competency, consider the trends in determining capabilities, and higher education formal learning opportunities. 
Ethical considerations for change management should be an area of further research. This was a limited area of research and was not directly mentioned by participants. This is an under researched topic in change management and is critical due to implications and potential for abuse and manipulation instead of the intended help to employees (Burnes \& By, 2012). The concept of change fatigue is a related are of research around how much change are employees capable of withstanding and what types of resources should be made available in the event of continuous change. Most of the current research is based on analyzing change management as a one-time event, but as Worley \& Mohrman (2014) state that with change becoming more common and complex, our concept of change management may need to adapt as well.

Measurement of change management success is also an area for additional research. For decades, the perception of change management efforts as largely unsuccessful is in part due to a lack of a standard way to measure the change management outcome. Change management is similar to adult learning theory in a few key areas, such as acquisition of new knowledge and skills, non-formal and informal learning opportunities, and being embedded in the context. Therefore, an area of further research should explore the use of Kirkpatrick's levels of evaluation, especially levels 3 and level 4 to measure the non-formal and informal learning that takes place during change management.

Although outside of the scope of this study, it does appear that change management is a macro-competency that includes other competencies such as communication. Further research should seek to establish the micro-competencies that make up change management. This study examined some of the activities involved in change management and those are certainly a start for some of the knowledge and skill areas. However, a more in-depth empirical study would be 
needed to identify the micro-competencies that make up change management. Additionally, further research is needed to understand the relationship of change management to other competencies from a meta-competency perspective. This study also indicates that change management may also be a meta-competency for HR professionals allowing them to be more successful across other aspects of their work. This is consistent with the grouping that Ulrich (2017) has for the "organization enabler" category. However, the participants in this study feel change management can be an enabler to other areas of their responsibilities that would fall more in the category of core competencies. Especially the relationship with communication should be further explored. Understanding this dynamic relationship seems fundamental to furthering the efforts of change management within organizations. Having excellent communication skills might not encompass all that would be needed to fully communicate change management efforts such as specific messages to different audiences to ensure clarity of expectations and benefits of change to enhance adoption. However, without proficiency in communication skills, understanding what needs to be communicated and when can also thwart change management efforts.

A related topic is the trend toward capabilities instead of competencies. Although some may use the terms interchangeably, Bersin (2019) defines capability as a "combination of the skills, knowledge, and experiences" (paragraph 14) needed to succeed and are likely unique to the organization. This is idea of going beyond the technical skill and knowledge of a competency and understanding what makes employees capable of the delivering results in the areas needed by the organization. Change is noted by Bersin as a capability needed for HR. Further research 
would be needed to understand the difference and interaction between a change management competency and the capability of leading change.

As discussed in the literature, there is a gap in the higher education offerings of courses including change management (Kuchinke, 2002; Lim \& Rager, 2015; Ramlall \& Sheppeck, 2007). The experience of these participants was consistent with that gap with most noting a lack of formal learning opportunities. A multi-discipline approach to creating this curriculum would be recommended to encompass the different fields of HRM, HRD, and OD. Additionally, this study suggests that all three types of learning are necessary for full comprehension of a topic. Much has been written about the benefit in informal learning supplementing both formal and non-formal learning (Manuti et al., 2015). However, more research is needed to recommend the best way to increase intent to learn to enhance informal learning that is most common in the workplace.

\section{Professional Networks and Certifications}

In this case study, two certifying bodies were used by the HR professionals with very different perspectives on change management, SHRM and ATD. While these are both intended for HR professionals ATD is more focused on talent management and organizational learning. Likely because of that focus, that certification appeared to better prepare one participant for change management over the others who had SHRM certifications. Change management is more complex than just gaining buy-in which appears to be the focus of the SHRM certification and those participants were not as versed in other components of change management. This is an area where these agencies can collaborate for the benefit of HR professionals who wear many hats. 
SHRM could benefit from expanding the knowledge area around change management so that HR professionals understand this is a key competency and are more prepared in the workplace.

\section{Conclusions}

This study sought to understand the different ways HR professionals manage change within their organization. Specifically, the study focused on: how HR professionals perceive the competency of change management as critical to their work, how they define the HR competency of change management, and how they developed acumen in the change management competency. In this context, change management is one of several competencies that are considered critical for the role of HR professionals in research and the study provided specific insights into those and other competencies as well. The lens of adult learning theory was used to analyze the responses of participants regarding how they have developed their competency in change management.

Strategic HRM requires a specific set of competencies in which HR professionals are proficient to meet the business needs of organizations. Collectively, the group mentioned all but three of the change management activities that I found in my research. However, it was clear that those with higher level positions had more experience with those activities than others regardless of years of experience in HR. Practice literature was found to have influenced their understanding of their role and change management more so than academic literature. This has implications for how academic research needs to further influence practice literature and the first step to do that is to incorporate more reviews of practice literature in academic research. 
Collectively, the twelve participants mentioned most of the activities that research indicates as an important part of organizational change management. However, the only one that all of them mentioned was explaining the reasons for change. Change management is much more complex as a topic, than merely communicating the change. HR professionals and the organizations they support would benefit from a more comprehensive skill set in change management. 


\section{REFERENCES}

Alagaraja, M. (2012). HRD and HRM perspectives on organizational performance: A review of literature. Human Resource Development Review, 12(2), 117-143.

Alagaraja, M. (2013). Mobilizing organizational alignment through strategic human resource development. Human Resource Development International, 16(1), 74-93. doi:10.1080/13678868.2012.740794

Alfes, K., Truss, C., \& Gill, J. (2010). The HR manager as change agent: Evidence from the public sector. Journal of change management, 10(1), 109-127.

Appelbaum, S. H., Habashy, S., Malo, J., \& Shafiq, H. (2012). Back to the future: revisiting Kotter's 1996 change model. Journal of Management Development, 31(8), 764-782.

Association for Talent Development (ATD). (2019). ATD competency model. Retrieved April 21, 2020 from https://www.td.org/certification/atd-competency-model.

Barends, E., Janssen, B., ten Have, W., \& ten Have, S. (2014). Difficult but doable: Increasing the internal validity of organizational change management studies. The Journal of Applied Behavioral Science, 50(1), 50-54.

Bartlett, C. A., \& Ghoshal, S. (2002). Building competitive advantage through people. MIT Sloan management review, 43(2), 34 . 
Bernardin, H. J. \& Russell, J. (2013). Human resource management: An experiential approach. ( $6^{\text {th }}$ ed.) New York, NY: McGraw-Hill.

Bersin, J. (2019). The capability academy: Where corporate training is going. Retrieved November 1, 2020 from https://joshbersin.com/2019/10/the-capability-academy-wherecorporate-training-is-going/.

Beyerlein, M., Jones, T., \& Peck Parrott, K. (2017). Redesigning an undergraduate HRD program with stakeholder guidance. Advances in Developing Human Resources, 19(2), $138-156$.

Boudreau, J., \& Lawler III, E. E. (2014). Stubborn traditionalism in HRM: Causes and consequences. Human Resource Management Review, 24(3), 232-244.

Boudreau, J., Navin, P., \& Creelman, D. (2017). Why more executives should consider becoming a CHRO. Harvard Business Review. Retrieved May 17, 2020 from https://hbr.org/2017/05/why-more-executives-should-consider-becoming-achro\#comment-section.

Boyatzis, R. E. (1999). Self-directed change and learning as a necessary meta-competency for success and effectiveness in the twenty-first century. Keys to employee success in coming decades, 15-32. Westport, CN: Greenwood Publishing.

Brewerton, P. M., \& Millward, L. J. (2001). Organizational research methods: A guide for students and researchers. Thousand Oaks, CA: Sage. 
Bridges, W. (1991). Managing transitions: Making the most of change. Reading, MA: AddisonWesley.

Brockbank, W. (1999). If HR were really strategically proactive: Present and future directions in HR's contribution to competitive advantage. Human Resource Management: Published in Cooperation with the School of Business Administration, The University of Michigan and in alliance with the Society of Human Resources Management, 38(4), 337-352.

Buller, P. F., \& McEvoy, G. M. (2012). Strategy, human resource management and performance: Sharpening line of sight. Human resource management review, 22(1), 43-56.

Burnes, B., \& By, R. T. (2012). Leadership and change: The case for greater ethical clarity. Journal of Business Ethics, 108(2), 239-252.

By, R. T., Oswick, C., \& Burnes, B. (2014). Looking back and looking forward: Some reflections on journal developments and trends in organizational change discourse. Journal of Change Management, 14(1), 1-7.

Caldwell, R. (2001). Champions, adapters, consultants and synergists: the new change agents in HRM. Human Resource Management Journal, 11(3), 39-52.

Caldwell, R. (2008). HR business partner competency models: Re-contextualising effectiveness. Human Resource Management Journal, 18(3), 275294. doi:10.1111/j.1748-8583.2008.00071.x 
Campion, M. A., Fink, A. A., Ruggeberg, B. J., Carr, L., Phillips, G. M., \& Odman, R. B. (2011). Doing competencies well: Best practices in competency modeling. Personnel Psychology, 64(1), 225-262.

Capaldo, G., Iandoli, L., \& Zollo, G. (2006). A situationalist perspective to competency management. Human Resource Management: Published in Cooperation with the School of Business Administration, The University of Michigan and in alliance with the Society of Human Resources Management, 45(3), 429-448.

Cappelli, P. (2015). Why we love to hate HR... and what HR can do about it. Harvard Business Review, 93(7/8), 54-61.

Chen, D., \& Wang, Z. (2014). The effects of human resource attributions on employee outcomes during organizational change. Social Behavior and Personality: An International Journal, 42(9), 1431-1443.

Cohen, D. J. (2015). HR past, present and future: A call for consistent practices and a focus on competencies. Human Resource Management Review, 25(2), 205-215. doi:10.1016/j.hrmr.2015.01.006

Creswell, J. W. (2013). Qualitative inquiry and research design: Choosing among five approaches ( $3^{r d}$ ed.). Los Angeles, CA: Sage.

Creswell, J. W. (2014). Research design; Qualitative, quantitative, and mixed methods approaches. $\left(4^{\text {th }}\right.$ ed.). Los Angeles, CA: Sage. 
Creswell, J. W. \& Poth, C. (2018). Qualitative inquiry and research design: Choosing among five approaches ( $4^{\text {th }}$ ed.). Los Angeles, CA: Sage.

Crouse, P., Doyle, W., \& Young, J. D. (2011). Workplace learning strategies, barriers, facilitators and outcomes: A qualitative study among human resource management practitioners. Human Resource Development International, 14(1), 39-55.

doi:10.1080/13678868.2011.542897

Decius, J., Schaper, N., \& Seifert, A. (2019). Informal workplace learning: Development and validation of a measure. Human Resource Development Quarterly, 30(4), 495-535. doi:10.1002/hrdq. 21368

Duncan, W. J. (1978). Organizational Behavior. Boston, MA: Houghton Mifflin Harcourt ( $\mathrm{HMH})$.

Edmonds, J. (2011). Managing successful change. Industrial and Commercial Training, 43(6), 349-353.

Ellinger, A. D., \& Yang, B. (2011). Creating a whole from the parts: Qualities of good writing. In Rocco, T. \& Hatcher, T (Eds.), The Handbook of Scholarly Writing and Publishing (115-124). San Francisco, CA: Jossey-Bass.

Eraut, M. (2004). Informal learning in the workplace. Studies in Continuing Education, 26(2), 247-273.

Fleming, D. (1991). The concept of meta-competence. Competence and Assessment, 16(1), 9-12. 
French, W.L., \& Bell, C.H., (1999). Organization Development (6th ed.) Englewood Cliffs, NJ.: Prentice-Hall.

Galanis, N., Mayol, E., Alier, M., \& García-Peñalvo, F. J. (2016). Supporting, evaluating and validating informal learning. A social approach. Computers in Human Behavior, 55(1), 596-603.

Gaudet, C. H., Brown, H. Q., \& Lunsford, D. L. (2017). HRD curriculum meets global human capital challenge. Advances in Developing Human Resources, 19(2), 124-137.

Gerpott, F. H. (2015). The right strategy? Examining the business partner model's functionality for resolving Human Resource Management tensions and discussing alternative directions. German Journal of Human Resource Management, 29(3-4), 214234.

Glesne, C. (2015). Becoming qualitative researchers: An introduction. Boston, MA: Pearson.

Google Scholar (n.d.). [Dave Ulrich]. Retrieved May 17, 2020 from https://scholar.google.com/citations?user=jTa6a6QAAAAJ\&hl=en.

Gorman, P., McDonald, B., Moore, R., Glassman, A., Takeuchi, L., \& Henry, M. J. (2003). Custom needs assessment for strategic HR training: The Los Angeles county experience. Public Personnel Management, 32(4), 475-495.

Graham, M. E., \& Tarbell, L. M. (2006). The importance of the employee perspective in the competency development of human resource professionals. Human Resource Management: Published in Cooperation with the School of Business Administration, The 
University of Michigan and in alliance with the Society of Human Resources

Management, 45(3), 337-355.

Griffith-Cooper, B., \& King, K. (2007). The partnership between project management and organizational change: Integrating change management with change leadership. Performance Improvement, 46(1), 14-20.

Guest, G., Bunce, A., \& Johnson, L. (2006). How many interviews are enough? An experiment with data saturation and variability. Field Methods, 18(1), 59-82.

Hamlin, B., \& Stewart, J. (2011). What is HRD? A definitional review and synthesis of the HRD domain. Journal of European Industrial Training, 35(3), 199-220.

Harvard Business Review's paid circulation climbs to 340,000, the highest in its 97-year history. (2019, August 15). Retrieved October 03, 2020, from https://www.hbs.edu/news/releases/Pages/harvard-business-reviews-paid-circulationclimbs-to-340000.aspx.

Haslinda, A. (2009). Evolving terms of human resource management and development. The Journal of International Social Research, 2(9), 180-186.

Heery, E., \& Noon, M. (2017). A Dictionary of Human Resource Management. New York, NY: Oxford University Press.

Higgs, M., \& Rowland, D. (2009). Change leadership: case study of a global energy company. Strategic Change, 18(1-2), 45-58. 
Hornstein, H. A. (2015). The integration of project management and organizational change management is now a necessity. International Journal of Project Management, 33(2), 291-298.

Hughes, M. (2007). The tools and techniques of change management. Journal of Change Management, 7(1), 37-49.

Hughes, M. (2011). Do 70 per cent of all organizational change initiatives really fail? Journal of Change Management, 11(4), 451-464.

Ingham, J., \& Ulrich, D. (2016). Building better HR departments. Strategic HR Review, 15(3), $129-136$.

Jackson, S. E., Schuler, R. S., \& Jiang, K. (2014). An aspirational framework for strategic human resource management. The Academy of Management Annals, 8(1), 1-56.

Jamieson, D., \& Rothwell, W. (2015). The convergence of organization development and human resource management. In Practicing Organization Development (pp. 384-392). Hoboken, NJ: Wiley \& Sons, Inc. doi:10.1002/9781119176626.ch28

Jarvis, P. (2007). Globalization, Lifelong Learning and the Learning Society: Sociological Perspectives. London: Routledge

Jick, T. D., \& Sturtevant, K.D.M. (2017). Taking stock of 30 years of change management: Is it time for a reboot? Research in Organizational Change and Development, 25(1), 33-79. doi:10.1108/S0897-301620170000025002 
Johnston, R. (2001). Challenges in human resource development practitioner preparation. Studies in Continuing Education, 23(1), 37-53.

Kalyani, M., \& Sahoo, M. P. (2011). Human resource strategy: A tool of managing change for organizational excellence. International Journal of Business and Management, 6(8), 280286.

Kanaane, R., Akabane, G., Peterossi, H., \& Endler, D. C. N. (2015). Organizational change management in a strategic perspective. American Journal of Management, 15(2), 88-93.

Kelly, C., \& Rapp, K. (2018). The HR function in 2021: Models \& competencies (CAHRS White Paper). Ithaca, NY: Cornell University, ILR School, Center for Advanced Human Resource Studies.

Kerber, K., \& Buono, A. F. (2005). Rethinking organizational change: Reframing the challenge of change management. Organization Development Journal, 23(3), 23-40.

Killick, D. (2020). Beyond competencies and silos: Embedding graduate capabilities for a multicultural globalizing world across the mainstream curriculum. Research in Comparative and International Education, 15(1), 27-35. Kippenberger, T. (1998). Planned change: Kurt Lewin's legacy. The Antidote, 3(4), 10-12. doi:10.1108/EUM0000000006617

Knodel, T. (2004). Preparing the organizational 'soil' for measurable and sustainable change: Business value management and project governance. Journal of Change Management, 4(1), 45-62. 
Kotter, J. P. (1995). Leading change: Why transformation efforts fail. Harvard Business Review, $73(2), 59-67$.

Kuchinke, K. P. (2002). Institutional and curricular characteristics of leading graduate HRD programs in the United States. Human Resource Development Quarterly, 13(2), 127-143. doi:10.1002/hrdq.1019

Kuna, S., \& Nadiv, R. (2018). Divided we stand? Occupational boundary work among human resource managers and external organization development practitioners. Employee Relations, 40(5), 848-867. doi:10.1108/ER-07-2017-0160

Kryscynski, D., \& Ulrich, D. (2015). Making strategic human capital relevant: A time-sensitive opportunity. The Academy of Management Perspectives, 29(3), 357-369.

Kyndt, E., Dochy, F., \& Nijs, H. (2009). Learning conditions for non-formal and informal workplace learning. Journal of Workplace Learning. 21(5), 369-383.

Lee, E., \& Yu, K. S. (2013). How are Global HR Competency Models Evolving for the Future?. Retrieved July 30, 2018 from https://digitalcommons.ilr.cornell.edu/student/17/

Lewin, K. (1947). Frontiers in group dynamics: II. channels of group life; social planning and action research. Human Relations, 1(2), 143-153. doi:10.1177/001872674700100201

Liao, Y. S. (2005). Business strategy and performance: The role of human resource management control. Personnel Review, 34(3), 294-309. 
Lim, D. H., \& Rager, K. (2015). Perceived importance of curricular content of graduate HRD programs in the U.S. New Horizons in Adult Education \& Human Resource Development, 27(2), 13-27. doi:10.1002/nha3.20099

Long, C. S. (2013). Transformation of HR professionals to be a change agent: Realistic goal or just a dream. Journal of Advanced Management Science, 1(1), 50-53. doi:10.12720/joams.1.1.50-53

Mahajan, R. (2017). Importance of informal learning over formal learning in 21st century. International Journal of Advance Research and Innovation, 5(2), 152-154.

Maheshwari, S., \& Vohra, V. (2015). Identifying critical HR practices impacting employee perception and commitment during organizational change. Journal of Organizational Change Management, 28(5), 872-894.

Malcolm, J., Hodkinson, P., \& Colley, H. (2003). The interrelationships between informal and formal learning. Journal of Workplace Learning. 15(7/8), 313-318.

Mankin, D. P. (2001). A model for human resource development. Human Resource Development International, 4(1), 65-85.

Manuti, A., Pastore, S., Scardigno, A. F., Giancaspro, M. L., \& Morciano, D. (2015). Formal and informal learning in the workplace: a research review. International journal of training and development, 19(1), 1-17.

Marsick, V. J., \& Watkins, K. E. (2001). Informal and incidental learning. New directions for adult and continuing education, 2001(89), 25-34. 
Mazor, A. H., \& Johnsen, G. (2017). Deloitte's high-impact HR operating model: Business HR Retrieved June 30, 2020 from: https://www2.deloitte.com/global/en/pages/humancapital/articles/high-impact-hr-operating-model.html

McCall, M. W. (2004). Leadership development through experience. The Academy of Management Executive, 18(3), 127-130.

McClelland, D. C. (1973). Testing for competence rather than intelligence. American Psychologist, 28, 1-14. doi: 10.1037/h0034092

Merriam, S. B. (2004). The changing landscape of adult learning theory. In Review of Adult Learning and Literacy, Volume 4 (pp. 213-234). New York, NY: Routledge.

Merriam, S. B. (2018). Adult learning theory: Evolution and future directions. In Contemporary Theories of Learning: Learning Theorists ... In Their Own Words. (pp. 83-96). New York, NY: Routledge.

Mezirow, J. (1981). A critical theory of adult learning and education. Adult education, 32(1), 324.

Miles, M. B., Huberman, A. M., \& Saldaña, J. (2013). Qualitative data analysis: A methods sourcebook ( $3^{\text {rd }}$ ed.). Los Angeles, CA: Sage.

Milligan, S. (2018). HR 2025: 7 critical strategies to prepare for the future of HR. Retrieved April 21, 2020 from https://www.shrm.org/hr-today/news/hr-magazine/1118/pages/7critical-strategies-to-prepare-for-the-future-of-hr.aspx. 
Mitchell, G. (2013). Selecting the best theory to implement planned change. Nursing Management-UK, 20(1), 32-37.

Mosca, J. B., Puches, L., \& Buzza, J. (2015). Human resource managers implement effective organizational change through leadership \& process management. International Journal of Management \& Information Systems (Online), 19(4), 115-122.

Naznin, H., \& Hussain, M. A. (2016). Strategic value contribution role of HR. Vision, 20(2), 135-138.

Newman, A. (2016). Communication planning: A template for organizational change. Cornell Hospitality Report, 16(3), 3-6.

Ogilvie, J. R., \& Stork, D. (2003). Starting the HR and change conversation with history. Journal of Organizational Change Management, 16(3), 254-271.

O'Neil, J., \& Marsick, V. J. (2009). Peer mentoring and action learning. Adult Learning, 20(1-2), 19-24.

Parker, D., Charlton, J., Ribeiro, A., \& Pathak, R. D. (2013). Integration of project-based management and change management: Intervention methodology. International Journal of Productivity and Performance Management, 62(5), 534-544.

Petrou, P., Demerouti, E., \& Xanthopoulou, D. (2017). Regular versus cutback-related change: The role of employee job crafting in organizational change contexts of different nature. International Journal of Stress Management, 24(1), 62-85. 
Pollack, J., \& Algeo, C. (2014). Perspectives on the formal authority between project managers and change managers. Project Management Journal, 45(5), 27-43.

Pries, C., \& Stone, M. (2004). Managing CRM implementation with consultants-CRM or change management? Journal of Change Management, 4(4), 351-370.

Project Management Institute. (2004). A guide to the project management body of knowledge (PMBOK ${ }^{\circledR}$ Guide) (2004 ed.). Newtown Square, PA: Project Management Institute.

Pylat, N. (2016). Expected HR competencies: What do companies want from HR managers?. Educational Reflective Practices. 1(1), 67-85.

Ramlall, S. J. (2006). Identifying and understanding HR competencies and their relationship to organizational practices. Applied HRM Research, 11(1), 27-38.

Ramlall, S., \& Sheppeck, M. (2007). Educating highly competent and principled HR professionals in the 21st century. International Journal of Human Resources Development and Management,7(3/4). 215-226. doi:10.1504/IJHRDM.2007.017130

Ray, K. W., \& Goppelt, J. (2011). Understanding the effects of leadership development on the creation of organizational culture change: A research approach. International Journal of Training and Development, 15(1), 58-75.

Ripamonti, S., \& Scaratti, G. (2012). Weak knowledge for strengthening competences: A practice-based approach in assessment management. Management Learning, 43(2), 183197. 
Roberts, C. M. (2010). The dissertation journey: A practical and comprehensive guide to planning, writing, and defending your dissertation. Thousand Oaks, CA: Corwin Press.

Ruona, W. E. (2016). Evolving human resource development. Advances in Developing Human Resources, 18(4), 551-565.

Ruona, W. E., \& Gibson, S. K. (2004). The making of twenty-first-century HR- An analysis of the convergence of HRM, HRD, and OD. Human Resource Management, 43(1), 49-66. doi:10.1002/hrm.20002

Schulz, A. C., \& Nicolai, A. T. (2015). The intellectual link between management research and popularization media: A bibliometric analysis of the Harvard Business Review. Academy of Management Learning \& Education, 14(1), 31-49.

SHRM (2016). SHRM Competency Model. Retrieved Feb 22, 2020 from https://www.shrm.org/learningandcareer/career/pages/shrm-competency-model.asp.

SHRM (2017). SHRM Certification Marks 100,000 ${ }^{\text {th }}$ Certificant. Retrieved May 17, 2020 from https://www.shrm.org/about-shrm/press-room/press-releases/pages/shrm-certificationmarks-100,000th-certificant.aspx.

Smollan, R. K. (2015). Causes of stress before, during and after organizational change: A qualitative study. Journal of Organizational Change Management, 28(2), 301-314

Spender, J. (2014). The business school model: A flawed organizational design? Journal of Management Development, 33(5), 429-442. doi:10.1108/JMD-02-2014-0019

Stake, R. E. (1995). The art of case study research. Thousand Oaks, CA: Sage. 
Stevens, G. W. (2013). A critical review of the science and practice of competency modeling. Human Resource Development Review, 12(1), 86107. doi: $10.1177 / 1534484312456690$

Stone, D. L., \& Deadrick, D. L. (2015). Challenges and opportunities affecting the future of human resource management. Human Resource Management Review, 25(2), 139-145.

Suddaby, R., \& Foster, W. M. (2017). History and organizational change. Journal of Management, 43(1), 19-38.

Trehan, K. (2004). Who is not sleeping with whom? What's not being talked about in HRD? Journal of European Industrial Training, 28(1), 23-38.

Ulrich, D. (1997). Human Resource Champions: The Next Agenda for Adding Value and Delivering Results. Boston, MA: Harvard Business School Press.

Ulrich, D. (2016). HR at a crossroads. Asia Pacific Journal of Human Resources, 54(2), 148164.

Ulrich, D. (2017). Have HR professionals made progress? The 30-year evolution of HR competencies. Retrieved August 1, 2020 from: https://www.linkedin.com/pulse/have-hrprofessionals-made-progress-30-year-evolution-dave-ulrich/.

Ulrich, D., Brockbank, W., Ulrich, M., \& Kryscynski, D. (2015). Toward a synthesis of HR competency models: The common HR" food groups". People and Strategy, 38(4), 56-66. 
Ulrich, D., Brockbank, W., Yeung, A. K., \& Lake, D. G. (1995). Human resource competencies: An empirical assessment. Human Resource Management, 34(4), 473-495. doi:10.1002/hrm.3930340402

Ulrich, D., \& Dulebohn, J. H. (2015). Are we there yet? What's next for HR? Human Resource Management Review, 25(2), 188-204.

Ulrich, D., \& Grochowski, J. (2018). Building a world class HR department. Strategic HR Review 17(4), 181-185.

Ulrich, D., Kryscynski, D., Ulrich, M., \& Brockbank, W. (2017). Competencies for HR Professionals Who Deliver Outcomes. Employment Relations Today, 44(2), 37-44.

Ulrich, D., Younger, J., Brockbank, W., \& Ulrich, M. (2012). HR talent and the new HR competencies. Strategic HR Review, 11(4), 217-222. doi:10.1108/14754391211234940

Ulrich, D., Younger, J., Brockbank, W., \& Ulrich, M. D. (2013). The state of the HR profession. Human Resource Management, 52(3), 457-471.

U.S. Bureau of Labor Statistics (2020). [Occupational Outlook Handbook]. Retrieved April 21, 2020 from.https://www.bls.gov/ooh/business-and-financial/human-resourcesspecialists.htm.

Van Buren III, H. J., Greenwood, M., \& Sheehan, C. (2011). Strategic human resource management and the decline of employee focus. Human Resource Management Review, 21(3), 209-219. 
Werner, J. M. (2014). Human resource development $\neq$ human resource management: So what is it? Human Resource Development Quarterly, 25(2), 127-139.

Werner, J.M., \&DeSimone, R.L. (2006), Human Resource Development, 4th edition., Mason, $\mathrm{OH}$ : Thomson South-Western.

Woodman, R. W. (2014). The science of organizational change and the art of changing organizations. The Journal of Applied Behavioral Science, 50(4), 463-477.

Worley, C. G., \& Mohrman, S. A. (2014). Is change management obsolete? Organizational Dynamics, 43(3), 214-224.

Wright, P.M. and McMahan, G.C. (1992). Theoretical perspectives on strategic human resource management. Journal of Management, 18(2), 295-320.

Wright, P. M., \& McMahan, G. C. (2011). Exploring human capital: putting 'human’ back into strategic human resource management. Human Resource Management Journal, 21(2), 93-104.

Yin, R. K. (2011). Applications of Case Study Research. Los Angeles, CA: Sage.

Yin, R.K. (2014). Case Study Research: Design and Methods ( $5^{\text {th }}$ ed.). Thousand Oaks, CA: Sage.

Younger, J., Younger, A., \& Thompson, N. (2011). Developing the skills of HR business partnership: consulting and change management. Strategic HR Review, 10(1), 6-14. 


\section{Appendix A: Interview Protocols}

\section{Interview Protocol: Describing the HR manager's experience}

1. How many years of experience do you have in HR? Briefly describe that experience.

2. What are the primary job duties and job competencies for an HR manager from your perspective?

3. Specifically, what are your thoughts on change management as a competency for an HR manager?

a. How would you describe the change management competency in your own words?

b. Describe a recent event in which your knowledge of change management was beneficial to the organization.

c. Describe a recent event in which you felt you needed additional knowledge, skills, and/or abilities associated with change management to be fully successful.

d. Are there additional tools and techniques that you have used or are aware of for managing organizational change?

e. How would you rate your personal proficiency in this competency?

f. What are the benefits to employees and the organization for HR managers to be proficient in change management?

g. How have you developed your knowledge, skills, and abilities in this competency?

h. What types of learning activities (internal or external) would be most helpful to you in further developing your proficiency in change management? 
4. Are there additional thoughts you would like to share on this topic? 
Appendix B: Data Accounting Log

\begin{tabular}{|c|c|c|c|c|}
\hline Data Type & Date & Proposed Collection Method & $\begin{array}{c}\text { Actual } \\
\text { Collection }\end{array}$ & Notes \\
\hline $\begin{array}{l}\text { Organizationa } \\
\text { l Competency } \\
\text { Document }\end{array}$ & $\begin{array}{l}\text { Nov 1, } \\
2019\end{array}$ & $\begin{array}{l}\text { Word document with } \\
\text { organizational competencies by } \\
\text { management level }\end{array}$ & Completed & $\begin{array}{l}\text { Leadership Courage is } \\
\text { overarching title of change } \\
\text { competency }\end{array}$ \\
\hline $\begin{array}{l}\text { Interviews } \\
\text { with } 12 \\
\text { participants } \\
\text { that meet } \\
\text { criteria }\end{array}$ & $\begin{array}{l}\text { Nov } 1 \text {, } \\
2019 \text { to } \\
\text { Dec } 31 \\
2019\end{array}$ & $\begin{array}{l}30-60 \text { minute sessions; recorded } \\
\text { as .wav file and researcher's } \\
\text { written notes. }\end{array}$ & Completed & $\begin{array}{l}\text { One interview was } \\
\text { completed after the intended } \\
\text { date due to holidays on } \\
1 / 3 / 20 \text {. }\end{array}$ \\
\hline $\begin{array}{l}\text { Training } \\
\text { Report }\end{array}$ & $\begin{array}{l}\text { Jan } 6 \\
2020\end{array}$ & $\begin{array}{l}\text { Training report for all } \\
\text { participants on all titles available } \\
\text { from CyberU provider } \\
\text { beginning Jan } 2018 \text { when } \\
\text { content was added. }\end{array}$ & Completed & $\begin{array}{l}\text { None of the } 12 \text { participants } \\
\text { had accessed any of the four } \\
\text { titles available related to } \\
\text { change management. }\end{array}$ \\
\hline $\begin{array}{l}\text { Talent Profile } \\
\text { Cards of } \\
\text { participants }\end{array}$ & $\begin{array}{l}\text { Jan } 6 \\
2020\end{array}$ & Excel file per participant & Completed & $\begin{array}{l}\text { Organizational document } \\
\text { with demographic data and } \\
\text { previous experience. }\end{array}$ \\
\hline $\begin{array}{l}\text { Job } \\
\text { Descriptions }\end{array}$ & $\begin{array}{l}\text { Jan } 6 \\
2020\end{array}$ & $\begin{array}{l}\text { Word document for all available } \\
\text { HR positions in this study }\end{array}$ & & $\begin{array}{l}\text { Organizational document } \\
\text { with the stated job duties and } \\
\text { competencies for the HR } \\
\text { positions }\end{array}$ \\
\hline
\end{tabular}




\begin{tabular}{|c|c|c|c|c|}
\hline $\begin{array}{l}2019 \\
\text { Performance } \\
\& \\
\text { Competency } \\
\text { Assessment } \\
\text { Data }\end{array}$ & $\begin{array}{l}\text { Jan } 6 \\
2020\end{array}$ & $\begin{array}{l}\text { Excel report with the ratings for } \\
\text { all participants available }\end{array}$ & Completed & $\begin{array}{l}\text { Two participants were too } \\
\text { new to the company to have } \\
\text { a performance review. } \\
\text { Annual reviews only assess } \\
\text { the top three competencies, } \\
\text { so several participants did } \\
\text { not have a competency } \\
\text { rating. }\end{array}$ \\
\hline $\begin{array}{l}\text { Interview } \\
\text { Transcripts } \\
\text { Reviewed by } \\
\text { Participants }\end{array}$ & $\begin{array}{l}\text { Jan } 18, \\
2020\end{array}$ & $\begin{array}{l}\text { Word document with full } \\
\text { interview transcription }\end{array}$ & Completed & $\begin{array}{l}\text { No changes/ clarification } \\
\text { requested }\end{array}$ \\
\hline $\begin{array}{l}\text { Member } \\
\text { Checking }\end{array}$ & $\begin{array}{l}\text { Feb 14, } \\
2020\end{array}$ & $\begin{array}{l}\text { Review of initial analysis tables } \\
10 \text { and } 13 \text { with participants to } \\
\text { ensure correct understanding/ } \\
\text { interpretation. }\end{array}$ & Completed & $\begin{array}{l}\text { No changes/ clarification } \\
\text { requested }\end{array}$ \\
\hline
\end{tabular}




\section{CURRICULUM VITA}

NAME: $\quad$ Angela Booth Jorgensen

ADDRESS: Department of Educational Leadership, Evaluation and Organizational Development

347 Woodford R. and Harriett B. Porter Building

College of Education \& Human Development

The University of Louisville

Louisville, Kentucky 40292

EDUCATION \&

TRAINING: $\quad$ B.S., Middle School Education

University of Louisville

$1986-1992$

M.A. Ed., Adult Education

University of Phoenix

$2003-2006$

PRESENTATIONS: 2018 Academy for Human Resource Development, International Research Conference of the Americas-Published manuscript and presentation"Human Resource Change Management Competencies: Recommendation vs Reality"

2015 University of Louisville Spring Research Conference_- "Change Management in HRM, HRD, and OD” 